\title{
Invited review: Mineral absorption mechanisms, mineral interactions that affect acid-base and antioxidant status, and diet considerations to improve mineral status
}

\author{
Jesse P. Goff ${ }^{1}$ \\ Biomedical Sciences, College of Veterinary Medicine, lowa State University, Ames 50011
}

\begin{abstract}
Several minerals are required for life to exist. In animals, 7 elements (Ca, P, Mg, Na, K, Cl, and S) are required to be present in the diet in fairly large amounts (grams to tens of grams each day for the dairy cow) and are termed macrominerals. Several other elements are termed microminerals or trace minerals because they are required in much smaller amounts (milligrams to micrograms each day). In most cases the mineral in the diet must be absorbed across the gastrointestinal mucosa and enter the blood if it is to be of value to the animal. The bulk of this review discusses the paracellular and transcellular mechanisms used by the gastrointestinal tract to absorb each of the various minerals needed. Unfortunately, particularly in ruminants, interactions between minerals and other substances within the diet can occur within the digestive tract that impair mineral absorption. The attributes of organic or chelated minerals that might permit diet minerals to circumvent factors that inhibit absorption of more traditional inorganic forms of these minerals are discussed. Once absorbed, minerals are used in many ways. One focus of this review is the effect macrominerals have on the acid-base status of the animal. Manipulation of dietary cation and anion content is commonly used as a tool in the dry period and during lactation to improve performance. A section on how the strong ion theory can be used to understand these effects is included. Many microminerals play a role in the body as cofactors of enzymes involved in controlling free radicals within the body and are vital to antioxidant capabilities. Those same minerals, when consumed in excess, can become pro-oxidants in the body, generating destructive free radicals. Complex interactions between minerals can compromise the effectiveness of a diet in promoting health and productivity of the cow.
\end{abstract}

Received May 3, 2017.

Accepted December 6, 2017.

${ }^{1}$ Corresponding author: jpgoff@iastate.edu
The objective of this review is to provide insight into some of these mechanisms.

Key words: fatty acid, adipogenesis, lipogenesis, stromal vascular cell

\section{GENERAL MODELS FOR ABSORPTION OF MINERALS}

Minerals in the diet must be absorbed across the epithelial cells that line the gastrointestinal (GI) tract to enter the blood for use by the tissues. Minerals can be absorbed from any portion of the GI tract. However, the bulk of absorption for most minerals takes place in the small intestine, so the general processes used for mineral absorption will be illustrated using the small intestine as the model. Both the small and large intestines are lined by a single layer of epithelial cells joined together by proteins such as occludins, claudins, and e-cadherens that form a tight junction between adjacent cells. A portion of the cell membrane of each intestinal epithelial cell is in contact with the lumen of the gut. This is the apical surface of the cell. The apical membrane is thrown into many tiny folds that project out into the lumen. These microvilli, also called the brush border, greatly increase the surface area available for absorption. A thin layer of mucus and glycoproteins known as the glycocalyx overlies the apical membrane, and above this an unstirred water layer adheres to the glycocalyx by surface tension. The remaining surface of the epithelia cell below the tight junctions is in contact with extracellular fluids and is called the basolateral membrane of the cell. The epithelial cells sit on a highly permeable meshwork of protein known as the basement membrane. Beneath this lies the lamina propria. The lamina propria is loose connective tissue with extracellular fluids and a rich vascular and lymphatic network within it. Lymphatic capillaries, known as lacteals, take up absorbed dietary lipids that have been packaged into chylomicrons and recover plasma proteins that may have leaked from the capillary bed. The vascular capillaries are fenestrated, with wide openings between 


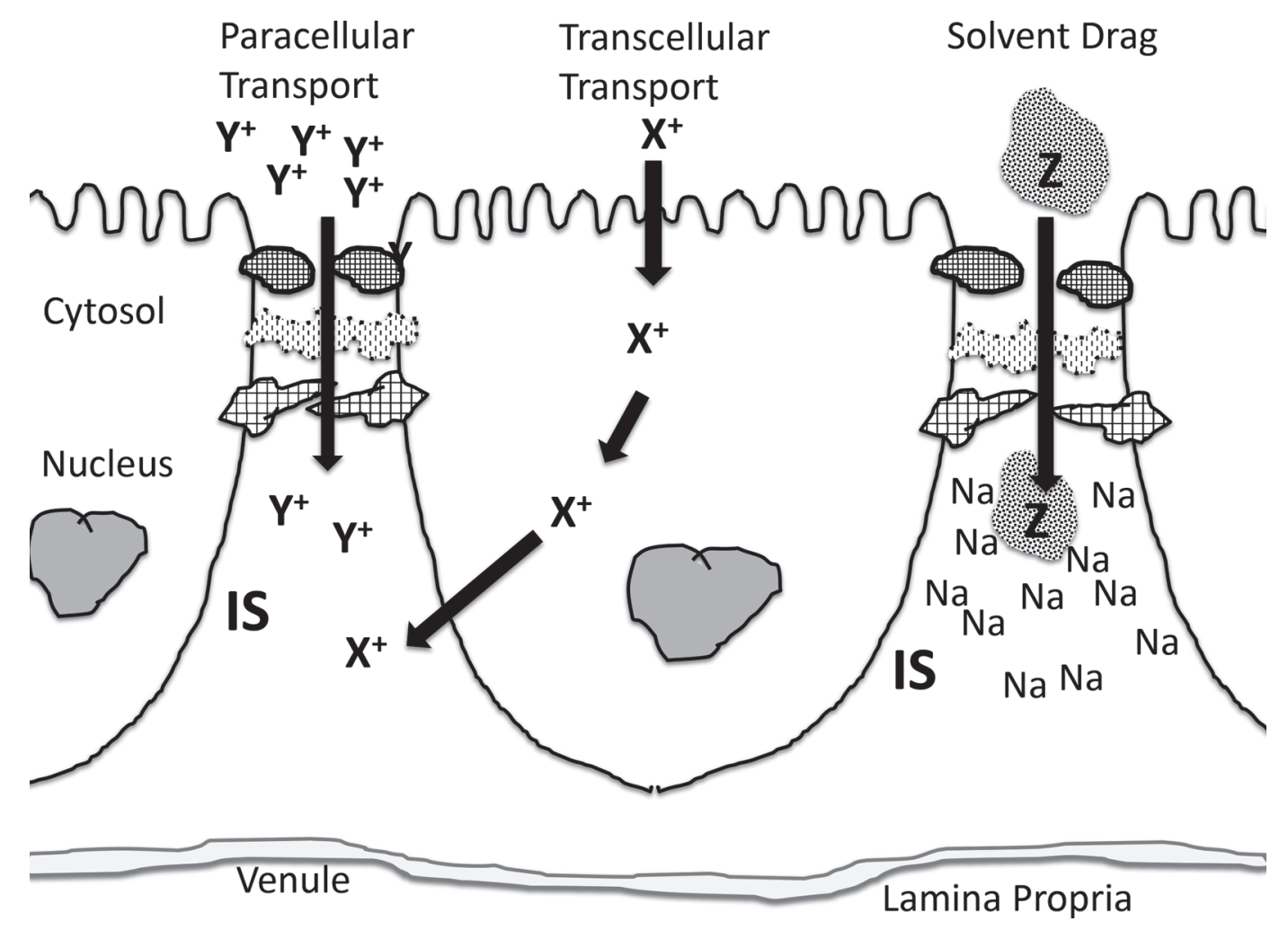

Figure 1. Enterocytes lining the gastrointestinal tract are connected to each other by tight junction proteins. Paracellular absorption involves movement of ions, designated by $\mathrm{Y}^{+}$, by diffusion down their electrochemical gradient through pores in the tight junction and into the interstitial space (IS) across the tight junctions. Minerals dissolved in water, designated by Z, can move across the tight junction with the bulk flow of water, which is known as solvent drag. Transcellular absorption involves mechanisms that allow minerals, such as $\mathrm{X}^{+}$, to cross the apical membrane, to move across the cytosol of the cell, and to move the ion across the basolateral cell membrane into the IS and lamina propria for entry into the vasculature.

endothelial cells, to aid absorption of sugars, AA, and minerals into the blood (Goff, 2015). Together the cells and tight junctions form an effective barrier to invasion by most bacteria and large molecules in the lumen that might be toxins (Figure 1). This barrier also typically blocks the passage of sugars, AA, and other large products of digestion.

The tight junctions between cells are not completely solid. There are small fissures, pores, and channels within the protein meshwork forming the tight junction. The tight junction meshwork normally offers resistance to mineral (and water) absorption - that is, the openings are too small for easy penetration by minerals. In addition, there is an electrical potential difference (PD) across the tight junctions - about +5 $\mathrm{mV}$ (lumen side negative, interstitial space side positive) in the small intestine and as high as $+30 \mathrm{mV}$ in the large intestine (Field, 2003) - that offers resistance to absorption of cations across the tight junctions but provides a force that promotes absorption of anions across the tight junctions.

The resistance to movement across the tight junction can be overcome if the concentration of mineral, in a freely ionized state, dissolved in the fluids overlying the luminal side of the tight junction greatly exceeds the ionized concentration of that mineral in the extracellular fluids within the interstitial space (a cleft between adjacent enterocytes) on the other side of the tight junction. Ionized mineral concentration implies that the mineral is in a state where it is not bound to proteins or other large substances and is in solution. The diffusional force created by differences in the ionized mineral concentration on each side of the tight junction can be great enough to push the mineral through the tight junction into the interstitial space, and from there it passes through the openings in the capillary endothelium and into the blood. This process is known as paracellular absorption. It is possible whenever the concentration of a mineral in solution over the tight junction is significantly greater than the concentration of the mineral in the extracellular fluids. Like all processes driven by diffusion, the size of the mineral atom and its electrical charge also determines how easily a mineral will cross the tight junction. Because the driving force to push minerals across the tight junctions is dependent on large concentration gradients, paracellular absorp- 
tion of minerals is most likely to occur in diets that have a relatively "high" concentration of the mineral (Nellans, 1991). This process is not saturable - that is, it has unlimited capacity to transport mineral into the blood. It is limited only by the electrochemical gradient developed by the concentration of ionized mineral in solution on the luminal side of the tight junctions.

The pores or ion channels within the tight junction have been of great interest. Cadherin and occludens proteins function mainly to hold adjacent epithelial cells together and form a barrier, whereas the claudin proteins seem to play a more active role in controlling permeability of the tight junction (Hartsock and Nelson, 2008). Claudins are a family of tight junction proteins that have their amino and carboxy termini in the cytosol of the epithelial cell. Claudin proteins traverse the cell membrane 4 times and extend out from the cell to interact with the claudin protein of an adjacent cell. A great number $(>26)$ of claudin proteins have now been identified. Claudins 1, 3, and 5 appear to be important for sealing off the intercellular space from the lumen - that is, they tighten up the tight junction (Furuse et al., 2002). They can form dimers with one another from the same cell, and they can form dimers with the claudin proteins of adjacent cells (Günzel and Fromm, 2012). In some cases, the AA residues of the claudin proteins (e.g., claudins 2 and 15) within the pore region have a negative charge, which repels anions and attracts cations to the pore, thus forming a cationselective pore. Other claudins may form anion-selective pores within the tight junction, though they have not yet been identified in the intestine (Krug et al., 2012). Some claudins, including claudin 2 proteins that form cation-selective pores, also form water channels through the tight junction between cells (Rosenthal et al., 2017). The portion of claudin proteins within the cytosol of the epithelial cells is known to interact with actin cytoskeletal proteins, suggesting that contraction of the cytoskeleton within the cell can affect the size of pores formed by the claudin proteins outside the cell (Madara et al., 1987). Studies have demonstrated that the presence of glucose and AA in the lumen can affect the size of the pores that permit water through the tight junction (Madara and Pappenheimer, 1987). How this affects the cytoskeleton and tight junction proteins is unclear.

Paracellular mineral absorption has 2 important aspects to it (Figure 1). As described above, simple diffusion of minerals can occur through pores in the tight junction as long as the electrochemical gradient exists to push the ions through the pores. Although this review is focused on absorption of minerals, it should be kept in mind that when there is a build-up of mineral concentration in the interstitial space, the pores can also allow mineral to move out into the lumen, resulting in secretion of the mineral. A second facet of paracellular mineral absorption is movement of minerals while suspended in water that is moving through the tight junction pores. This is known as solvent drag (Figure 1). Free mineral ions can be held in water (solubilized) by water dipole-ion interactions. When water passes through the pore, the mineral suspended in the water can also be absorbed. Minerals complexed to various substances in the diet (AA, peptides, VFA) can also be absorbed by solvent drag as long as they are soluble in the unstirred water layer over the tight junctions. Molecules as large as $3.5 \mathrm{kDa}$ can move through these tight junction pores as long as they have been solubilized by the water (Pappenheimer and Reiss, 1987). These tight junction pores may be 10 to 30 angstroms in diameter (Hakim and Lifson, 1969). Because many liters of water are absorbed across the GI tract each day, solvent drag of minerals may be responsible for the absorption of a substantial portion of the minerals needed by animals (Nellans, 1991). Two forces are at work when movement of water across the tight junctions is considered (Curran and Macintosh, 1962). One is hydrostatic pressure. Water generally moves down the path of least resistance. The tight junction is fairly resistant to a build-up of water pressure within the lumen of the intestine. Water moves down the tract rather than through the tight junctions. Raising intraluminal water pressure to $22 \mathrm{~cm} \mathrm{H}_{2} \mathrm{O}$ does not increase water absorption (Hakim and Lifson, 1969). However, when fluid accumulates in the interstitial space below the tight junctions it raises the hydrostatic pressure within that space. The tight junction seems very sensitive to interstitial space hydrostatic pressure, as raising interstitial water pressure to $2 \mathrm{~cm} \mathrm{H}_{2} \mathrm{O}$ abolishes water absorption and increasing pressure beyond that leads to movement of water into the lumen (secretion of water; Karbach and Wanitschke, 1984). The second force involved in water movement is the osmotic pressure. Mass movement of water across the tight junction pores and into the interstitial space is almost totally dependent on the development of an osmotic gradient in the interstitial space. Sodium is the main contributor to the osmolarity of the interstitial space. The epithelial cells absorb $\mathrm{Na}$ across their apical membrane and pump it into the interstitial space using the $3 \mathrm{Na}^{+} / 2 \mathrm{~K}^{+}$ATPase electrogenic pump. Solutes such as chloride, glucose, and AA that might be cotransported with the $\mathrm{Na}^{+}$also contribute to the osmolarity of the interstitial space. In the rumen, absorption of VFA contributes to the osmotic gradient below the rumen epithelium and helps pull water across the rumen epithelium (Holtenius and Dahlborn, 1990). The water, and the minerals and molecules solubilized in the water, will move through the 
water pores into the interstitial space and from there into the capillary beds within the lamina propria (Nellans, 1991). Again, this movement of water can occur in both directions. Solvent drag can also move minerals out into the lumen, especially if hydrostatic pressure builds up in the interstitial space, as might occur during normal contraction of the upper small intestine during digestion (Sjövall et al., 1990). Interstitial space hydrostatic pressure leading to water secretion also increases if perfusion of the gut is compromised and in response to enterotoxins (Burns et al., 1978; Nellans, 1991). The bulk flow of water and electrolytes occurs more freely in the upper small intestine than in the lower small intestine. This may be due to the presence of larger water pores in the upper intestine (Smyth, 2013).

The epithelial cells lining the GI tract have a cell membrane comprising a phospholipid bilayer that effectively blocks the movement of water, making it even more impervious to diffusion of water-borne minerals than are the tight junctions. Most minerals in solution also carry a positive or negative charge, which also prevents them from crossing the lipid bilayer barrier. The interior of epithelial cells is negatively charged compared with both the digestive fluids overlying the apical surface of the epithelial cell and the extracellular fluids outside the basolateral cell surface. This charge is between -25 and $-40 \mathrm{mV}$ and is referred to as the PD across the membrane. Negatively charged mineral ions (such as $\mathrm{Cl}^{-}$) try to move from the lumen of the intestine into the cell across the apical membrane against their electrical gradient. Positively charged ions such as $\mathrm{Ca}^{2+}$ and $\mathrm{Na}^{+}$cross the apical membrane into the negatively charged cell cytosol more easily as they are moving down their electrical gradient. However, at the other side of the cell, moving positively charged minerals such as $\mathrm{Ca}^{2+}$ or $\mathrm{Na}^{+}$out of the cell across the basolateral membrane into the extracellular fluid will involves moving those ions into a more positive environment against their electrical gradient (Goff, 2015).

Fortunately, the absorptive cells of the GI tract often have specialized mechanisms that allow for the efficient uptake of many of the soluble minerals, even when their concentration in the diet is quite low. This is known as transcellular transport, and it is a 3-step process (Goff, 2015). In step 1, the mineral moves from the digestive fluids through the unstirred water layer and glycocalyx and reaches the apical membrane surface (Figure 1). The mineral must be soluble in the digestive fluids bathing the cell surface for this to occur. Unfortunately, the phospholipid bilayer that makes up the cell membrane is totally impervious to water and minerals. To allow movement of a water-soluble mineral across the phospholipid bilayer into the cell, the cell makes use of mineral or "ion" channels (transporters). These consist of specialized proteins in the cell membrane that facilitate diffusion of the mineral. In general, these transporters bind minerals only if they are in the ionized form and, in many cases, the transporters bind the mineral only if it has a certain valence or charge to it.

In some cases, the channels or transport proteins are regulated and allow minerals through the apical membrane only if the body needs that particular mineral. Other minerals cross the membrane when cotransported with another molecule; for example, $\mathrm{Na}$ is often cotransported into the cell with glucose molecules by special glucose transporter proteins embedded in the apical membrane. These are also called symporters, as they move both substances in the same direction. Some minerals cross the apical membrane using transporter proteins that act as ion exchangers; they bring one type of ion into the cell while sending another ion, usually with the same charge, out into the lumen to maintain electroneutrality.

In step 2 of transcellular transport, the mineral must move from the apical membrane to the basolateral membrane of the cell across the cytosol of the cell. For some minerals this is by simple diffusion across the cell. For most minerals, specialized proteins or, in some cases, transport vesicles carry out this function. These transporter proteins, often called chaperones, serve another vital function: they bind the mineral so that it does not exist in the free, ionized state within the cytosol, as this could affect cell function. For example, an increase in cytosolic $\mathrm{Ca}^{2+}$ concentration can act as a "second messenger" to initiate various cell metabolic pathways, typically in response to hormones or cytokines. In addition, many minerals are strongly oxidizing when in the free unbound state, so they must be bound to prevent damage to the cell (discussed further in the section "Minerals as Pro-Oxidants and Antioxidants"). Furthermore, by binding the ions once they reach the cytosol, these transporters also help keep the ionized mineral concentration low in the cytosol. This promotes further influx of ions across the apical membrane by diffusion down their concentration gradient. Finally, in step 3 the mineral must be moved from the cytosol of the epithelial cell across the basolateral membrane to the interstitial space below the tight junctions. In some cases the mineral can diffuse down its concentration or electrical gradient through protein channels in the basolateral membrane. However, in many cases the process involves moving the mineral from an area of low concentration (the inside of the cell) to an area of high concentration (the extracellular fluids). Moving a mineral into the extracellular fluid against its concentra- 
tion gradient, and perhaps also its electrical gradient, often requires specialized proteins that form a mineral pump within the basolateral membrane. These pumps often require expenditure of energy in the form of ATP to power the pumping mechanism. Ion exchangers may use the potential energy derived from ions moving in or out of the cell down their electrochemical gradient to power movement of other ions into or out of the cell against their electrochemical gradient. A common tactic is to use the force generated by 1 or more $\mathrm{Na}^{+}$ ions moving into the cell down their large concentration and electrical gradient to power movement of other ions or molecules into the cell across the apical membrane (e.g., $\mathrm{Na}^{+} /$hexose symporters; Röder et al., 2014) or move ions out of the cell across the basolateral membrane (e.g., $\mathrm{Na}^{+} / \mathrm{Mg}^{2+}$ exchanger that moves $\mathrm{Mg}^{2+}$ out of rumen epithelia cells; Schweigel et al., 2006). The electrogenic $\mathrm{Na}^{+} / \mathrm{K}^{+}$ATPase pump then restores normal cell $\mathrm{Na}$ concentration and membrane potential by moving $3 \mathrm{Na}^{+}$ions back out into the extracellular fluids and lets $2 \mathrm{~K}^{+}$ions into the cell (Castillo et al., 2015).

Once ions, glucose, VFA, or AA are transported into the interstitial space they create an osmotic gradient that will pull water into the interstitial space. This water can move into this space by using pores in the tight junction formed by certain tight junction proteins, such as claudin-2 (Rosenthal et al., 2017). Water can also take a transcellular route. Water can follow solute across the apical membrane into the cytosol and then follow solute across the basolateral membrane through water channels known as aquaporins to enter the interstitial space (Zhu et al., 2016).

The active transcellular mineral transport processes permit an animal to absorb minerals from the diet even when they are present in very low concentrations in the intestinal lumen. The transport mechanisms are generally very specific for a given mineral and readily saturable, meaning that they can transport only a limited amount of mineral in a given amount of time. In some cases, the efficiency of these transporter systems can be upregulated when the body needs that particular mineral or downregulated when the body has ample supplies of a mineral. There also can be antagonists to these transport processes. For instance, high dietary Fe can interfere with the absorption of $\mathrm{Zn}$ across the small intestine.

\section{Ruminant Forestomach: Movement of Minerals Across a Stratified Squamous Epithelium}

Unlike the small intestine and large intestine, the epithelia lining the forestomach walls are not a single cell layer thick. The rumen, reticulum, and omasum surfaces facing the lumen of the digestive tract are lined with stratified squamous epithelia that may be tens of cells thick. They occur in 4 layers (Figure 2). The layer adhered to the basement membrane, the stratum basale, gives rise to the other layers. These cells have many mitochondria and high levels of the $\mathrm{Na} / \mathrm{K}$ ATPase pump in their basolateral membranes (Graham and Simmons, 2005). As these cells divide, they push the older cells toward the lumen. The next more mature layers are the stratum spinosum and the stratum granulosum. As cells in the stratum granulosum age, they become keratinized and die, forming the tough stratum corneum layer that protects the underlying mucosa from diet forage stems that might otherwise scratch the surface of the rumen mucosa. The dead keratinized cells that form the stratum corneum layer have lost the ability to make the proteins that compose the tight junctions holding them together. Although they offer physical protection against abrasion, they are not a barrier to absorption of nutrients. Tight junctions can be found between adjacent cells of the stratums basale, spinosum, and granulosum. Tight junction proteins are most numerous in the stratum granulosumthe live cells closest to the rumen fluid. Tight junctions here help form a strong surface that can withstand the abrasive nature of the forages ruminants ingest. They also keep the rumen microbes from gaining access to the lamina propria (Stumpff et al., 2011). The rumen's multiple layers of cells with multiple tight junctions to cross would seem to form a very formidable barrier to absorption of minerals, particularly by paracellular processes. However, the basale, spinosum, and granulosum layers have unique gap junctions that run between adjacent cells. Gap junctions are protein channels running from one cell to another that allow movement of ions and small molecules from the cytosol of one cell to the cytosol of another by simple diffusion (Graham and Simmons, 2005). Cytosols of the cells in the stratum granulosum are connected to the cytosol of the cells of the stratum basale by the gap junctions. This forms a syncytium of cells that are physiologically able to act as a single cell unit. The stratum granulosum cell apical membrane forms the first membrane that minerals, and other nutrients such as VFA, must cross. The mineral can then diffuse through the gap junctions to the basolateral membrane of the stratum basale cells. Mechanisms such as pumps and ion exchangers are found in the basolateral membrane of the stratum basale cells to move minerals from the cytosol to the extracellular fluids (Graham and Simmons, 2005). This system allows ions (and VFA) to move efficiently across multiple cell layers to reach the extracellular fluids of the lamina propria. 


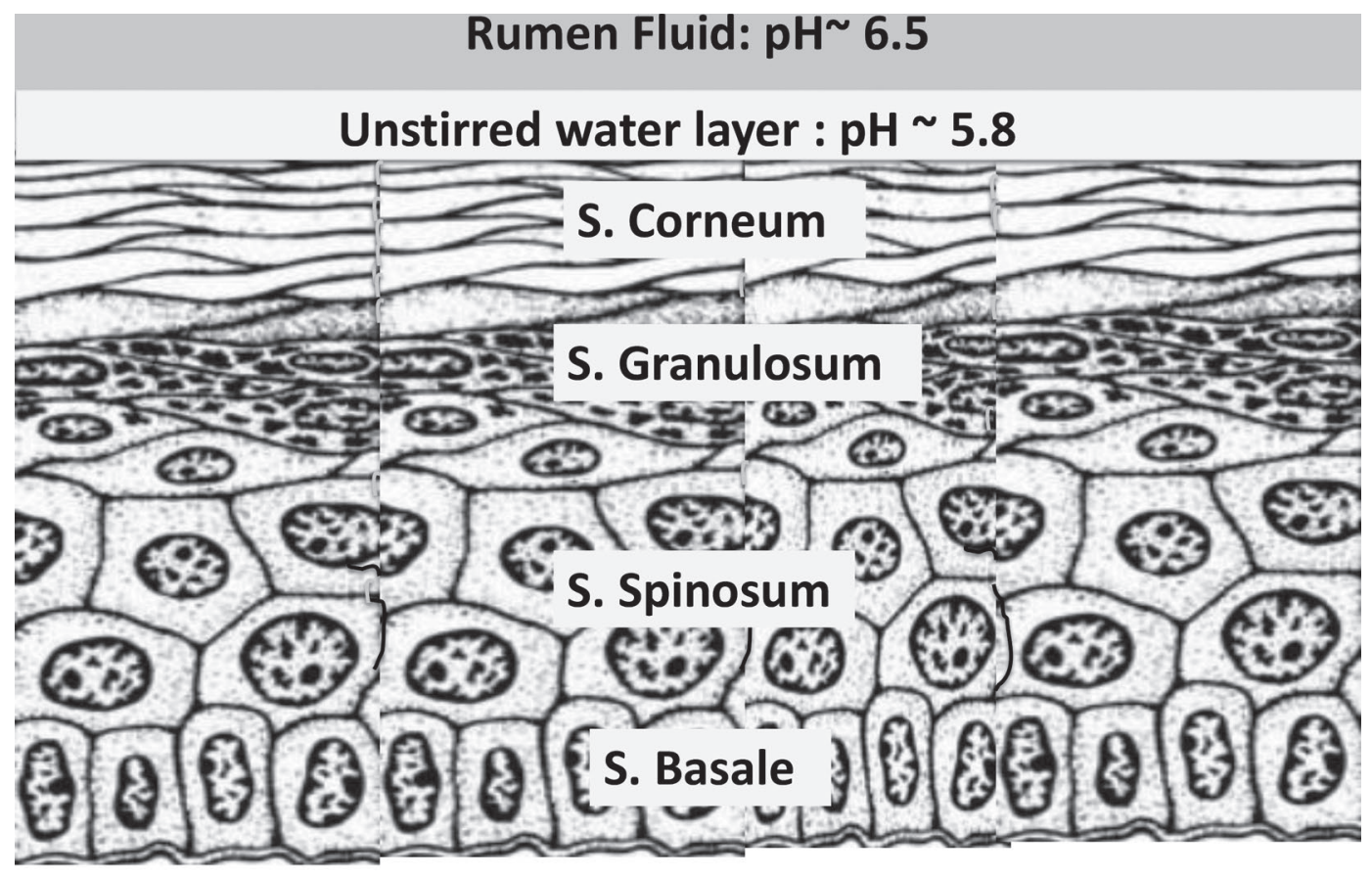

\section{Lamina Propria}

Figure 2. The mucosal lining of the rumen, reticulum, and omasum comprises stratified squamous epithelial cells. Cells in the stratum basale multiply and give rise to the cells of the other layers. A stratum corneum layer, consisting of sloughing dead cells, overlies the stratum granulosum layer, which overlies the stratum spinosum layer. Tight junctions between cells of the 3 living cell layers result in a barrier that is highly resistant to invasion. However, gap junctions exist between layers of cells that allow ions to freely diffuse from one layer to another down concentration gradients. An unstirred water layer with a $\mathrm{pH}$ slightly below that of rumen fluid overlies the stratified squamous epithelium.

\section{Paracellular Versus Transcellular Absorption}

To keep the role of tight junctions and paracellular absorption of minerals in perspective, it is interesting to consider the amount of surface area represented by the tight junctions in the intestinal tract. An aerial view of the surface of the small intestine would suggest that about $8 \%$ of the surface is made up of tight junctions between cells. However, when the surface area contributed by the microvilli of each enterocyte is also considered, the tight junction surface in contact with luminal fluids is just about $0.1 \%$ of the available absorptive surface area (Pappenheimer and Reiss, 1987; Nellans, 1991). That means that more than $99 \%$ of the absorptive surface is lined by apical membranes of cells with their attendant transcellular transport mechanisms. Paracellular absorption of minerals by diffusion through tight junction cation or anion pores may predominate when diets are higher in mineral content. However, when mineral content of the diet is marginal to deficient, transcellular transport mechanisms are more likely to be responsible for the bulk of mineral absorption. The effect of solvent drag of minerals through the tight junction water pores in the rumen and the small and large intestines is hard to quantify. Presumably, solvent drag of minerals can contribute to the nutrition of the animal only in those sites where there is net absorption of water (Nellans, 1991). Net water absorption is greatest in the omasum, ileum, and colon of ruminants (Argenzio et al., 1975; Edrise et al., 1986). The abomasum, duodenum, and upper jejunum are actually sites of net water secretion in ruminants (Sklan and Hurwitz, 1985). As water is removed from the ingesta within the lumen, the concentration $(\mathrm{mol} / \mathrm{L})$ of mineral remaining in the ingesta increases. Increased mineral concentration within the lumen would be expected to facilitate passive diffusion of minerals through the pores of the tight junctions.

\section{Dietary Recommendations}

A proper diet for the cow fulfills her requirements for absorbed minerals used in maintenance, growth, pregnancy, and lactation. Dividing the sum of the tissue requirements for a mineral by the fraction of the mineral absorbed from the diet provides a good approximation of the amount of mineral that must be in the diet to meet the requirement of the animal. For instance, for a 
corn silage, alfalfa hay, and calcium carbonate $\left(\mathrm{CaCO}_{3}\right)$ diet fed to a lactating cow to be balanced for $\mathrm{Ca}$, the number of grams of $\mathrm{Ca}$ absorbed from each diet ingredient must equal the sum of the grams of Ca required:

$$
\begin{gathered}
\text { maintenance } \mathrm{Ca} \text { requirement }+ \text { lactation } \mathrm{Ca} \\
\text { requirement }=\mathrm{Ca} \text { absorbed from corn silage }+\mathrm{Ca} \\
\text { absorbed from alfalfa }+\mathrm{Ca} \text { absorbed from } \mathrm{CaCO}_{3} .
\end{gathered}
$$

Minerals within feed ingredients used in diets are typically found within plant fiber and protein matrices. The availability of the mineral from these feedstuff sources varies from feedstuff to feedstuff and with the rate and extent of digestion of the binding material. Inorganic sources of minerals are commonly used to supplement diet minerals, and they can differ dramatically in the extent to which they are solubilized in the fluids overlying the epithelial cell absorptive surfaces.

Because the cow requires a certain number of grams or milligrams of a mineral to be absorbed from the diet each day, the NRC (2001) model tried to determine how many grams or milligrams of each mineral would be absorbed from each feedstuff or supplemental mineral source used in formulating a diet. A coefficient for absorption (Abs Coeff) representing the fraction of mineral that was likely to be absorbed was estimated for each mineral from each of the commonly used feedstuffs or inorganic mineral sources used in diets. Using our Ca example again, the grams of absorbed Ca supplied by the diet could be expressed as

$$
\begin{aligned}
& \text { absorbed } \mathrm{Ca}=(\mathrm{g} \text { of } \mathrm{Ca} \text { in corn silage } \times \text { corn silage } \\
& \mathrm{Ca} \text { Abs Coeff })+(\mathrm{g} \text { of } \mathrm{Ca} \text { in alfalfa } \times \text { alfalfa } \mathrm{Ca} \mathrm{Abs} \\
& \text { Coeff })+\left(\mathrm{g} \text { of } \mathrm{Ca} \text { in } \mathrm{CaCO}_{3} \times \mathrm{CaCO}_{3} \mathrm{Ca} \mathrm{Abs} \text { Coeff }\right)
\end{aligned}
$$

This model has allowed more accuracy in formulating rations to meet mineral needs of all classes of cows. Since the introduction of the NRC model in 2001, it has become clear that some of the estimates of mineral absorption coefficients for some feed ingredients were not accurate. Also, as illustrated later, the absorption coefficient for a mineral is not a fixed number and can be greatly influenced by the presence of antagonists to absorption of the mineral.

\section{Macrominerals and Acid-Base Physiology}

Acid-base physiology has traditionally been based on the view of Bronsted and Lowry, who independently suggested that an acid was a substance that can donate a proton $\left(\mathrm{H}^{+}\right)$and a base was a substance that could accept a proton. In biological fluids such as blood, traditional acid-base considerations tend to revolve around the Henderson-Hasselbalch equation (Hasselbalch, 1917). A weak acid in the nondissociated state can be described as HA. This HA is considered an acid because it can donate a proton. How much of the HA will dissociate is described by the negative logarithm (base 10) of the dissociation constant for the acid $\left(\mathbf{p} \boldsymbol{K}_{\mathrm{a}}\right)$. In the dissociated state, the weak acid can be described by its components: an $\mathrm{H}^{+}$and the anion $\mathrm{A}^{-}$. The anion of the weak acid is considered a base because it can accept a proton. The Henderson-Hasselbalch equation, $\mathrm{pH}=$ $\mathrm{p} K_{\mathrm{a}}+\log 10$ (base/acid), has long been clinically useful because it allows easy prediction of $\mathrm{pH}$ changes when considering weak acids or bases in biological fluids. This is particularly true of blood $\mathrm{pH}$ and consideration of the bicarbonate buffer system where blood $\mathrm{pH}$ is often described as $\mathrm{pH}=6.1+\log 10\left(\mathrm{HCO}_{3}{ }^{-} / \mathrm{H}_{2} \mathrm{CO}_{3}\right)$. Here bicarbonate anion $\left(\mathrm{HCO}_{3}{ }^{-}\right)$is considered a base because it can accept a proton. The nondissociated carbonic acid, $\mathrm{H}_{2} \mathrm{CO}_{3}$, is considered an acid because it can donate a proton. The amount of $\mathrm{H}_{2} \mathrm{CO}_{3}$ in the blood is proportional to the amount of $\mathrm{CO}_{2}$ in the blood and the solubility of $\mathrm{CO}_{2}$ in water. Respiration removes $\mathrm{CO}_{2}$ from the body, which in essence removes $\mathrm{H}_{2} \mathrm{CO}_{3}$ (acid) from the system, increasing the $\mathrm{pH}$. The role metabolic processes and other possible acids and bases might have in acid-base status is solved in this approach by the anion gap equation, where anion gap $=\left(\left[\mathrm{Na}^{+}\right]+\left[\mathrm{K}^{+}\right]\right)$ $-\left(\left[\mathrm{Cl}^{-}\right]+\left[\mathrm{HCO}_{3}^{-}\right]\right)$. The value of anion gap is typically between 10 and $20 \mathrm{mEq} / \mathrm{L}$ of plasma. When below normal, it implies that the animal has alkalosis; when too high, it implies acidosis (Oh and Caroll, 1977). It does not tell why an acid-base disturbance exists.

From a nutritional standpoint, a major problem of the traditional Henderson-Hasselbalch approach to acid-base physiology is that it does not predict the effect that feeding anionic salts such as $\mathrm{CaCl}_{2}$ would have on the $\mathrm{pH}$ of the animal's blood. Fortunately, there is another way to consider acid-base physiology that takes into account the effects strong ions (e.g., $\mathrm{Na}, \mathrm{Cl}$, and $\mathrm{K}$ ) and weak acids (e.g., albumin or inorganic phosphate) can have on $\mathrm{pH}$ of solutions (Constable, 2014; Trefz et al., 2015). It is called the strong ion difference approach and was championed by Peter Stewart, a Canadian physician (Stewart, 1981). It is in many ways a return to the original thoughts on acid-base chemistry proposed by Michael Faraday in 1830 and Svante Arrhenius in 1887 (Arrhenius, 1912). They suggested that acids were substances that, when dissolved in water, produced an increase in the concentration of $\mathrm{H}^{+}$in the solution. A base is a substance that, when dissolved in water, reduces the concentration of $\mathrm{H}^{+}$. 
In any solution, be it the blood, cell cytosol, intestinal lumen fluid, or a liter of water, there must be an equal number of positive and negative charges. In a liter of pure water, there will be $55.6 \mathrm{~mol}$ of $\mathrm{H}_{2} \mathrm{O}$. The only ions present are positively charged hydrogen ions $\left(\mathrm{H}^{+}\right)$and negatively charged hydroxyl ions $\left(\mathrm{OH}^{-}\right)$. Both are present at a concentration of $1 \times 10^{-7} \mathrm{M}$, so this is an electrically neutral solution. $\mathrm{pH}$ is defined as the $\log$ of $1 /\left[\mathrm{H}^{+}\right]$, so the $\mathrm{pH}$ of pure water is $\log 1 /(1$ $\times 10^{-7}$ ), which equals 7.0. If positively charged cations, such as $\mathrm{Na}^{+}$, were added to that solution, the charge of the solution would no longer be neutral. To maintain electroneutrality, the solution will undergo a reduction in positively charged $\mathrm{H}^{+}$and an increase in negatively charged $\mathrm{OH}^{-}$until the number of positively charged $\mathrm{H}^{+}$and $\mathrm{Na}^{+}$ions equals the number of $\mathrm{OH}^{-}$ions in the solution. Because $\mathrm{pH}$ is defined based on the concentration of $\mathrm{H}^{+}$, the $\mathrm{pH}$ increases - that is, the solution is now alkaline. The $\mathrm{Na}^{+}$ion is an Arrhenius base. Conversely, adding negatively charged anions to a solution, such as $\mathrm{Cl}^{-}$, will cause a corresponding increase in $\mathrm{H}^{+}$ and a reduction in $\mathrm{OH}^{-}$to neutralize the charge of the added anions. The number of negative charges in the solution (e.g., $\left[\mathrm{Cl}^{-}\right]+\left[\mathrm{OH}^{-}\right]$) must equal the number of positive charges in the solution, which are contributed by the $\left[\mathrm{H}^{+}\right]$. The solution becomes more acidic because $\mathrm{Cl}^{-}$has been added. The chloride anion is an Arrhenius acid.

The $\mathrm{H}^{+}$and $\mathrm{OH}^{-}$concentrations are manipulated through the dissociation of water $\left(\mathrm{H}_{2} \mathrm{O} \leftrightarrow \mathrm{H}^{+}+\mathrm{OH}^{-}\right)$ in response to the presence of atoms that alter the charge of the solution. The altered charge of the blood forces the water to come to a new state of equilibrium (Stewart, 1981). Expressed another way, when an $\mathrm{Na}^{+}$ ion is added to a solution, an equilibrium is established so that these 2 equations are solved simultaneously: $\left[\mathrm{Na}^{+}\right]+\left[\mathrm{H}^{+}\right]=\left[\mathrm{OH}^{-}\right]$, and $\left[\mathrm{H}^{+}\right] \times\left[\mathrm{OH}^{-}\right]=1 \times 10^{-14}$ (= $K_{\mathrm{w}}$, the dissociation constant of water).

In normal blood, the number of cations slightly exceeds the number of anions present, making normal blood $\mathrm{pH}$ slightly alkaline. Blood hydrogen ion concentration must be kept within very tight limits for life to exist. Expressed on a negative logarithmic scale, the $\mathrm{pH}$ $\left(\log 1 /\left[\mathrm{H}^{+}\right]\right)$of the venous blood is typically about 7.36 $\left(\mathrm{H}^{+}\right.$concentration $\left.=0.000000043 \mathrm{M}\right)$. If venous blood $\mathrm{pH}$ falls below $7.2\left(\mathrm{H}^{+}\right.$concentration $\left.=0.000000064 M\right)$ or increases above $7.6\left(\mathrm{H}^{+}\right.$concentration $=0.000000025$ $M)$, the animal will be seriously ill or dead. Blood electrical charge, and therefore $\mathrm{pH}$, is dependent on 3 factors. The first is respiration, which removes negative charges from the blood in the form of the bicarbonate anion whenever carbon dioxide is exhaled as predicted by the Henderson-Hasselbalch equation (Hasselbalch, 1917). The second is the concentration of proteins in the blood. Proteins are produced primarily in the liver and are generally negatively charged. The third is the strong ion difference of the blood (Stewart, 1981). Strong ions are minerals within the blood that carry a charge, either positive or negative. Ultimately, they enter the blood and body from the animal's diet.

Cations and anions in the diet can alter the blood $\mathrm{pH}$ only if they are absorbed from the diet to enter the blood. Diet $\mathrm{Na}^{+}, \mathrm{K}^{+}$, and $\mathrm{Cl}^{-}$are absorbed with almost $100 \%$ efficiency and enter the blood. Sulfate anions can also be absorbed from the diet, but only with about $60 \%$ efficiency (Goff et al., 2004). Sulfate anions can also be liberated into the blood during cellular metabolism of sulfur-containing AA absorbed from the diet. Diet $\mathrm{Ca}^{2+}, \mathrm{Mg}^{2+}$, and phosphate $\left(\mathrm{PO}_{4}{ }^{-3}\right)$ are also common cations and anions. They are generally absorbed with lower efficiency from the diet than $\mathrm{Na}^{+}, \mathrm{K}^{+}, \mathrm{Cl}^{-}$, and $\mathrm{SO}_{4}^{-2}$, but they are often present in diets in relatively high amounts. They too can play a role in the strong ion difference of the blood and thus the blood $\mathrm{pH}$. In theory, dietary trace mineral cations and anions that are absorbed into the blood also alter blood acidbase balance. However, they are present in such small amounts that their effects are negligible compared with the macrominerals and can be ignored.

If one adds $\mathrm{NaCl}$ to a diet, practically all of the $\mathrm{Na}^{+}$ cations and the $\mathrm{Cl}^{-}$anions are absorbed into the blood. Each positive charge entering the blood from $\mathrm{Na}^{+}$is offset by the entry of a negatively charged $\mathrm{Cl}^{-}$. The charge of the blood does not change, so the $\mathrm{pH}$ of the blood does not change. If calcium chloride $\left(\mathrm{CaCl}_{2}\right)$ is added to the diet, again almost all of the $\mathrm{Cl}^{-}$anions would enter the blood. However, the proportion of the $\mathrm{Ca}^{2+}$ cations that will enter the blood is likely to be much less than $100 \%$. In dry cows before calving, this proportion is often less than $20 \%$. For illustration purposes, let's say that $20 \%$ of the $\mathrm{Ca}^{2+}$ is absorbed and $100 \%$ of the $\mathrm{Cl}^{-}$is absorbed from $\mathrm{CaCl}_{2}$. For every 100 molecules of $\mathrm{CaCl}_{2}$ fed, 200 negative charges and 40 positive charges would enter the blood (each $\mathrm{Ca}^{2+}$ carries 2 positive charges). Because more anions than cations have been absorbed into the blood, the blood has become more negatively charged. A qualitative, very simplified equation to describe this would be $(20$ $\left.\left[\mathrm{Ca}^{2+}\right]+\left[\mathrm{H}^{+}\right]\right)=\left(200\left[\mathrm{Cl}^{-}\right]+\left[\mathrm{OH}^{-}\right]\right)$. To maintain electroneutrality, the extra negative charges must be offset by an increase in $\mathrm{H}^{+}$ions and a decrease in $\mathrm{OH}^{-}$, keeping in mind that the equation for the dissociation of water must also be satisfied: $\left[\mathrm{H}^{+}\right] \times\left[\mathrm{OH}^{-}\right]=1 \times 10^{-14}$. Increased $\left[\mathrm{H}^{+}\right]$means the $\mathrm{pH}$ is lower (more acidic). Conversely, if sodium bicarbonate $\left(\mathrm{NaHCO}_{3}\right)$ is added to a diet, almost $100 \%$ of the Na enters the blood. The majority of the $\mathrm{HCO}_{3}{ }^{-}$anions are converted to $\mathrm{CO}_{2}$ and $\mathrm{H}_{2} \mathrm{O}$ in the rumen and do not enter the blood. For 
every 100 molecules of $\mathrm{NaHCO}_{3}$ in the diet, almost 100 positive charges enter the blood and a few negative charges enter the blood. To maintain electroneutrality, the extra positive charges contributed by $\mathrm{Na}^{+}$must be offset by a decrease in $\mathrm{H}^{+}$ions and an increase in $\mathrm{OH}^{-}$. Decreased $\left[\mathrm{H}^{+}\right]$means the $\mathrm{pH}$ is higher (more alkaline).

Herbivores consume diets largely comprising forages. Forages are generally high in cations, such as $\mathrm{K}^{+}$and $\mathrm{Ca}^{2+}$, and relatively low in anions, such as $\mathrm{Cl}^{-}, \mathrm{SO}_{4}{ }^{-2}$, and $\mathrm{PO}_{4}{ }^{-3}$. This highly positive DCAD increases the $\mathrm{pH}$ of the blood of herbivores on high-forage diets slightly above that of nonherbivores (cow venous blood $\mathrm{pH}$ generally is $\sim 7.38$ ). This places the herbivore in a state of compensated metabolic alkalosis. It is referred to as a compensated alkalosis because no ill effects of the $\mathrm{pH}$ change are observed. The kidneys work to keep the alkalosis from becoming life threatening by excreting the extra $\mathrm{K}^{+}$into the urine. The high cation content of the urine produces an alkaline urine. Cow urine usually has a pH between 7.8 and 8.4 (Goff et al., 2004).

Highly positive DCAD in prepartum dairy cow diets is a major cause of acute periparturient hypocalcemia that occurs at the onset of lactation, better known as milk fever. Normally, blood Ca is kept within a very narrow range-between 9 and $10 \mathrm{mg} / \mathrm{dL}(2.25-2.5$ $\mathrm{m} M$ ). Calcium homeostasis is dependent on the action of the parathyroid glands, which secrete parathyroid hormone whenever a decrease in blood Ca concentration occurs. Parathyroid hormone will reduce urinary Ca excretion, activate bone Ca release, and stimulate renal synthesis of the hormonal form of vitamin $\mathrm{D}$ (1,25-dihydroxyvitamin D) to enhance intestinal Ca absorption. These actions will normally bring blood Ca back within the normal range within hours. Unfortunately, metabolic alkalosis caused by a high $\mathrm{K}^{+}$, and therefore high DCAD, diet interferes with the ability of parathyroid hormone to interact with its receptors on bone and kidney tissues, upsetting Ca homeostasis. The cow is unable to compensate for the flow of blood Ca into the mammary gland for colostrum and milk production and develops severe hypocalcemia (Goff, 2014).

During lactation, many organic acids are generated as a result of the enhanced metabolism of the cow as she tries to consume and digest enough calories to support milk production. Addition of cations to the diet can assist rumen $\mathrm{pH}$ stabilization as rumen buffers $\left(\mathrm{NaHCO}_{3}\right.$ and $\mathrm{KHCO}_{3}$ ) or rumen alkalinizers $(\mathrm{MgO})$. While in the rumen, cations act to buffer or neutralize rumen acids. If the cations are later absorbed, they alkalinize the blood. Several equations have been developed to describe the DCAD of a diet. They estimate the relative effect that diet macrominerals and their charges might have on the animal's blood pH. The DCAD mineral concentrations are generally expressed as milliequivalents per kilogram of diet or milliequivalents per $100 \mathrm{~g}$ of diet.

$$
\begin{gathered}
\mathrm{DCAD}=(\mathrm{Na}+\mathrm{K}) / \mathrm{Cl}(\text { Mongin, 1981) } \\
\mathrm{DCAD}=(\mathrm{Na}+\mathrm{K})-(\mathrm{Cl}+\mathrm{S}) \\
(\text { Ender et al., 1971; Sanchez et al., 1994) } \\
\mathrm{DCAD}=(\mathrm{Na}+\mathrm{K}+0.15 \mathrm{Ca}+0.15 \mathrm{Mg}) \\
-(\mathrm{Cl}+0.6 \mathrm{~S}+0.5 \mathrm{P})(\mathrm{NRC}, 2001) \\
\mathrm{DCAD}=(\mathrm{Na}+\mathrm{K})-(\mathrm{Cl}+0.6 \mathrm{~S})(\text { Goff et al., 2004) }
\end{gathered}
$$

The differences in the equations reflect whether all macrominerals were considered and whether efficiency of absorption of the mineral from the diet was considered.

Meta-analyses of published studies suggest that the optimal DCAD for lactating cows is between +250 and $+350 \mathrm{mEq} / \mathrm{kg}$ using the equation $\mathrm{DCAD}=(\mathrm{Na}+\mathrm{K})-$ $(\mathrm{Cl}+\mathrm{S})$ (Sanchez et al., 1994; Hu and Murphy, 2004). Similar results were reported regardless of whether $\mathrm{Na}$ or K was used to achieve the same DCAD (West et al., 1992). Increasing DCAD often increases milk fat percentage as well (Hu et al., 2007). It is unclear whether these effects are mediated by rumen buffering or faster rate of passage of digesta from the rumen (when using $\mathrm{NaHCO}_{3}$ or $\mathrm{K}_{2} \mathrm{CO}_{3}$ as the means of raising DCAD). There might also be some direct effect on energy metabolism or mammary fat synthesis when DCAD and blood $\mathrm{pH}$ are elevated in lactation.

Heat stress has mixed effects on acid-base physiology. During the heat of the day, the cow typically will have a higher respiratory rate, using movement of air in and out of the respiratory tract to reduce body heat (similar to the panting dog). This causes blood carbon dioxide levels to decrease, which lowers blood $\mathrm{HCO}_{3}{ }^{-}$ anion concentration, resulting in respiratory alkalosis. In severe heat stress the animal may drool excessively, resulting in the loss of large amounts of salivary $\mathrm{K}$ (and some Na) cations from the body, which can cause a metabolic acidosis. Whether respiratory alkalosis or metabolic acidosis predominates determines blood $\mathrm{pH}$. Heat stress also causes reduced DMI during the day. In the evening when heat abates, the respiration rate and drool losses return to normal. The cow's appetite returns, and there is a tendency for her to slug feed at night. This can promote rumen acidosis. A higher DCAD diet helps overcome the rumen acidosis associated with heat stress (Beede and Collier, 1986). A K 
concentration of $1.5 \%$ of DM during heat stress may maximize lactational performance (Beede and Shearer, 1991).

Much of this review is focused on movement of minerals across membranes and tight junctions of the GI tract. Movement of those minerals and ions can change the $\mathrm{pH}$ of the compartments the minerals move through. Two examples illustrate the differences between the traditional Henderson-Hasselbalch view of acid-base physiology and the strong ion difference approach.

In example 1, parietal cell secretions cause the $\mathrm{pH}$ of the lumen of the abomasum to be very acidic. The traditional view of acid-base physiology describes a proton pump at the apical surface of parietal cells that brings $1 \mathrm{~K}^{+}$into the cell from the lumen of the abomasum and moves $1 \mathrm{H}^{+}$out into the lumen from the cytosol $-\mathrm{a} \mathrm{K} \mathrm{K}^{+} / \mathrm{H}^{+}$exchanger. The strong ion approach suggests that the parietal cell simply removes a $\mathrm{K}^{+}$ion from the chyme. Removal of a positive charge from the lumen causes an electrical imbalance in that fluid. Water in the chyme will undergo a shift in its dissociation equilibrium and increase $\mathrm{H}^{+}$to return the solution to electroneutrality. The lumen fluid becomes more acidic. At the same time, the cytosol of the parietal cell has gained a positive charge from the $\mathrm{K}^{+}$. The water in the cytosol will undergo a shift in its dissociation equilibrium to reduce the $\mathrm{H}^{+}$content of the cytosol solution to maintain electroneutrality. In the strong ion model, the increased $\mathrm{H}^{+}$in the lumen of the abomasum did not come from the cytosol of the parietal cell; it comes from the dissociation of water.

In example $2, \mathrm{Na}^{+}$enters the epithelial cell down its electrical and chemical gradient through an apical membrane $\mathrm{Na}^{+}$transporter referred to as an $\mathrm{Na}^{+} / \mathrm{H}^{+}$ exchanger. Several isoforms are known to exist in the gut (Gurney et al., 2017). This transport mechanism removes $\mathrm{Na}^{+}$from the unstirred water layer adhering to the mucosal surface, which increases the $\mathrm{H}^{+}$concentration (reduces the $\mathrm{pH}$ ) of that fluid. The traditional view of acid-base physiology dictates that the $\mathrm{Na}^{+} /$ $\mathrm{H}^{+}$exchanger moves an $\mathrm{H}^{+}$from the cytosol to the unstirred water layer to lower the $\mathrm{pH}$ of the unstirred water layer. However, the strong ion theory of acidbase physiology dictates that only $\mathrm{Na}^{+}$moves out of the unstirred water layer through an $\mathrm{Na}$ channel. This causes the net charge of the unstirred water layer to be more negative, necessitating the establishment of a new water dissociation equilibrium, which will result in higher $\mathrm{H}^{+}$concentration in that fluid. The additional $\mathrm{H}^{+}$in the unstirred water layer did not originate in the cytosol in the strong ion theory model.

Because most publications view acid-base physiology from the traditional view, many of the exchangers in the GI tract are named as $\mathrm{Na}^{+} / \mathrm{H}^{+}, \mathrm{K}^{+} / \mathrm{H}^{+}$, or $\mathrm{Cl}^{-} /$
$\mathrm{OH}^{-}$exchangers. This review continues to use this nomenclature, but keep in mind that the strong ion model does not suggest that exchange is actually occurring.

\section{Minerals as Pro-Oxidants and Antioxidants}

During the course of catabolism, extremely dangerous compounds called free radicals are produced. A free radical is any atom or molecule capable of existing independently that contains 1 or more unpaired electrons. The unpaired electron makes free radicals unstable and very reactive; they tend to remove an electron from a neighboring compound or donate their extra electron to some other molecule or atom. Common free radicals generated during cellular respiration include the superoxide anion $\left(\mathrm{O}_{2}^{-}\right)$, hydrogen peroxide $\left(\mathrm{H}_{2} \mathrm{O}_{2}\right)$, and hydroxyl radicals $\left(\mathrm{OH}^{\bullet}\right)$. These are often termed reactive oxygen species. Less common, but even more destructive, are the free ionized metals in bodily fluids, particularly those trace minerals that fall into the category of transition metals in the periodic table of the elements (Valko et al., 2016). Primary targets that reactive oxygen species try to steal electrons from, or donate electrons to, include nitric oxide (creating reactive nitrogen species, such as peroxynitrite) and the carbon-carbon double bonds found in PUFA within the lipid bilayer of cell membranes. Formation of reactive nitrogen species depletes blood of nitric oxide, an important mediator of vascular smooth muscle contraction that regulates flow of blood to tissues. Reactive nitrogen species interact with the metals within molecules such as hemoglobin and ceruloplasmin, interfering with their function. Damage to DNA from the reactive nitrogen species can cause crosslinking of the DNA and block transcription. Peroxidation of cell membrane lipids by reactive oxygen species can cause cell membranes to lose integrity and become leaky (Dizdaroglu and Jaruga, 2012).

By stealing an electron from another molecule or perhaps donating an extra electron to another molecule, the free radical becomes stable and nonreactive. However, the devastating problem with free radicals is that the "stable" molecule they steal an electron from, or donate an electron to, will now have an unpaired electron, and so it now becomes a free radical. The new free radical - for example, an unsaturated lipid in the cell membrane that has lost an electron and is now a lipid peroxide - will in turn take electrons away from other molecules, setting off a chain reaction of electron removal or donation that will affect many more molecules until the reaction can be stopped through the action of the body's antioxidant systems.

All of the trace minerals that are classified as transition elements ( $\mathrm{Fe}, \mathrm{Cu}, \mathrm{Zn}, \mathrm{Mo}, \mathrm{Cr}$, and $\mathrm{Mn}$ ) have 
great oxidation-reduction potential, meaning that they have a strong tendency to obtain electrons from other molecules. However, they can do this only if they are in a free, ionized (charged) state in body fluids. The body attempts to minimize the existence of free metals in body fluids by producing proteins that form reversible bonds with the metal ions, where electrons are temporarily shared with or donated to the metal by the protein molecule. This prevents the metal from pulling electrons from lipids, DNA, or other molecules that are easier to steal an electron from rather than share an electron with (Sitar et al., 2013). These metal binding proteins are found inside and outside cells. Common metal binding proteins within blood include albumin (low affinity, high capacity) and more specific transporters such as transferrin or ceruloplasmin (high affinity, lower capacity). In these particular protein carriers, the metal becomes ligated to 1 or more nitrogen or oxygen groups on the side chains of AA such as lysine, histidine, and glutamate in a hydrophilic area of the protein molecule. Often, this area is then shielded from water, which might pull the metal off the protein by enveloping it in a hydrophobic group of AA on the protein (Yamashita et al., 1990; Berg et al., 2002). Unfortunately, when high amounts of the metals are ingested it is possible to absorb more metal than the metal binding proteins can successfully bind. At this point, free ionized metal concentration begins to increase, causing tissue damage. The pathologies associated with $\mathrm{Fe}, \mathrm{Cu}$, and $\mathrm{Zn}$ toxicity are often the result of damage to lipids in cell membranes leading to cell lysis. Typical symptoms include lysis of red blood cells causing jaundice ( $\mathrm{Cu}$ and $\mathrm{Zn}$ toxicity) or lysis of thrombocytes causing widespread hemorrhage (Fe toxicity).

Interestingly, the body takes advantage of the tendency of metal ions to donate and take up electrons by incorporating these metals in specialized antioxidant enzymes that can neutralize free radicals such as the reactive oxygen species. In this case, the enzyme carefully controls which molecules will be donating an electron to the metal or accepting an electron from the metal. In the example below, the dismutation, or removal, of superoxide anion $\left(\mathrm{O}_{2}{ }^{-}\right)$from fluids can be described by 2 half equations that occur rapidly to transform the $\mathrm{O}_{2}{ }^{-}$into less harmful oxygen and hydrogen peroxide molecules. These half reactions are described below for the $\mathrm{Cu}$ - and $\mathrm{Zn}$-containing superoxide dismutase (Cu-ZnSOD) found in the cytosol of all cells. The $\mathrm{Cu}^{2+}$ atom can take an electron from the $\mathrm{O}_{2}{ }^{-}$to create $\mathrm{O}_{2}$. It becomes $\mathrm{Cu}^{+}$in the process. The $\mathrm{Cu}^{+}$can then donate that electron to a second molecule of $\mathrm{O}_{2}{ }^{-}$, converting it to hydrogen peroxide.

$$
\begin{gathered}
\mathrm{Cu}^{2+}-\mathrm{ZnSOD}+\mathrm{O}_{2}^{-} \rightarrow \mathrm{Cu}^{+}-\mathrm{ZnSOD}+\mathrm{O}_{2} \\
\mathrm{Cu}^{+}-\mathrm{ZnSOD}+\mathrm{O}_{2}^{-}+2 \mathrm{H}^{+} \rightarrow \mathrm{Cu}^{2+}-\mathrm{ZnSOD}+\mathrm{H}_{2} \mathrm{O}_{2}
\end{gathered}
$$

The same equations could be used to describe the chemistry of a superoxide dismutase that utilizes $\mathrm{Mn}$ as the metal and serves as the primary antioxidant enzyme within mitochondria. The Mn is substituted for $\mathrm{Cu}$, and the $\mathrm{Mn}$ valence state would waver between +3 and +2 instead of the +2 and +1 for $\mathrm{Cu}$.

The hydrogen peroxide generated by the action of the superoxide dismutases can be subsequently converted to water and oxygen by catalase, an Fe-containing enzyme that is abundant in mammalian tissue. The $\mathrm{Fe}^{3+}$ incorporated into the catalase is used to donate an electron to 1 molecule of $\mathrm{H}_{2} \mathrm{O}_{2}$, becoming $\mathrm{Fe}^{4+}$ temporarily. Catalase temporarily holds the unstable oxygen atom created in the process. The $\mathrm{Fe}^{4+}$ now takes an electron away from a second molecule of $\mathrm{H}_{2} \mathrm{O}_{2}$. This allows the unstable oxygen atom held on the catalase to react with the second $\mathrm{H}_{2} \mathrm{O}_{2}$ to generate water and an oxygen molecule. It also returns the catalase $\mathrm{Fe}^{4+}$ to the $\mathrm{Fe}^{3+}$ state (McCord and Fridovich, 1988).

$$
\begin{gathered}
\mathrm{H}_{2} \mathrm{O}_{2}+\mathrm{Fe}(\mathrm{III}) \rightarrow \mathrm{H}_{2} \mathrm{O}+\mathrm{O}+\mathrm{Fe}(\mathrm{IV}) \\
\mathrm{H}_{2} \mathrm{O}_{2}+\mathrm{O}+\mathrm{Fe}(\mathrm{IV}) \rightarrow \mathrm{H}_{2} \mathrm{O}+\mathrm{Fe}(\mathrm{III})+\mathrm{O}_{2}
\end{gathered}
$$

Selenium is a component of the enzyme glutathione peroxidase, which has a unique role in the battle against oxidative stress. Two molecules of reduced glutathione (GSH) will each donate a hydrogen atom to an $\mathrm{H}_{2} \mathrm{O}_{2}$ molecule, forming 2 water molecules. The sulfhydryl groups of the 2 oxidized glutathione molecules join together, forming glutathione disulfide. Selenium is a cofactor necessary for function of glutathione peroxidase. This enzyme takes oxidized glutathione disulfide and reduces the sulfur-sulfur bond, regenerating 2 GSH molecules. The reduced glutathione can then be used to break down another hydrogen peroxide molecule. Lack of Se quickly leads to a lack of glutathione peroxidase and shortly after that a shortage of reduced GSH.

As with the transition metals, when fed in excess, inorganic forms of Se readily generate free radicals if allowed to exist in the unbound, ionized state. Inorganic Se can react with tissue thiols, such as glutathione and cysteinyl residues of proteins, to form selenotrisulphides, which in turn may react with other thiols to generate oxygen free radicals (Garberg et al., 1988). Feeding organically bound Se has lower potential to be toxic, but free ionized Se can still be generated during metabolism of the Se-containing molecules. 
Oxidative stress is a term used when the generation of free radicals in the tissues of the body exceeds the ability of the various systems of the body to neutralize the free radicals (primarily reactive oxygen species) or exceeds the ability of the body to repair the damage done by unquenched free radicals. Deficiency of the trace minerals involved in free radical neutralization can lead to oxidative stress.

Not all free radical generation is bad. Phagocytic cells of the immune system typically engulf invading bacteria within a phagosome. This phagosome then fuses with a lysosome - a vesicle within the phagocyte where free radicals such as $\mathrm{O}_{2}^{-}, \mathrm{H}_{2} \mathrm{O}_{2}, \mathrm{OH}^{\bullet}$, and nitric oxide have been generated. Upon fusing with the phagosome, the free radical reactive oxygen species (neutrophils) and reactive nitrogen species (macrophages) will attack bacterial lipids and DNA and hopefully kill the pathogens. In addition, myeloperoxidase (an enzyme that contains a heme molecule containing $\mathrm{Fe}$ ) found in many leukocytes produces hypochlorous acid $(\mathrm{HOCl})$ by reacting hydrogen peroxide $\left(\mathrm{H}_{2} \mathrm{O}_{2}\right)$ and $\mathrm{Cl}$ anion $\left(\mathrm{Cl}^{-}\right)$. Hypochlorous acid, the active ingredient of bleach, is deadly to most bacteria. These immune cell-generated free radicals are usually kept contained within the phagosome and therefore have few vital compounds to interact with and disrupt or damage in the cell. However, during prolonged inflammation, the hypochlorous acid and other free radicals can be released into extracellular fluids by activated neutrophils upon contact with bacteria (Zuo et al., 2015).

The following sections describe mechanisms used to absorb the various minerals critical to dairy cow nutrition. The review only briefly mentions the role the minerals play in bodily functions or animal requirements, as this information is widely available in many nutrition texts.

\section{MACROMINERALS}

\section{Calcium}

Calcium Homeostasis. Calcium is vital to normal bone structure. Blood Ca concentrations must be maintained within a very tight range to allow normal nerve and muscle function and to provide the Ca needed for new bone formation. Because the functions of $\mathrm{Ca}$ are so critical to life, an elaborate system has developed to facilitate maintenance of serum $\mathrm{Ca}$ concentration between approximately 9.0 and $10 \mathrm{mg} / \mathrm{dL}(2.25-2.5 \mathrm{mM})$ in the cow.

Calcium leaves the extracellular fluids during bone formation as digestive secretions, sweat, and urine. An especially large loss of $\mathrm{Ca}$ to milk occurs during lactation in the cow. If $\mathrm{Ca}$ loss from the extracellular fluids exceeds the amount of Ca entering the extracellular fluids, the concentration of $\mathrm{Ca}$ in plasma decreases. The parathyroid glands sense the decrease in blood Ca and secrete parathyroid hormone. Parathyroid hormone increases renal $\mathrm{Ca}$ reabsorption mechanisms to reduce urinary Ca loss. If this is not adequate to restore blood Ca concentration, the parathyroid hormone will stimulate the kidney to produce a hormone from vitamin D called 1,25-dihydroxyvitamin $\mathrm{D}$. The 1,25-dihydroxyvitamin D stimulates processes to enhance intestinal absorption of dietary Ca. Prolonged parathyroid hormone secretion will trigger bone cells to resorb bone $\mathrm{Ca}$ and pump it into the blood.

Calcium Absorption. Ultimately, dietary Ca must enter the extracellular fluids to permit optimal performance of the animal (Figure 3). Paracellular Ca absorption can occur by passive diffusion between epithelial cells across any portion of the digestive tract whenever ionized $\mathrm{Ca}$ concentration in the digestive fluids directly over the mucosa and tight junctions exceeds approximately $6 \mathrm{mM}$, which is almost 5 -fold greater than ionized $\mathrm{Ca}$ concentration within the extracellular fluids (Bronner, 1987). These concentrations are rapidly reached when calves are fed all-milk diets and when cows are given oral Ca drenches or boluses for prevention of hypocalcemia (Goff and Horst, 1993). The effect is relatively short lived. For instance, when a bolus oral dose of $\mathrm{CaCl}_{2}$ is administered, the concentration of Ca rapidly increases above $6 \mathrm{~m} M$ over a portion of the digestive tract mucosa allowing paracellular $\mathrm{Ca}$ absorption. But as a result of dilution of the $\mathrm{Ca}$ and the presence of materials that complex or chelate the $\mathrm{Ca}$ ions in the rumen fluids so they are no longer in the ionized state, the ionized Ca concentration falls below $6 \mathrm{~m} M$ in a few hours.

In nonruminant species, studies suggest that more than $50 \%$ of $\mathrm{Ca}$ absorbed from typical diets is absorbed by the passive paracellular route (Nellans, 1988). It is unknown how much passive absorption of $\mathrm{Ca}$ occurs from diets typically fed to dairy cattle. The diluting effect of the rumen and the chelation of $\mathrm{Ca}$ within the rumen would likely reduce the degree to which passive Ca absorption would occur. As Ca complexes and less soluble salts, such as $\mathrm{CaCO}_{3}$, move through the abomasum and interact with $\mathrm{HCl}$ they can often become more soluble, which will increase ionized Ca concentrations in the fluids entering the duodenum. Also, as water is removed from the digesta as it moves through the duodenum and jejunum, the concentration of $\mathrm{Ca}$ in the remaining chyme increases. This allows paracellular absorption of some portion of the dietary $\mathrm{Ca}$ in the ileum. In dry cows fed diets containing more than $0.5 \% \mathrm{Ca}$, if just $40 \%$ of diet $\mathrm{Ca}$ is absorbed paracellularly, it will provide the Ca required to maintain Ca homeostasis. 


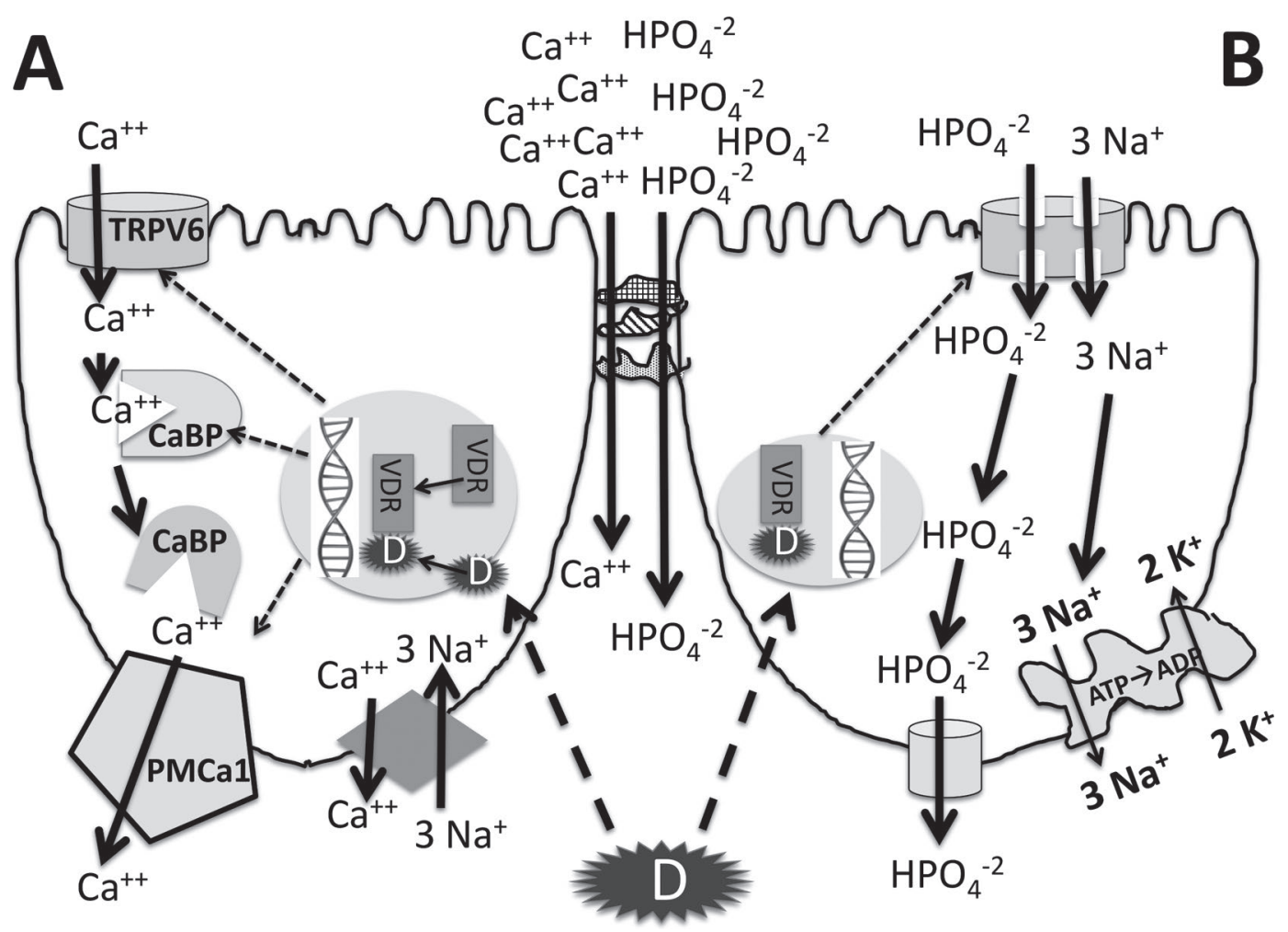

Figure 3. Calcium and phosphate absorption mechanisms in the small intestine. Both Ca and phosphate ions can be absorbed paracellularly through pores in the tight junction and transcellularly. (A) Transcellular absorption of Ca is stimulated by 1,25-dihydroxyvitamin D (D), which binds to vitamin D receptor (VDR) in the nucleus and stimulates production of an apical membrane Ca channel protein (TRPV6) to let Ca into the cell, a calbindin- $\mathrm{D}_{9 \mathrm{~K}}$ protein $(\mathrm{CaBP})$, which complexes the free $\mathrm{Ca}^{2+}$ ions and carries them across the cell. A vitamin D-dependent plasma membrane Ca ATPase pump (PMCa1) uses energy from ATP to move the Ca into the extracellular fluids. A vitamin D-independent 3 Na ${ }^{+} /$ $\mathrm{Ca}^{2+}$ exchanger also exists in the basolateral membrane to move Ca across the basolateral membrane. (B) Transcellular absorption of phosphate is also enhanced by 1,25-dihydroxyvitamin $\mathrm{D}$, which stimulates production of an $\mathrm{Na}$ /phosphate cotransporter in the apical membrane that uses either 2 or $3 \mathrm{Na}^{+}$ions to cotransport an $\mathrm{HPO}_{4}{ }^{-2}$ anion. Phosphate diffuses across the cell and exits the basolateral membrane by facilitated diffusion through a phosphate channel. The $\mathrm{Na}^{+}$ions that were used to aid $\mathrm{Ca}$ and phosphate transport are pumped into the extracellular fluids by the electrogenic $\mathrm{Na}^{+} / \mathrm{K}^{+}$ATPase pump in the basolateral membrane. ADP = adenosine diphosphate.

The proteins that form the tight junctions between intestinal epithelial cells include claudin 2 and claudin 12. These proteins can form Ca-specific channels through the tight junctions of cells (Fujita et al., 2008). There is growing evidence that 1,25-dihydroxyvitamin $\mathrm{D}$ affects the protein composition of the tight junctions, including increased expression of claudins 2 and 12, to increase paracellular absorption of $\mathrm{Ca}$ (Christakos et al., 2011; Elfers et al., 2016).

Active transcellular transport of $\mathrm{Ca}$ is a predominant route for $\mathrm{Ca}$ absorption in mature ruminants fed typical diets, particularly in early lactation when the cow is in negative $\mathrm{Ca}$ balance. This process is controlled by 1,25-dihydroxyvitamin $\mathrm{D}$, the hormone synthesized from vitamin D. By carefully regulating the amount of 1,25-dihydroxyvitamin D produced, the amount of dietary $\mathrm{Ca}$ absorbed can be adjusted to help maintain constant extracellular Ca concentration (Wasserman, 1981).
The 1,25-dihydroxyvitamin $\mathrm{D}$ circulating in the blood enters the enterocytes and binds to vitamin D receptors, initiating transcription and translation of several proteins necessary for active transport of $\mathrm{Ca}$ (Figure 3). The first protein produced in response to 1,25-dihydroxyvitamin $\mathrm{D}$ is transient receptor potential cation channel subfamily V member 6 (TRPV6), an apical membrane $\mathrm{Ca}$ channel. This allows lumen Ca to cross the apical membrane to enter the cell. The ionized Ca concentration inside the epithelial cell is lower than the Ca concentration in the lumen of the digestive tract, so ionized Ca within the area of the microvilli of the enterocyte will readily move into the cell if the Ca channel is present. Note that TRPV6 may not be the only channel Ca can use to cross the apical membrane, as mice that have had the TRPV6 gene knocked out still absorb Ca well (Kutuzova et al., 2008). The next protein produced in response to 1,25-dihydroxyvitamin $\mathrm{D}$ is calbindin- $\mathrm{D}_{9 \mathrm{~K}}(\mathrm{CaBP})$, which binds the $\mathrm{Ca}$ ions 
coming in through the TRPV6 and other Ca channels in the apical membrane (free ionized $\mathrm{Ca}$ within the cytosol could disrupt cell functions) and transports the $\mathrm{Ca}$ across the enterocyte. It then passes the Ca off to the third vitamin $\mathrm{D}$-dependent protein located in the basolateral membrane. This is the plasma membrane Ca ATPase pump 1 (PMCA 1), which pumps Ca out of the cell using the energy supplied by ATP. The $\mathrm{Ca}^{2+}$ concentration in the interstitial space is approximately 5,000 -fold greater than that in the cytosol, so the pump is working to move $\mathrm{Ca}^{2+}$ against a large electrochemical gradient. A vitamin D-independent $3 \mathrm{Na}^{+} / \mathrm{Ca}^{2+}$ exchanger also exists in the basolateral membrane to move $\mathrm{Ca}$ across the basolateral membrane (Hoenderop et al., 2005). It uses the electromotive force provided by the entry of $3 \mathrm{Na}^{+}$into the cell to power movement of Ca into the interstitial space (Hildmann et al., 1982). It is not thought to play a major role in mammalian Ca extrusion across the basolateral membrane of the small intestine (Hoenderop et al., 2005). The $\mathrm{Ca}^{2+}$ moves into the extracellular fluids of the lamina propria, where it diffuses into the circulation (Fleet and Schoch, 2010).

Calcium can be absorbed across the rumen epithelium as well (Care et al., 1989). The rumen wall may present a bigger challenge to paracellular absorption than does the single cell layer of the small intestine. However, placement of large amounts of $\mathrm{Ca}(50 \mathrm{~g}$ or more) into the rumen results in rapid absorption of a small portion of the $\mathrm{Ca}$ into the blood of the cow for several hours (Goff and Horst, 1993). It lasts only as long as the ionized $\mathrm{Ca}$ concentration in the rumen fluid remains high enough to provide the electrochemical gradient force needed to move Ca across the tight junctions between epithelial cells of the stratum granulosum. Schroder et al. (2015) calculated that a 40-g bolus of $\mathrm{Ca}$ (as $\mathrm{Ca}$ chloride or $\mathrm{Ca}$ propionate) in a $100-\mathrm{L}$ rumen of a cow results in a $10-\mathrm{m} M \mathrm{Ca}$ concentration in the rumen fluids (though not all of it is likely to remain in an ionized state within the rumen fluid because there are many substances in rumen fluid that might form complexes with the $\mathrm{Ca}$ ions). Simulating this level of $\mathrm{Ca}$ in vitro resulted in a rapid and dramatic increase in the net flux of $\mathrm{Ca}$ across rumen epithelium preparations. This suggests rapid paracellular transport of Ca across the rumen wall (Schroder et al., 2015). Transcellular absorption of Ca across the rumen epithelium also occurs at rumen Ca concentrations above $1 \mathrm{~m} M$ (Höller et al., 1988). However, transcellular Ca transport across the rumen may occur by mechanisms that are different from that in the small intestine. For example, the receptor for 1,25-dihydroxyvitamin $\mathrm{D}$ is reported to be present in rumen epithelium in very low amounts (Schröder et al., 2001), if present at all (Riner et al., 2008). The Ca channel, TRPV6, that is found in the apical membrane of small intestinal epithelia and is responsive to 1,25-dihydroxyvitamin $\mathrm{D}$ does not seem to exist in rumen epithelia (Schroder et al., 2015). The Ca pump PMCA1 is present in rumen epithelia (Schroder et al., 2015) but may not be important to Ca absorption in the rumen because blocking the activity of the PMCA1 pump with pervanadate has no effect on in vitro Ca flux across the rumen epithelium (Schröder et al., 1999). Instead, the $\mathrm{Na} / \mathrm{Ca}$ exchanger may be more important for extrusion of $\mathrm{Ca}$ from the rumen epithelium to the interstitial fluid (LeonhardMarek et al., 2010). The CaBP protein needed to move Ca across the cell does not appear to be present in sheep rumen (Schröder et al., 2001) but is present in goat rumen (Sidler-Lauff et al., 2010). Interestingly, vitamin $\mathrm{D}$ (1,25-dihydroxyvitamin $\mathrm{D})$ increases the active transport of $\mathrm{Ca}$ across the rumen wall of goats (Schröder et al., 1997). One laboratory reported that sheep also increase ruminal Ca transport in response to 1.25-dihydroxyvitamin D (Hyde and Fraser, 2014), whereas another laboratory found no response in sheep (Schröder et al., 1999). In vitro studies have established that short-chain fatty acids must be present in the rumen fluid if $\mathrm{Ca}$ is to be absorbed by active transport across the rumen epithelium (Leonhard-Marek et al., 2010; Schroder et al., 2015), but it is unknown whether the availability of short-chain fatty acids would ever limit $\mathrm{Ca}$ absorption by the rumen in the living ruminant. The mechanisms used in the rumen, particularly of cattle, for active Ca transport remain unknown, but they are clearly different than the mechanisms used in the small intestine.

High dietary Ca (above $\sim 120 \mathrm{~g} / \mathrm{d}$ ) in the cow increases the fraction of diet Ca absorbed by the rumen, and it may exceed the amount absorbed in the small intestine (Grace et al., 1974; Khorasani et al., 1997; Schröder and Breves, 2006). At low dietary Ca content, the rumen may even be a site of net secretion of $\mathrm{Ca}$ (Schroder et al., 2015). Addition of anions to the diet of sheep increases the percentage of ionized $\mathrm{Ca}$ in the rumen and increases the flux of Ca across the rumen wall (Wilkens et al., 2016), probably via the paracellular route. In summary, the rumen is a major site of Ca absorption when diet $\mathrm{Ca}$ is high or when cows are treated with oral Ca drenches and boluses for acute prevention of hypocalcemia. Although the rumen is likely able to increase active transport of $\mathrm{Ca}$ in response to 1,25-dihydroxyvitamin D (Hyde and Fraser, 2014), the rumen is unlikely to be as important as the small intestine in providing ruminants an effectual means of adapting to a low-Ca diet. The solubility of common feedstuff sources of $\mathrm{Ca}$ in rumen fluid tends to be low in a lowCa diet. The small intestine has the advantage in that many sources of diet $\mathrm{Ca}$, such as limestone, are made 
much more soluble upon passage through the abomasum, where active transport in the small intestine can now utilize this dietary Ca.

Calcium Absorption Coefficients for Diet Formulation. The amount of dietary Ca needed to meet the cow's requirement for absorbed $\mathrm{Ca}$ is dependent on the availability of the different forms of $\mathrm{Ca}$ in the diet. It is often further complicated by the Ca status of the animal, as this affects 1,25-dihydroxyvitamin D synthesis and the efficiency of intestinal Ca absorption. The amount of $\mathrm{Ca}$ absorbed from the diet will normally equal, but not exceed, the requirement of the body for $\mathrm{Ca}$ if the diet contains enough available $\mathrm{Ca}$. The proportion of dietary $\mathrm{Ca}$ absorbed will decrease as dietary Ca content increases as the animal downregulates the efficiency of transcellular intestinal $\mathrm{Ca}$ absorption. The animals being tested should be fed a Ca-deficient diet to truly determine the absorbability of Ca from a feedstuff. This will ensure that intestinal Ca absorption mechanisms are fully activated so the animal will absorb every bit of the Ca available from the feedstuff that it possibly can (Martz et al., 1990). However, it is not advisable to formulate a diet for a cow based on how much Ca can theoretically be derived from a feedstuff when the intestine is fully activated for $\mathrm{Ca}$ absorption. It would not be desirable to place the cow in perpetual negative $\mathrm{Ca}$ balance to achieve fully activated intestinal Ca transport processes. Instead, the strategy is to use an estimate of Ca absorbability from a feedstuff or supplement based on the premise that the average cow will not have intestinal Ca absorption mechanisms turned on maximally.

The NRC (2001) Nutrient Requirements of Dairy Cattle subcommittee used an efficiency of absorption of 0.30 for $\mathrm{Ca}$ from forages based on just a few key studies (Hibbs and Conrad, 1983; Martz et al., 1990; Khorasani et al., 1997). Inorganic mineral sources were generally given higher coefficients of absorption - for instance, the NRC (2001) model suggests that $70 \%$ of the $\mathrm{Ca}$ in limestone is absorbable. Unfortunately, new knowledge of the efficiency of absorption of Ca from individual feedstuffs remains limited. In many diets, the forages and feedstuffs can supply almost all the Ca a growing heifer or close-up dry cow would need to meet its requirements for absorbed Ca. During lactation, the diet would generally have to be supplemented with inorganic sources of Ca. It would seem that the current NRC (2001) estimates for absorption coefficients from feedstuffs and inorganic Ca supplements are reasonable.

\section{Phosphorus}

Phosphorus is found within the body as the phosphate anion (typically in the bodily fluids as $\mathrm{HPO}_{4}^{-2}$ or $\mathrm{H}_{2} \mathrm{PO}_{4}^{-}$), and this is the form of $\mathrm{P}$ referred to when describing dietary $\mathrm{P}$. It is the form that carries out all biological roles of $\mathrm{P}$ in animals.

Phosphorus Utilization and Homeostasis. Net absorption of phosphate can occur in all sections of the rumen and the small and large intestines, but the bulk of absorption is in the duodenum and jejunum in ruminants (Breves and Schroder, 1991; Wadhwa and Care, 2002). Absorption of phosphate is generally in direct relation to supply of potentially absorbable phosphate in the lumen of the small intestine (Care et al., 1980). Presumably, as in nonruminants, absorption occurs via 2 distinct mechanisms (Figure 3). First, passive paracellular absorption of phosphate predominates when normal to large amounts of soluble $\mathrm{HPO}_{4}{ }^{-2}$ or $\mathrm{H}_{2} \mathrm{PO}_{4}{ }^{-}$ are consumed (Wasserman and Taylor, 1976). Second, when diets are low or marginal in $\mathrm{P}$, a saturable, active transcellular transport system can be activated. The rumen and upper intestinal cells can produce type II $\mathrm{Na}^{+}$-coupled phosphate cotransporter proteins (SLC34 family) in their apical membrane (Wadhwa and Care, 2002; Sabbagh et al., 2011). The phosphate is moving into the cytosol against its electrical and chemical gradient. The transporter protein uses the cotransport of $3 \mathrm{Na}^{+}$ions moving down their electrical and chemical gradient to provide the driving force to move a phosphate ion across the apical membrane. The transporter seems to be fairly specific for transport of divalent $\mathrm{HPO}_{4}{ }^{-2}$, so 3 positive charges enter the cell along with 2 negative charges, so the cytosol becomes less negative (increases intracellular $\mathrm{pH}$ slightly; Wagner et al., 2014). The phosphate diffuses across the cell to the basolateral membrane. A constitutive phosphate channel coupled to the Na/K ATPase pump moves the phosphate across the basolateral membrane into the extracellular fluids. Two factors are the primary determinants of whether the transcellular pathway is activated. The hormone 1,25-dihydroxyvitamin D acts through the vitamin $\mathrm{D}$ receptor to stimulate transcription of the apical membrane type II $\mathrm{Na}^{+}$-coupled phosphate cotransporter protein. Production of 1,25-dihydroxyvitamin D by kidney cell 1- $\alpha$ hydroxylase (CYP27B1) is primarily regulated in response to low blood $\mathrm{Ca}$ and is mediated by parathyroid hormone. However, high blood phosphate associated with feeding a higher $\mathrm{P}$ diet can also affect activity of the CYP27B1 enzyme. Elevations in blood phosphate cause bone osteocytes and osteoblasts to secrete a peptide hormone called fibroblast growth factor 23 (FGF23). The FGF23 circulates in the blood and binds to a fibroblast growth factor receptor (FGFR) on kidney cells, but only if a transmembrane enzyme called $\alpha$-Klotho is also bound to the FGFR (Martin and Quarles, 2012; Gonciulea and Jan De Beur, 2017). The FGF23/ $\alpha-$ Klotho/FGFR 
complex formation has several effects on the renal cell. It inhibits expression of the CYP27B1, reducing renal synthesis of 1,25-dihydroxyvitamin $\mathrm{D}$. It also causes upregulation of CYP24A1, an enzyme that will speed degradation of 1,25-dihydroxyvitamin $\mathrm{D}$. The FGF23/ $\alpha$-Klotho/FGFR complex also prevents renal tubule reabsorption of phosphate, promoting urinary excretion of phosphate. Reducing blood 1,25-dihydroxyvitamin D concentrations will reduce phosphate absorption (Erben, 2016). Unfortunately, reducing production of 1,25-dihydroxyvitamin $\mathrm{D}$ can have negative consequences on Ca homeostasis. This helps explain the well-known inhibition of diet Ca absorption that occurs with high-phosphate diets.

Feeding a very low $\mathrm{P}$ diet results in suppression of FGF23 and increases production of 1,25-dihydroxyvitamin D, which causes upregulation of the type II $\mathrm{Na}^{+}-$ coupled phosphate cotransporter protein (Sabbagh et al., 2011). Epidermal growth factor, thyroid hormone, growth hormone, glucocorticoids, and estrogens also play a minor role in upregulation of type II $\mathrm{Na}^{+}$-coupled phosphate cotransporter protein to enhance phosphate transcellular transport, but it is not known how they work at the cellular level.

Phytate-bound phosphate is only slightly available to nonruminants. However, phytase activity of ruminal microorganisms renders almost all of the phytate $\mathrm{P}$ available for absorption. Absorbed $\mathrm{P}$ may be retained for use (milk, fetal skeleton, bone growth, and remodeling). A large amount of $\mathrm{P}$ is also secreted in saliva (as much as $90 \mathrm{~g} / \mathrm{d}$ ) and intestinal gland secretions into the digestive tract. Most of this phosphate is reabsorbed, and only a small portion is excreted in feces.

Coefficients of Absorption for Phosphorus. The dietary requirement is the sum of the requirements for absorbed P for maintenance, growth, pregnancy, and lactation divided by the absorption coefficient(s) of the diet components. The absorption coefficients of $\mathrm{P}$ used in the NRC (2001) model for most feedstuffs commonly fed to younger cattle are 0.90 for calves consuming milk or milk replacer and 0.78 for young ruminating calves between 100 and $200 \mathrm{~kg}$ of BW. For adult cows, absorption coefficients of 0.64 and 0.70 were used for forages and concentrates, respectively, in the NRC (2001) model. These coefficients suggested that cows could utilize diet $\mathrm{P}$ much more efficiently than earlier versions of the NRC (1989) predicted and resulted in formulation of diets with much lower levels of P. No detrimental effects have been observed with these lower $\mathrm{P}$ diets, and experience with these diets suggests that the coefficient for absorption of $\mathrm{P}$ may still be underestimated for some feedstuffs (Peterson et al., 2005; Feng et al., 2016). This may offer further opportunity, as phosphate is the most expensive macro- mineral used in diets of dairy cattle and the mineral of greatest environmental concern (Wu et al., 2001).

\section{Sodium and Chloride}

Sodium and Chloride Absorption. Sodium is the predominant cation of the blood and extracellular fluids and plays a crucial role in absorption of dietary sugars, AA, and water. Chloride is the major anion in the body involved in regulation of osmotic pressure, making up more than $60 \%$ of the total anion equivalents in the extracellular fluid. Chloride is the chief anion in gastric secretions and is responsible for the low $\mathrm{pH}$ in the lumen of the abomasum. Chloride is actively secreted into the intestinal lumen by crypt epithelial cells and acts as the driving force for $\mathrm{Na}$ movement into the lumen of the gut to satisfy needs of $\mathrm{Na}$ /hexose and $\mathrm{Na}$ / AA symporters. Both $\mathrm{Na}$ and $\mathrm{Cl}$ always exist in a fully dissociated (ionized) state when in solution.

Cattle and most land vertebrates evolved without abundant diet Na. Therefore, the body developed very efficient and redundant mechanisms for $\mathrm{Na}$ absorption. Sodium and $\mathrm{Cl}$ can be absorbed from the rumen and the small and large intestines. Almost $100 \%$ of diet $\mathrm{Na}$ and more than $90 \%$ of diet $\mathrm{Cl}$ is absorbed. Because $\mathrm{Na}$ and $\mathrm{Cl}$ transporters across the epithelium are often coupled to maintain electroneutrality, $\mathrm{Na}$ and $\mathrm{Cl}$ absorption are discussed together.

Paracellular Absorption of Sodium and Chloride. Passive paracellular diffusion of $\mathrm{Na}$ across the tight junctions is not likely unless diet $\mathrm{Na}$ and lumen $\mathrm{Na}$ are very high. This is because the interstitial space below the tight junction generally has a high $\mathrm{Na}$ concentration as a result of the large amounts of $\mathrm{Na}$ pumped into the interstitial space during transcellular absorption of Na. The $\mathrm{Na}^{+}$presence also gives the interstitial space a positive charge relative to the lumen. The $\mathrm{Na}^{+}$moving out of the lumen would have to move against its concentration and electrical gradient to move across the tight junction. On the other hand, paracellular diffusion of $\mathrm{Cl}^{-}$is promoted by the electrical PD created by the presence of high $\mathrm{Na}^{+}$concentration in the interstitial space. This is particularly true in the upper duodenum and jejunum, where $\mathrm{Cl}$ concentration of chyme leaving the abomasum is high and crypt cell secretion of $\mathrm{Cl}$ is greatest. This is also the area where transcellular $\mathrm{Na}^{+}$absorption is greatest as a result of the activity of the $\mathrm{Na}$ /hexose and $\mathrm{Na} / \mathrm{AA}$ symporters, which also contribute to the high $\mathrm{Na}^{+}$concentration in the interstitial space.

The presence of high $\mathrm{Na}^{+}$concentration in the interstitial space promotes bulk flow of water through the pores of the tight junctions. Chloride (and other solutes) can then move with the bulk flow of water 
across the tight junctions into the interstitial space and then into capillaries of the lamina propria (Fordtran et al., 1968). Solvent drag of solute can occur throughout the entire digestive tract.

Transcellular Sodium and Chloride Absorption. Sodium absorption is almost exclusively carried out by transcellular transport processes. Chloride can also be absorbed transcellularly (Figure 4). Various mechanisms are used, and $\mathrm{Na}^{+}$and $\mathrm{Cl}^{-}$absorption can occur in the forestomachs, abomasum, and small and large intestines. The differences in all these transport mechanisms revolve around how $\mathrm{Na}^{+}$and $\mathrm{Cl}^{-}$move across the apical membrane. In all cases $\mathrm{Na}^{+}$moves across the apical membrane down its electrical and concentration gradient. Regardless of the method used to cross the apical membrane, $\mathrm{Na}^{+}$diffuses through the cytosol to the basolateral membrane. The $\mathrm{Na}^{+}$is pumped into the interstitial space, against its concentration gradient and electrical gradient, by the electrogenic $\mathrm{Na}^{+} / \mathrm{K}^{+}$ATPase pump (Gurney et al., 2017).

Chloride will always be moving against its electrical gradient when it crosses the apical membrane to enter the cell. Its transcellular transport must therefore always be linked to $\mathrm{Na}^{+}$transport (described below). Once $\mathrm{Cl}^{-}$has crossed the apical membrane, it diffuses to the basolateral membrane. The bulk of the $\mathrm{Cl}^{-}$ crosses the basolateral membrane into the interstitial space through $\mathrm{Cl}^{-}$channels. Diffusion of $\mathrm{Cl}^{-}$through the channels is dependent on the basolateral membrane electrogenic $\mathrm{Na}^{+} / \mathrm{K}^{+}$ATPase pump. The pump moves $3 \mathrm{Na}^{+}$ions out of the cell and pumps $2 \mathrm{~K}^{+}$ions into the cell. The PD generated across the basolateral membrane $(-25$ to $-40 \mathrm{mV})$ allows $\mathrm{Cl}^{-}$in the cytosol to move into the positively charged interstitial space fluids down its electrical gradient through the $\mathrm{Cl}^{-}$channels (Smyth, 2013). In some cases, $\mathrm{Cl}^{-}$may leave the cell using a $\mathrm{K}^{+} / \mathrm{Cl}^{-}$cotransport system (Reuss, 1989; Holtug et al., 1996).

Not all sections of the digestive tract have all $\mathrm{Na}^{+}$ and $\mathrm{Cl}^{-}$transporters operating. Each $\mathrm{Na}^{+}$and $\mathrm{Cl}^{-}$ transport mechanism is described separately, and then the coupled transport of $\mathrm{Na}^{+}$and $\mathrm{Cl}^{-}$is discussed.

1. $\mathrm{Na}^{+} / \mathbf{H}^{+}$Exchange: All Sections of the GI Tract. Sodium enters the epithelial cell down its elec-

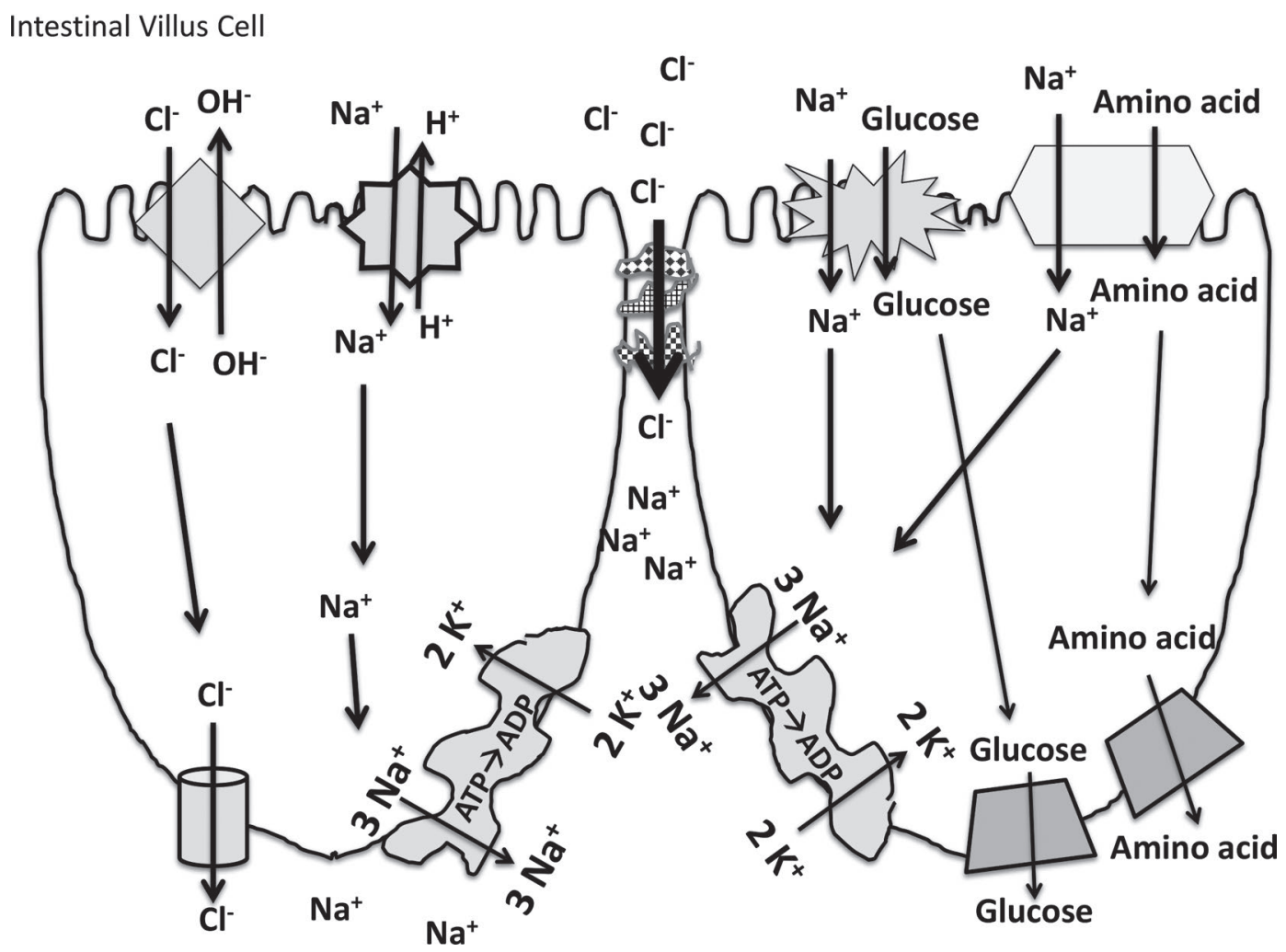

Figure 4. Absorption of $\mathrm{Na}$ and chloride by small intestinal villus cells. The $\mathrm{Na}$ can cross the apical membrane of enterocytes using $\mathrm{Na}^{+} / \mathrm{H}^{+}$ exchangers, $\mathrm{Na}^{+} /$hexose, and $\mathrm{Na}^{+} / \mathrm{AA}$ symporters. The $\mathrm{Na}^{+}$diffuses through the cytosol to reach the basolateral membrane. The Na/K ATPase electrogenic pump moves $\mathrm{Na}^{+}$into the interstitial space. Chloride, in high concentration as chyme leaves the abomasum, is absorbed paracellularly in the upper duodenum. Chloride $/ \mathrm{OH}^{-}$and $\mathrm{Cl}^{-} / \mathrm{HCO}_{3}{ }^{-}$exchangers, linked to the $\mathrm{Na}^{+} / \mathrm{H}^{+}$exchangers, bring chloride across the apical membrane. Chloride diffuses to the basolateral membrane, where it passes through chloride channels in the basolateral membrane to enter the interstitial space. ADP = adenosine diphosphate. 
trical and chemical gradient through an apical membrane $\mathrm{Na}^{+} / \mathrm{H}^{+}$exchanger (Martens and Gäbel, 1988; Figure 4). Several isoforms are known to exist in the gut (Gurney et al., 2017). This transport mechanism removes $\mathrm{Na}^{+}$from the unstirred water layer adhering to the mucosal surface, which increases the $\mathrm{H}^{+}$concentration (reduces the $\mathrm{pH}$ ) of that fluid.

Half of the diet and saliva $\mathrm{Na}$ entering the rumen is absorbed across the stratified squamous epithelium of the rumen, reticulum, and omasum (Dobson, 1959). This is an incredible feat considering that a cow producing $190 \mathrm{~L}$ of saliva/d can secrete $700 \mathrm{~g}$ of $\mathrm{Na}$ in her saliva (NRC, 2001). Sodium is absorbed using $\mathrm{Na}^{+} /$ $\mathrm{H}^{+}$exchangers in the apical membranes of cells of the stratum granulosum, a layer of cells that contains tight junctions that form a barrier between the rumen fluid and the underlying mucosa. The $\mathrm{Na}^{+}$then diffuses through gap junctions that connect cells of the stratum granulosum with cells of the stratum spinosum and stratum basale until it reaches the basolateral membrane of the stratum basale. Stratum basale cells have high numbers of mitochondria, which supply the ATP needed to fuel the $\mathrm{Na}^{+} / \mathrm{K}^{+}$ATPase pump that will move the $\mathrm{Na}^{+}$into the interstitial space (Martens et al., 1991; Graham and Simmons, 2005).

The $\mathrm{Na}^{+} / \mathrm{H}^{+}$exchanger increases $\mathrm{H}^{+}$concentration in the unstirred water layer adhered to the cell surfaces, and this can have an important effect on nutrition of the cow (Shiau et al., 1985; Bugaut, 1987). The $\mathrm{pH}$ in this microenvironment can be 0.3 to $0.7 \mathrm{pH}$ units lower than in the intestinal lumen or rumen fluid (assuming it behaves similarly to the human colon; McNeil et al., 1987). As nonionic diffusion of VFA is an important pathway for absorption of VFA across the rumen and colon wall, the lower $\mathrm{pH}$ created in the fluid at the cell surface by the $\mathrm{Na}^{+} / \mathrm{H}^{+}$exchangers can promote VFA absorption by causing more of the VFA to be in the nondissociated (protonated) state (Shiau, 1990; Sehested et al., 1996; Graham et al., 2007; Aschenbach et al., 2011). In the nondissociated state, the VFA have no electrical charge and are small enough and lipid soluble enough to diffuse across the apical membrane of the stratum granulosum or colon cells. For example, the $\mathrm{p} K_{\mathrm{a}}$ of propionate is 4.88 . If rumen fluid $\mathrm{pH}$ is 6.88 , just $1 \%$ of the propionate would be expected to exist in the nondissociated state. However, if the $\mathrm{pH}$ of the unstirred water layer has been reduced to 6.38 through the action of the $\mathrm{Na}^{+} / \mathrm{H}^{+}$exchanger, the nondissociated propionate increases to $3 \%$ of the total propionate, a 3 -fold increase in the propionate that can be absorbed by nonionic diffusion.

Upon entry to the cytosol, the $\mathrm{pH}$ of the cytosol (7.0-7.2) strongly favors dissociation of the protonated VFA, and the increased concentration of "dissociated"
VFA anions would be expected to reduce cytosol $\mathrm{pH}$. Fortunately, the $\mathrm{Na}^{+} / \mathrm{H}^{+}$exchanger also increases cytosolic $\mathrm{pH}$ to counteract the effect of the acidity that accompanies the appearance of the nonprotonated VFA (Rabbani et al., 2011). Once inside the cytosol of the rumen epithelium syncytium, the VFA diffuse through gap junctions from cell to cell to reach the basolateral membrane of the stratum basale cells. A new equilibrium is set up between dissociated and nondissociated VFA forms, and the nondissociated, protonated VFA then diffuse through the basolateral membrane. The activity of the $\mathrm{Na}^{+} / \mathrm{K}^{+}$ATPase pump in the basolateral membrane creates a large electrical PD across the membrane, making the interstitial space more highly positive. Anion channels linked to the $\mathrm{Na}^{+} / \mathrm{K}^{+}$ATPase pump in the basolateral membrane have been described, and they represent a means of moving dissociated VFA (nonprotonated) out of the cells for entry into the blood (Georgi et al., 2014).

The activity of the $\mathrm{Na}^{+} / \mathrm{H}^{+}$exchanger at the apical surface may be modified by the presence of ammonia $\left(\mathrm{NH}_{3}\right)$ in rumen fluid that has a high $\mathrm{pH}$. Once the ammonia diffuses into the stratum granulosum cells it can form $\mathrm{NH}_{4}^{+}$, and this increases the cytosolic $\mathrm{pH}$. This reduces the activity of the $\mathrm{Na}^{+} / \mathrm{H}^{+}$exchanger (Abdoun et al., 2005). On the other hand, situations that reduce cytosolic $\mathrm{pH}$, such as absorption of VFA, activate the $\mathrm{Na}^{+} / \mathrm{H}^{+}$exchanger. The $\mathrm{Na}^{+} / \mathrm{H}^{+}$exchanger protein has an $\mathrm{H}^{+}$sensitive activation site on it and its main function may be to keep cytosolic $\mathrm{pH}$ from becoming too acidic, which might damage the cell (Gleeson, 1992).

The activity of the $\mathrm{Na}^{+} / \mathrm{H}^{+}$exchanger is also reduced by nitric oxide and by Escherichia coli enterotoxins (McEwan et al., 1988; Shimada and Hoshi, 1988). This increases the $\mathrm{pH}$ of the unstirred water layer and could affect absorption of $\mathrm{Na}$ and other nutrients such as VFA and Fe (Shawki et al., 2016), which in turn will affect water absorption as well.

2. $\mathrm{Na}^{+} /$Hexose and $\mathrm{Na}^{+} / \mathrm{AA}$ Symporters of the Duodenum and Jejunum. The $\mathrm{Na}^{+} /$glucose and $\mathrm{Na}^{+} /$AA symporters are located on the apical membranes of intestinal villus cells in the duodenum and jejunum (Wright, 1993). Sodium ions, moving down their electrical and chemical gradient across the apical membrane, provide the force that drives facilitated diffusion of AA and glucose across the apical membrane of villus cells of the small intestine (Figure 4).

3. Epithelial $\mathrm{Na}^{+}$Channels of the Colon. An $\mathrm{Na}^{+}$transporter known as the epithelial $\mathrm{Na}^{+}$channel exists in the colon. It permits $\mathrm{Na}$ absorption even when the $\mathrm{Na}$ content of the colon lumen is low. The $\mathrm{Na}^{+}$ moves through this channel down its electrical and chemical gradient. Experimentally, this $\mathrm{Na}^{+}$channel can be blocked with amiloride (Rossier et al., 2015). 
The epithelial $\mathrm{Na}^{+}$channels can be hormonally regulated. Aldosterone, secreted in response to low blood pressure, enhances absorption of $\mathrm{Na}^{+}$across the colon by inducing synthesis of the epithelial $\mathrm{Na}^{+}$channel proteins. This brings even that small amount of $\mathrm{Na}$ that might have ended up in the feces into the blood (Kunzelmann and Mall, 2002). As the $\mathrm{Na}$ is absorbed, it is followed by water restoring blood volume and blood pressure. Beyond its normal role in removing the final portion of water from normal feces, this also allows the colon to adapt and compensate when water is not being absorbed properly by the small intestine during malabsorptive diarrhea (such as rotavirus infection of calves) or if $\mathrm{Na}$ and water are secreted excessively by the small intestine during diseases such as enterotoxigenic E. coli diarrhea.

4. $\mathrm{Na}^{+} / \mathrm{HCO}_{3}{ }^{-}$Cotransporters in the Ileum and Colon. Apical membrane $\mathrm{Na}^{+} / \mathrm{HCO}_{3}{ }^{-}$cotransporters are likely in all portions of the GI tract but seem to be most active in the ileum and colon. They bring an $\mathrm{Na}^{+}$and an $\mathrm{HCO}_{3}{ }^{-}$across the apical membrane of the colon epithelium, so they are electrically neutral (Gleeson, 1992; Sandle, 1998).

5. $\mathrm{Cl}^{-} / \mathrm{OH}^{-}$and $\mathrm{Cl}^{-} / \mathrm{HCO}_{3}{ }^{-}$Exchangers and Linkage to $\mathrm{Na}^{+}$Absorption. The $\mathrm{Cl}^{-} / \mathrm{OH}^{-}$and $\mathrm{Cl}^{-} /$ $\mathrm{HCO}_{3}{ }^{-}$exchangers are found in the apical membrane of rumen and small and large intestine cells (Martens and Blume, 1987). The $\mathrm{Cl}^{-} / \mathrm{HCO}_{3}{ }^{-}$exchangers seem to be more prominent in the ileum and colon (Smyth, 2013). Movement of $\mathrm{Cl}^{-}$into the cell by either exchanger will cause the unstirred water layer to become more alkaline and the cytosol to become more acidic - the opposite effect of the $\mathrm{Na}^{+} / \mathrm{H}^{+}$exchanger.

The interior of absorptive cells is highly negative compared with the intestinal lumen, so the $\mathrm{Cl}^{-}$exchangers would have to move the $\mathrm{Cl}^{-}$into the cell against its electrical gradient. To get around this hurdle, the activity of the $\mathrm{Cl}^{-} / \mathrm{OH}^{-}$and $\mathrm{Cl}^{-} / \mathrm{HCO}_{3}{ }^{-}$exchangers is almost always coupled to the activity of the $\mathrm{Na}^{+} /$ $\mathrm{H}^{+}$exchanger (Figure 4). As the $\mathrm{Na}^{+} / \mathrm{H}^{+}$exchanger brings $\mathrm{Na}^{+}$into the cell, it creates a small zone under the apical membrane that is not as negatively charged as the cytosol as a whole. This permits the entry of $\mathrm{Cl}^{-}$through the $\mathrm{Cl}^{-} / \mathrm{OH}^{-}$and $\mathrm{Cl}^{-} / \mathrm{HCO}_{3}{ }^{-}$exchangers (Gleeson, 1992). The coupling of $\mathrm{Na}^{+}$and $\mathrm{Cl}^{-}$exchangers is controlled by the $\mathrm{pH}$ of the cytosol. An increase in $\mathrm{pH}$ of the cytosol due to increased activity of the $\mathrm{Na}^{+} / \mathrm{H}^{+}$exchanger activates apical $\mathrm{Cl}^{-} / \mathrm{OH}^{-}$and $\mathrm{Cl}^{-} /$ $\mathrm{HCO}_{3}^{-}$exchangers. The $\mathrm{Cl}^{-} / \mathrm{HCO}_{3}^{-}$exchanger has been shown to have an $\mathrm{OH}^{-}$sensitive activation site (Mugharbil et al., 1990).

Fortunately, movement of $\mathrm{Na}^{+}$across the apical membrane into the cell is often coupled with movement of $\mathrm{Cl}^{-}$across the apical membrane and into the cell. This has the net effect of bringing a positive and a negative charge out of the unstirred water layer and into the cytosol, so both solutions remain electroneutral and the $\mathrm{pH}$ does not change. However, this is not always the case. Because the $\mathrm{pH}$ of the unstirred water layer is slightly lower than the $\mathrm{pH}$ of lumen fluid, it is evident that the activity of the $\mathrm{Na}^{+} / \mathrm{H}^{+}$exchanger outpaces the activity of the $\mathrm{Cl}^{-} / \mathrm{OH}^{-}$and $\mathrm{Cl}^{-} / \mathrm{HCO}_{3}{ }^{-}$exchangers. This is true throughout the entire digestive tract (Said et al., 1986).

Intestinal Secretion and Absorption of Sodium and Chloride. The amount of $\mathrm{Na}^{+}$needed at the duodenum and jejunum villus cell apical membrane for the $\mathrm{Na}^{+}$/hexose and $\mathrm{Na}^{+} / \mathrm{AA}$ transporters to operate during digestion and absorption of carbohydrates and proteins exceeds the amount of $\mathrm{Na}^{+}$provided by the diet, salivary secretions, or pancreatic juices. The rest of the $\mathrm{Na}^{+}$needed for absorption of hexoses and AA is provided by small intestine secretion of $\mathrm{Na}^{+}$(Figure 5). The process begins with movement of extracellular fluid $\mathrm{Cl}^{-}$into the crypt cell across the basolateral membrane via an $\mathrm{Na}^{+} / \mathrm{K}^{+} / 2 \mathrm{Cl}^{-}$cotransporter. The crypt cells of the small intestine secrete $\mathrm{Cl}$ into the lumen utilizing a $\mathrm{Cl}$ channel, the cystic fibrosis transmembrane conductance regulator (CFTR; Barrett and Keely, 2000). The permeability of this channel is normally tightly controlled (described below). As $\mathrm{Cl}^{-}$leave the cytosol and enter the lumen, they create a small area of negative charges over the crypt cell epithelium. This causes $\mathrm{Na}^{+}$ within the interstitial space fluid to move out into the lumen through cation-selective pores within the tight junction. Recall that the PD across the tight junctions is typically +5 to $8 \mathrm{mV}$ (interstitial space positive with respect to the lumen; Field, 2003), so the addition of $\mathrm{Cl}^{-}$ions to the lumen fluid increases this $\mathrm{PD}$ and helps drive the $\mathrm{Na}^{+}$out into the lumen. Water will follow both solutes into the lumen through tight junction water pores. The $\mathrm{Na}^{+}$ions diffuse to the villus cell brush border, where they aid absorption of hexoses and AA.

Normally, intestinal $\mathrm{Cl}^{-}$and $\mathrm{Na}^{+}$secretion is activated in response to the presence of carbohydrate and AA in the lumen. This is regulated by the enteric nervous system with input from the parasympathetic nervous system and endocrine and paracrine hormones produced in the digestive tract. These regulators activate cell membrane receptors (typically G-coupled protein receptors), resulting in an increase in crypt cell cytosolic cyclic AMP or cyclic guanosine monophosphate. The cyclic nucleotides cause release of $\mathrm{Ca}^{2+}$ from endoplasmic reticulum stores. The $\mathrm{Ca}^{2+}$ can then bind to calmodulin, activating it. The $\mathrm{Ca}^{2+}$-calmodulin complex moves to the CFTR $\mathrm{Cl}^{-}$channel, causing a conformational change that opens the channel. This allows large amounts of chloride to be moved out into 


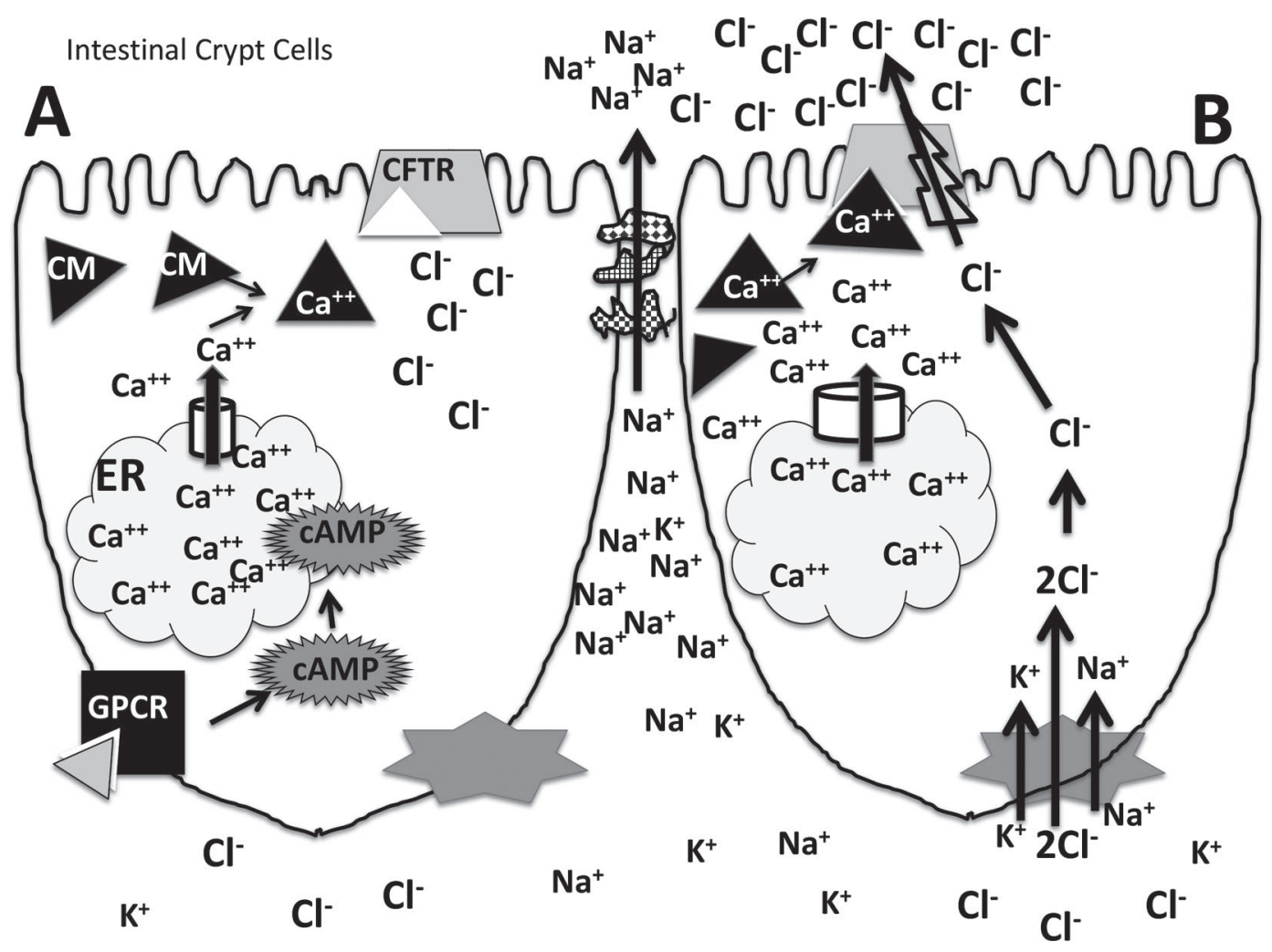

Figure 5. Intestinal crypt cell secretion of chloride, followed by $\mathrm{Na}^{+}$and water, into the lumen of the intestine. (A) Neurotransmitters and hormones produced in the gut can bind to receptors (GPCR) on crypt cells, causing an increase in intracellular cyclic AMP (cAMP). Cyclic AMP causes $\mathrm{Ca}^{2+}$ channels within the endoplasmic reticulum (ER) to open, releasing $\mathrm{Ca}^{2+}$ to the cytosol. The $\mathrm{Ca}^{2+}$ binds to calmodulin (CM), and the Ca-calmodulin complex moves to the apical membrane, where it interacts with a chloride channel (CFTR). (B) Once Ca-calmodulin binds to the CFTR, it opens the channel and large amounts of $\mathrm{Cl}^{-}$move into the lumen of the intestine. This creates a negatively charged zone above the tight junctions of the enterocytes. Positively charged $\mathrm{Na}^{+}$ions move from the interstitial space into the lumen across the tight junctions. The osmotic gradient created will cause interstitial space water to follow the $\mathrm{Na}^{+}$and $\mathrm{Cl}^{-}$into the lumen. The cytosol $\mathrm{Cl}^{-}$secreted into the lumen is replenished by bringing interstitial fluid $\mathrm{Cl}$ into the cell using an $\mathrm{Na} / \mathrm{K} / 2 \mathrm{Cl}$ cotransporter.

the lumen (Figure 5). Although the permeability of the CFTR $\mathrm{Cl}^{-}$channel is normally regulated, enterotoxins (e.g., those produced by E. coli) and inflammatory cytokines can cause unbridled activation of intestinal $\mathrm{Cl}^{-}$and $\mathrm{Na}^{+}$secretion, resulting in a secretory diarrhea (Field, 2003; Goff, 2015).

\section{Potassium}

Cows require more $\mathrm{K}$ each day than any other mineral. Application of manures or fertilizers rich in $\mathrm{K}$ to cropland can result in high $\mathrm{K}$ in the soil and very high $\mathrm{K}$ content of forages, making $\mathrm{K}$ deficiency unlikely. Potassium is involved in osmotic pressure and acid-base regulation (see "Macrominerals and Acid-Base Physiology"), water balance, resting membrane potential, nerve impulse transmission, and muscle contraction. It is the major intracellular mineral, with concentrations in the range of 150 to $155 \mathrm{mEq} / \mathrm{L}$. In contrast to $\mathrm{Na}$ and $\mathrm{Cl}$, extracellular and plasma concentrations of $\mathrm{K}$ are very low (about $3.7-5 \mathrm{mEq} / \mathrm{L}$ ). Saliva typi- cally contains $<10 \mathrm{mEq} / \mathrm{L}$, whereas concentrations in rumen fluid range from 40 to $100 \mathrm{mEq} / \mathrm{L}$. Potassium is the major mineral found in milk at a concentration of about $1.5 \mathrm{~g}$ of $\mathrm{K} / \mathrm{L}$. Potassium absorbed in excess of requirements is primarily excreted in urine.

Potassium in feeds and mineral supplements is readily solubilized, exists in the ionized state during the digestive processes, and is readily available for absorption. Dietary K is almost completed absorbed, and its absorption coefficient, regardless of source, is estimated to be 0.90 (Hemken, 1983; Miller, 1995). Potassium is absorbed in all sections of the digestive tract. The bulk of $\mathrm{K}$ absorption is by simple paracellular diffusion, particularly in the distal jejunum and ileum. This occurs because diet $\mathrm{K}$ is high, making lumen $\mathrm{K}$ concentration high. Extracellular fluid K concentration and interstitial space fluid is quite low, allowing a large concentration gradient to develop from lumen to extracellular fluids across the tight junctions. In addition, as water is removed from the digesta as it passes through the duodenum and jejunum, the concentration of $\mathrm{K}$ in the 
remaining digestive chyme increases. This further contributes to the concentration gradient that will drive $\mathrm{K}$ through the cation-selective pores of the tight junction barrier in the ileum. High lumen $\mathrm{K}^{+}$can overcome the electrical resistance to movement of $\mathrm{K}^{+}$into the interstitial space, which is already highly positive due to the presence of lots of $\mathrm{Na}^{+}$.

Transcellular $\mathrm{K}$ transport also exists in the stomach and small and large intestines but plays only a minor role in total $\mathrm{K}$ absorption. Parietal cells of the stomach are able to create an acidic environment in the lumen of the stomach by removing $\mathrm{K}$ from the stomach chime; this apical protein is known as the proton pump of the stomach (Gleeson, 1992). Electroneutral $\mathrm{K}^{+} / \mathrm{Cl}^{-}$ cotransporters exist in the apical membrane of small intestine and colon cells. Once the $\mathrm{K}$ enters the cell, simple diffusion carries it to the basolateral membrane. Because intracellular $\mathrm{K}$ concentration is around 150 $\mathrm{mEq} / \mathrm{L}$ and extracellular fluid $\mathrm{K}$ is 4 to $5 \mathrm{mEq} / \mathrm{L}$, the $\mathrm{K}$ readily diffuses through the basolateral membrane via $\mathrm{K}$ channels or electroneutral $\mathrm{K}^{+} / \mathrm{Cl}^{-}$cotransporters down its concentration gradient into the interstitial space (Heitzmann and Warth, 2008).

Rumen transcellular $\mathrm{K}$ transport can occur when $\mathrm{K}$ concentrations in the rumen are elevated, as might occur in cattle on high-K diets. This transporter seems to be an electrogenic transporter and causes the cytosol to become more positive, resulting in a reduction in the PD across the apical membrane of the stratum granulosum layer (Kronshage and Leonhard-Marek, 2009). It does not transport a large amount of the diet K, but it has great implications for $\mathrm{Mg}$ transport and $\mathrm{Mg}$ status (Martens and Schweigel, 2000).

The main excretory route of excess absorbed $\mathrm{K}$ is via the kidneys. Renal $\mathrm{K}$ excretion can be regulated by aldosterone, which increases $\mathrm{Na}$ reabsorption in the kidney in exchange for increased loss of $\mathrm{K}$ to the urine.

\section{Magnesium}

The $\mathrm{Mg}$ concentration in plasma of cows is normally between 0.8 and $1.0 \mathrm{mM}$ or 1.9 and $2.4 \mathrm{mg} / \mathrm{dL}$. Maintenance of normal plasma $\mathrm{Mg}$ concentration is almost totally dependent on daily dietary $\mathrm{Mg}$ absorption as there is no readily mobilizable $\mathrm{Mg}$ store. Cows with marginal or low extracellular $\mathrm{Mg}$ concentration are also likely to have low intracellular $\mathrm{Mg}$ concentration (Schweigel et al., 2009b). This is critically important because $\mathrm{Mg}$ is a major intracellular cation that is a necessary cofactor for enzymatic reactions that are vital to every major metabolic pathway. Extracellular Mg is vital to normal nerve conduction, muscle function, and bone mineral formation. Adequate blood $\mathrm{Mg}$ is also needed to allow normal secretion of parathryoid hormone and action of parathyroid hormone on its receptor. When $\mathrm{Mg}$ concentration in blood falls below $0.70 \mathrm{~m} M(1.7 \mathrm{mg} / \mathrm{dL})$, the ability of parathyroid hormone to activate its target tissues is reduced (Barber et al., 1983; Goff, 2014). This causes secondary hypocalcemia in the animals. It also reduces DMI and digestibility of the diet (Ammerman et al., 1971). Should blood Mg concentration fall below $0.5 \mathrm{~m} M(\sim 1.2 \mathrm{mg} / \mathrm{dL})$, nerves become overexcitable and the animal may develop muscle spasms and convulsions, often referred to as grass tetany or lactation tetany (Mayland, 1988). Magnesium insufficiency is readily diagnosed by blood $\mathrm{Mg}$ concentrations being lower than normal. In the cow, $\mathrm{Mg}$ absorbed from the diet in excess of needs is excreted in the urine. Low urine $\mathrm{Mg}$ concentration can also be an indication that the diet is marginal or insufficient in $\mathrm{Mg}$.

Magnesium Absorption. Magnesium is absorbed primarily from the small intestine and colon of young calves, just as it is in many monogastric species. However, as the rumen and reticulum develop they become the main, and perhaps the only, site for net Mg absorption (Martens and Gäbel, 1986). This was elegantly demonstrated by Tomas and Potter (1976), who fed sheep an Mg-deficient diet and infused an Mg solution directly into various sections of the digestive tract of the animals. Magnesium infused into the omasum, abomasum, or duodenum was not able to increase blood $\mathrm{Mg}$ concentration or urine $\mathrm{Mg}$ content, suggesting no net absorption of $\mathrm{Mg}$ from these sites. However, $\mathrm{Mg}$ infused into the rumenoreticulum did increase blood and urine $\mathrm{Mg}$ content, demonstrating that the rumen and reticulum epithelium are key to $\mathrm{Mg}$ homeostasis. Paracellular absorption of $\mathrm{Mg}^{2+}$ across the rumen wall is unlikely to occur with typical diets. However, in the small intestine paracellular secretion of $\mathrm{Mg}^{2+}$ can occur when $\mathrm{Mg}^{2+}$ within interstitial space fluid, which is in equilibrium with extracellular fluids, moves into the lumen with the bulk flow of water during crypt secretory processes. This loss can be several grams per day, making the small intestine a site of net secretion of Mg (Greene et al., 1983; Leonhard-Marek and Martens, 1996).

Transcellular movement of $\mathrm{Mg}$ across the various stratified squamous epithelial layers of the rumen and reticulum is the major absorption pathway (Figure 6). In nonruminants, $\mathrm{Mg}$ salts that are poorly soluble in water have an opportunity to become water soluble upon reaction with the acid of the stomach. This facilitates absorption of $\mathrm{Mg}$ in their small intestine. Solubilization of $\mathrm{Mg}$ by abomasal acid is of little help to ruminants. Magnesium absorption from the rumen is highly dependent on the concentration of $\mathrm{Mg}$ ions in solution in the rumen fluid, which typically has a $\mathrm{pH}$ above 5.8 . 


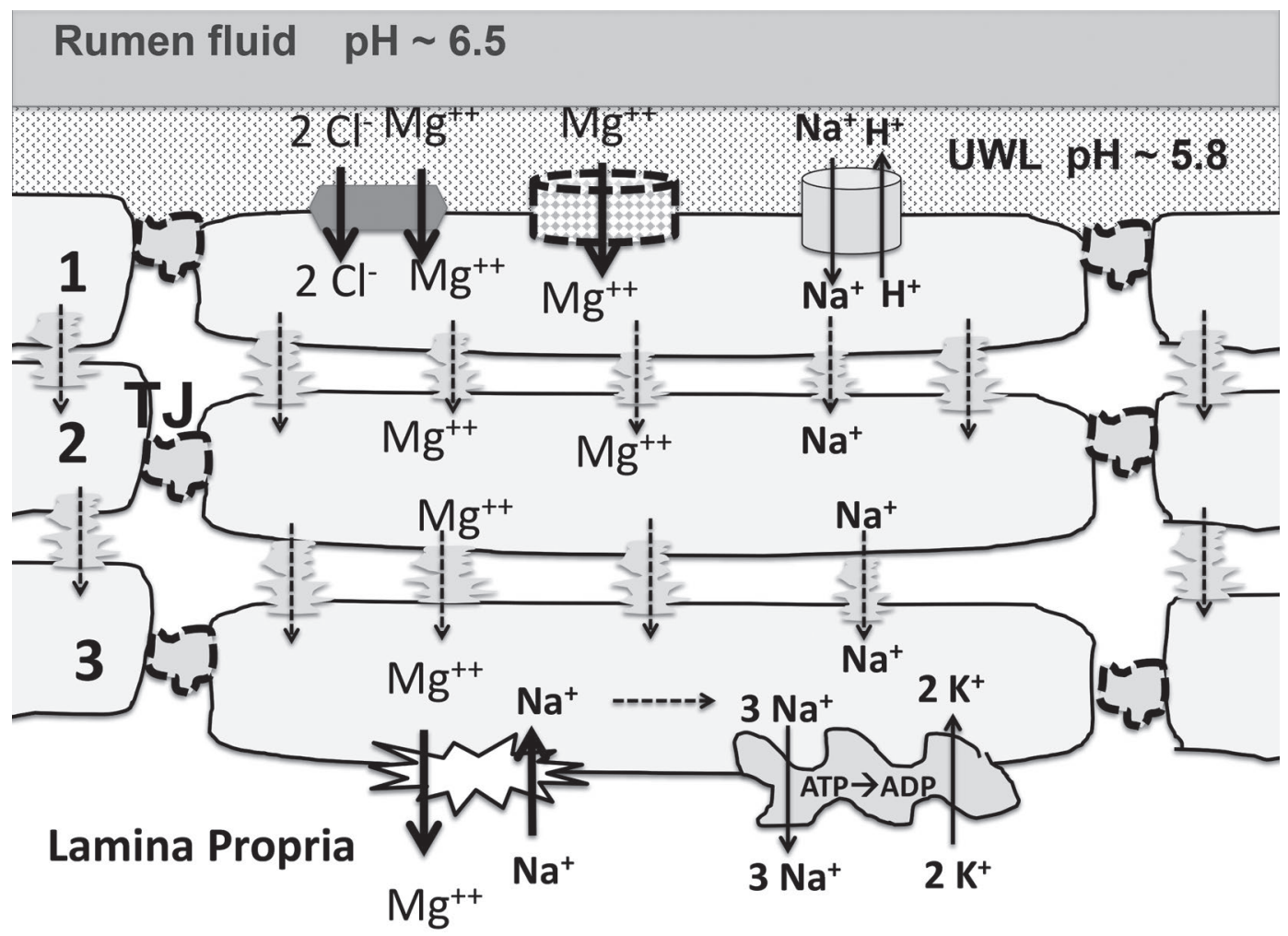

Figure 6. Rumen $\mathrm{Mg}$ absorption. Rumen $\mathrm{Mg}^{2+}$ can cross the apical membrane of the stratum granulosum cells (layer 1) using 2 different pathways. An $\mathrm{Mg}^{2+} / 2 \mathrm{Cl}^{-}$transporter that is independent of membrane potential difference and $\mathrm{K}$ insensitive uses ATP energy to pump $\mathrm{Mg}$ across the apical membrane, but operates only at high rumen fluid $\mathrm{Mg}$ concentration. $\mathrm{An}_{\mathrm{Mg}^{2+}}$ ion channel also exists in the apical membrane. Its function is dependent on the potential difference across the apical membrane of the stratum granulosum cells to drive Mg through this channel, and it can work when $\mathrm{Mg}$ concentration in rumen fluid is low. The concentration of $\mathrm{Mg}$ ions in the unstirred water layer (UWL) is higher than in rumen fluid because of its lower $\mathrm{pH}$. The lower $\mathrm{pH}$ is a result of $\mathrm{Na}^{+}$absorption from the UWL using an $\mathrm{Na}^{+} / \mathrm{H}^{+}$exchanger. The $\mathrm{Mg}^{2+}$ diffuses through the various layers of the rumen epithelium (layer 2) using gap junctions. At the basolateral membrane of the stratum basale cells (layer 3), an $\mathrm{Mg}^{2+}$ is moved out of the cell using the driving force supplied by 1 to as many as $3 \mathrm{Na}^{+}$ions moving into the cell. The Na ${ }^{+}$is then pumped back out of the cell in exchange for $\mathrm{K}^{+}$using the electrogenic $3 \mathrm{Na}^{+} / 2 \mathrm{~K}^{+}$ATPase pump. TJ = tight junctions between adjacent cells. ADP $=$ adenosine diphosphate.

As discussed earlier, the stratified squamous epithelial cells lining the rumen papillae are a syncytium of cells that are connected to each other by gap junctions. This effectively allows ions to diffuse from one cell to another and pass through the various layers of stratified squamous epithelium with little resistance. The first obstacle to $\mathrm{Mg}$ absorption across the rumen epithelium is getting the $\mathrm{Mg}$ across the apical membrane of the stratum granulosum cells facing the lumen (Figure 6). Rumen epithelial cells generally have a total intracellular $\mathrm{Mg}$ concentration between 5 and $20 \mathrm{mM}$, of which only about $0.72 \mathrm{~m} M$ (range: $0.4-1.0 \mathrm{mM}$ ) is freely ionized (not bound to proteins or sequestered in organelles; Schweigel et al., 2006). As discussed in the Na section, the unstirred water layer adhering to rumen epithelium surfaces is slightly more acidic than the $\mathrm{pH}$ found in the fluid in the lumen of the rumen (Sehested et al., 1996; Graham et al., 2007). This 0.3 to 0.7 decrease in $\mathrm{pH}$ in the unstirred water layer would be expected to promote greater solubility of $\mathrm{Mg}$ in that microenvironment. With typical diets, 2 to $6 \mathrm{~m} M$ ionized $\mathrm{Mg}$ is in the fluid overlying the stratum granulosum cells facing the lumen of the rumen (Johnson and Aubrey-Jones, 1989; Schweigel and Martens, 2000a). Therefore, under typical $\mathrm{Mg}$ diet situations, the ionized $\mathrm{Mg}$ concentration in rumen fluid will be higher than intracellular ionized $\mathrm{Mg}$ concentrations. In addition, the PD across the apical membrane of rumen cells may be as high as -67 $\mathrm{mV}$ (inside negative; Leonhard-Marek and Martens, 1996). This electrical gradient provides an even larger, and physiologically more important, force to move positively charged $\mathrm{Mg}$ ions across the apical membrane. Therefore, $\mathrm{Mg}^{2+}$ should readily move down its chemical and electrical gradient into the cytosol if there is an open $\mathrm{Mg}$ channel through the lipid bilayer. In addition, the transmural PD must be considered - that is, the potential electrical difference between the fluid overlying the rumen stratum granulosum cells and the fluid 
on the blood side of the stratum basale cells. This PD is typically about 40 to $70 \mathrm{mV}$, blood side being positive. This represents an impediment to movement of $\mathrm{Mg}$ into the blood (Martens and Harmeyer, 1978).

Two separate $\mathrm{Mg}$ transport processes work in parallel to move rumen fluid $\mathrm{Mg}$ across the apical membrane (Figure 6). The major transport mechanism consists of a divalent cation channel that permits $\mathrm{Mg}^{2+}$ to move across the apical membrane. This channel has been identified as the melastatin-related transient receptor potential 7 protein (TRPM7; Schweigel et al., 2009a). Movement of $\mathrm{Mg}^{2+}$ through this channel is highly dependent on the PD across the apical membrane of the forestomach stratum granulosum layer. At a normal $\mathrm{PD}$ of $-55 \mathrm{mV}$ (inside negative), the mechanism allows $\mathrm{Mg}$ transport at very low rumen $\mathrm{Mg}$ concentrations (Schweigel and Martens, 2000b). This is the main mechanism used to transport $\mathrm{Mg}$ across the apical membrane when diet $\mathrm{Mg}$ and rumen $\mathrm{Mg}$ concentrations are low. Schweigel et al. (2009b) have evidence that the amount of TRPM7 channel protein is upregulated when lumen $\mathrm{Mg}^{2+}$ concentrations are low, which may help the animal adapt to a lower $\mathrm{Mg}$ diet.

Unfortunately, high rumen fluid $\mathrm{K}$ concentration promotes diffusion of $\mathrm{K}^{+}$across the apical membrane of the stratum granulosum cells, causing a reduction in the PD across the apical membrane. The electrical force pulling $\mathrm{Mg}^{2+}$ through the $\mathrm{Mg}$ channel and into the negative interior of the cell, which may have been $-55 \mathrm{mV}$ (inside negative), is now reduced. Because the $\mathrm{PD}$ in electrical charge across the apical membrane was the major force driving movement of $\mathrm{Mg}$ through these channels at low diet $\mathrm{Mg}$ concentrations, the high $\mathrm{K}$ greatly reduces $\mathrm{Mg}$ transit (Martens and Kasebieter, 1983). Because PD can be reduced by high diet K content, this mechanism is referred to as PD-dependent, $\mathrm{K}$-sensitive $\mathrm{Mg}$ transport (Martens and Schweigel, 2000).

Greene et al. (1988) demonstrated that absorption of $\mathrm{Mg}$ across the rumen wall was enhanced in cattle fed the ionophore monensin. Monensin forms a lipid-soluble complex with $\mathrm{Na}$ and enhances the rate at which it crosses the apical membrane of the stratum granulosum cells. The increased rate of $\mathrm{Na}^{+}$entry causes increased activity of the $\mathrm{Na}^{+} / \mathrm{K}^{+}$ATPase pump in the cell membrane. Pumping $3 \mathrm{Na}^{+}$out of the cell and letting just $2 \mathrm{~K}^{+}$into the cell causes hyperpolarization of the cell membrane (Spears, 1990). The greater PD across the apical cell membrane (inside more negative) provides a greater driving force for the PD-dependent, K-sensitive $\mathrm{Mg}$ transport mechanism (Martens and Schweigel, 2000).

The second apical membrane $\mathrm{Mg}$ transport mechanism involves cotransport of $\mathrm{Mg}^{2+}$ and $\mathrm{Cl}^{-}$ions across the apical membrane of stratum granulosum cells (Schweigel and Martens, 2003). The $\mathrm{Mg}^{2+} / 2 \mathrm{Cl}^{-}$cotransporter is effective only when soluble rumen fluid $\mathrm{Mg}$ ion concentrations are high. This transport mechanism operates independent of the PD across the apical membrane of the forestomach stratum granulosum layer and is not affected by diet $\mathrm{K}$ content (PD-independent, $\mathrm{K}$-independent $\mathrm{Mg}$ transport; Martens and Schweigel, 2000). The presence of short-chain VFA in the rumen fluid aids $\mathrm{Mg}$ uptake by this mechanism. The VFA may be providing substrate to produce the energy needed to operate the transporter, or they may reduce intracellular $\mathrm{pH}$, which seems to promote activity of the $\mathrm{Mg}^{2+} / 2 \mathrm{Cl}^{-}$cotransporter (Schweigel and Martens, 2003). Increasing diet Mg content allows utilization of the $\mathrm{Mg}^{2+} / 2 \mathrm{Cl}^{-}$cotransporter, which is critical to maintenance of normal blood $\mathrm{Mg}$ concentration if diet $\mathrm{K}$ is elevated and has reduced the ability of the $\mathrm{Mg}$ channel to bring $\mathrm{Mg}$ into the stratum granulosum cell.

Once $\mathrm{Mg}$ has crossed the apical membrane of the stratum granulosa cells, it diffuses through the gap junctions of the stratum spinosum and stratum basale cells to reach the basolateral membrane of the stratum basale cells. Here an $\mathrm{Na}^{+} / \mathrm{Mg}^{2+}$ exchanger uses the electromotive force of $\mathrm{Na}^{+}$(perhaps $1-3 \mathrm{Na}^{+}$ions) moving into the cell down their concentration and electrical gradient to move a single $\mathrm{Mg}^{2+}$ into the extracellular fluids against its electrical gradient (Schweigel et al., 2006). The $\mathrm{Na}^{+}$ions are then pumped back out of the cell using the $\mathrm{Na}^{+} / \mathrm{K}^{+}$ATPase electrogenic pump (Figure 6). Schweigel et al. (2009a) demonstrated that the amount of $\mathrm{Na}^{+} / \mathrm{Mg}^{2+}$ exchanger protein expressed on the cell membrane can be regulated: it is upregulated when intracellular $\mathrm{Mg}$ concentrations increase and downregulated when they are low. Maintaining a constant intracellular $\mathrm{Mg}$ concentration may be critical to cell function. The activity of the $\mathrm{Na}^{+} / \mathrm{Mg}^{2+}$ exchanger is regulated by cyclic AMP, suggesting that external stimuli (perhaps hormones) can influence $\mathrm{Mg}$ efflux from the cell (Schweigel et al., 2009a).

This author's field observations of many cows with subclinical hypomagnesemia suggest that the NRC (2001) model may overestimate absorbed Mg supplied by diets. Calculations made using the NRC (2001) model suggest that diets with less than $0.2 \% \mathrm{Mg}$ (DM basis) can satisfy the requirements of growing heifers and dry cows. Diets with about $0.22 \%$ of $\mathrm{Mg}$ are calculated to satisfy requirements of lactating cows in many instances. The NRC (2001) model does not adjust the coefficient of absorption for $\mathrm{Mg}$ if diet $\mathrm{K}$ content is above required levels of $\operatorname{diet} \mathrm{K}(\sim 1 \% \mathrm{~K})$.

In a review of published studies with lactating cows, Weiss (2004) calculated an average apparent digestibility for diet $\mathrm{Mg}$, from all sources, of $24 \%$ when diet $\mathrm{K}$ 
was $1 \%$ (close to the $\mathrm{K}$ requirement). Study diets were from $0.20 \%$ to $0.36 \% \mathrm{Mg}$, and about $80 \%$ of diet $\mathrm{Mg}$ was from feedstuffs and 20\% from inorganic supplements $\left(\mathrm{MgO}\right.$ or $\left.\mathrm{MgSO}_{4}\right)$. The analysis also suggested that the apparent digestibility of $\mathrm{Mg}$ was reduced by $7.5 \%$ for every $1 \%$ increase in diet K. Schonewille et al. (2008) analyzed $\mathrm{Mg}$ absorption from a large number of studies involving 68 diets. The percentage of $\mathrm{Mg}$ absorbed (as a percentage of intake) decreased by $0.31 \%$ for every gram of $\mathrm{K}$ in the diet. Their analysis suggests that dietary $\mathrm{Mg}$ intake must be increased by $4 \mathrm{~g} / \mathrm{d}$ for every $1 \% \mathrm{~K}$ in the diet DM to maintain the same amount of absorbed $\mathrm{Mg}$. Using these equations, a lactating cow consuming $23 \mathrm{~kg}$ of diet with $2 \% \mathrm{~K}$ in the diet will meet her requirement with a diet that is close to $0.34 \% \mathrm{Mg}$.

The amount of $\mathrm{Mg}$ that must be in the rumen fluids to achieve a certain rate of $\mathrm{Mg}$ absorption in the face of a high-K diet has been examined. Jittakhot et al. (2004) fed dry cows varying amounts of $\mathrm{Mg}$ as $\mathrm{MgO}$. The diets were $3.0 \% \mathrm{~K}$, and DMI was about $7 \mathrm{~kg} / \mathrm{d}$. They measured rumen fluid soluble $\mathrm{Mg}$ concentration and calculated the $\mathrm{Mg}$ absorption rate. Magnesium absorption rate increased rapidly once rumen fluid concentration exceeded $12 \mathrm{~m} M$ and reached a plateau when soluble $\mathrm{Mg}$ in rumen fluid was about $20 \mathrm{~m} M$. Diet $\mathrm{Mg}$, using $\mathrm{MgO}$, had to be increased to $0.64 \%$ to achieve 12 $\mathrm{m} M \mathrm{Mg}$ in the rumen fluid. The soluble $\mathrm{Mg}$ concentration within the rumen fluid of cattle would need to be at least 11 to $12.5 \mathrm{mmol} / \mathrm{L}$ (Martens, 1983; Martens and Kasebieter, 1983) and perhaps as high as 17.5 to $20 \mathrm{mmol} / \mathrm{L}$ (Jittakhot et al., 2004) to maximize $\mathrm{Mg}$ transport by both mechanisms that move Mg across the apical membrane of the stratum basale cells. However, it is not necessary to fully saturate these mechanisms to permit adequate $\mathrm{Mg}$ absorption. In a study in sheep by Ram et al. (1998), increasing diet $\mathrm{Mg}$ from $0.25 \%$ to $0.37 \%$ using $\mathrm{MgO}$ increased daily $\mathrm{Mg}$ absorbed by $0.33 \mathrm{~g} / \mathrm{d}$. This was almost able to offset the $\mathrm{Mg}$ absorption inhibition of $0.36 \mathrm{~g}$ of $\mathrm{Mg}$ absorbed/d caused by increasing diet $\mathrm{K}$ from $1 \%$ to $3.6 \%$ of the diet. The average soluble $\mathrm{Mg}$ concentration in the rumen fluid reached only $9.7 \mathrm{mmol} / \mathrm{L}$ when diet $\mathrm{Mg}$ was increased to $0.37 \%$.

Another factor that reduces apparent absorption of $\mathrm{Mg}$ is high dietary $\mathrm{Ca}$. Rumen fluid $\mathrm{Ca}^{2+}$ may compete with $\mathrm{Mg}^{2+}$ for entry through the PD-dependent, Ksensitive divalent cation channel of the rumen epithelium apical membrane (Leonhard-Marek et al., 2005). When close-up dry cows were fed diets with $0.18 \% \mathrm{Mg}$ and $0.49,0.93$, or $1.36 \% \mathrm{Ca}$ (using limestone as the Ca source), the $1.39 \% \mathrm{Ca}$ diet significantly reduced apparent absorption of $\mathrm{Mg}$ and urinary excretion of $\mathrm{Mg}$ (Kronqvist et al., 2011).
Coefficients of Absorption for Magnesium Sources in Diet. Published studies suggest that the apparent absorption of $\mathrm{Mg}$ from natural feedstuffs varies from $11 \%$ to $37 \%$, with the majority of values falling between 20 and 30\% (Agricultural Research Council, 1980; Greene et al., 1983). The NRC (2001) model uses a coefficient of absorption for feedstuff $\mathrm{Mg}$ of 0.16 , which is on the lower end of the scale of study findings. This coefficient would seem to be a conservative and reasonable estimate for forage and feedstuff $\mathrm{Mg}$ absorbability.

Magnesium oxide is the most widely used inorganic source of $\mathrm{Mg}$ in lactating ruminant diets. It is used both as a source of $\mathrm{Mg}$ and because it can alkalinize rumen fluid. It is common for nutritionists to use a rumen buffer consisting of 2 parts $\mathrm{NaHCO}_{3}$ and 1 part $\mathrm{MgO}$. Magnesium oxide was used to increase diet $\mathrm{Mg}$ in the Jittakhot et al. (2004) study. Taking dietary Mg from $0.39 \%$ to $0.64 \%$ involved adding $7.6 \mathrm{~g}$ of $\mathrm{Mg}$ from $\mathrm{MgO}$ to the diet. The apparent absorption of dietary $\mathrm{Mg}$ was increased by $3.6 \mathrm{~g}$. This suggests that $\mathrm{MgO}$ had a coefficient of absorption of about 0.47 in this study, similar to the value of 0.50 that was described in the text of the NRC (2001) section on Mg availability. This suggests that the value of 0.70 used in the NRC (2001) ration evaluation model overestimates the absorbability of $\mathrm{MgO}$. Because NRC (2001) used MgO absorbability as a benchmark for establishing absorption coefficients for magnesium hydroxide $\left(\mathrm{MgOH}_{2}\right)$, magnesium chloride $\left(\mathrm{MgCl}_{2}\right)$, and magnesium sulfate $\left(\mathrm{MgSO}_{4}\right)$, it is likely that NRC (2001) also overestimates the absorbability of $\mathrm{Mg}$ from these sources by a similar amount.

Researchers working with $\mathrm{MgO}$ are generally aware of the effect that particle size and proper calcining have on availability of $\mathrm{MgO}$ supplements and use the more finely ground, and more reactive, $\mathrm{MgO}$ for their studies (Jesse et al., 1981; Schonewille et al., 1992). Unfortunately, the reactivity and particle size of $\mathrm{MgO}$ supplements used in the field are extremely variable. If rumen alkalinizing activity is valued in lactating cow diets, then the reactivity of $\mathrm{MgO}$ with acetic acid could give the nutritionist a simple test of the relative reactivity of the $\mathrm{MgO}$ being considered for use in rations. Place $3 \mathrm{~g}$ of an $\mathrm{MgO}$ source in a container and slowly add $40 \mathrm{~mL}$ of $5 \%$ acetic acid (white vinegar). Cap the container and shake well for $15 \mathrm{~s}$ and let sit. Shake again at the 15-min mark and then check the $\mathrm{pH}$ at $30 \mathrm{~min}$. Vinegar alone has a $\mathrm{pH}$ of 2.6 to 2.8. The best $\mathrm{MgO}$ sources will bring the $\mathrm{pH}$ up to 8.2 ; the worst to just 3.8 (Goff, 2014). Because pH is a log scale, this represents a $>10,000$-fold difference in the number of hydrogen ions neutralized. In an experiment with 4 cows with rumen fistulas, the solubility of $\mathrm{MgO}$ in vitro (tested in 
several ways) was found to parallel their solubility in the rumen and their urinary excretion - an indication that solubility predicted absorbability (Schonewille et al., 1992).

Magnesium sulfate and $\mathrm{MgCl}_{2}$ are very soluble and highly absorbable sources of $\mathrm{Mg}$; however, they are also relatively low in $\mathrm{Mg}$, being just 9 and $18 \% \mathrm{Mg}$, respectively, as the common salts are hydrated salts. They are not very palatable and are difficult to handle in a feed mill setting. They do not provide any rumen buffering action in lactating diets. They are acidifying and are commonly used in close-up dry cow diets to induce metabolic acidosis as a means of reducing the degree of hypocalcemia experienced by the cow at the onset of lactation (see "Macrominerals and Acid-Base Physiology"). Magnesium in $\mathrm{Mg}$ carbonate in magnesite ore and $\mathrm{Mg}$ in dolomitic limestone should be considered largely unavailable when formulating dairy rations. However, $\mathrm{MgCO}_{3}$ originating from certain mines or from calcareous marine algae deposits can be as reactive as some of the better magnesium oxides on the market. Processing procedures and particle size are important factors affecting availability of $\mathrm{Mg}$ from $\mathrm{MgCO}_{3}$ and $\mathrm{MgO}$.

\section{Sulfur}

Function of Sulfur. About $0.15 \%$ of BW is S. Sulfur is found in the AA methionine, cysteine (cystine), homocysteine, and taurine. It is also in chondroitin sulfate of cartilage and in the B-vitamins thiamin and biotin. The disulfide bonds of the S-containing AA are largely responsible for determining the tertiary structure of proteins. Methionine, thiamin, and biotin cannot be synthesized by cattle tissues. These nutrients must either be supplied in the diet or be synthesized by ruminal microbes. Oxidation of methionine and cysteine causes $\mathrm{S}$ to also exist in tissues as the sulfate anion, which influences the acid-base status of the animal.

Dietary Recommendations for Sulfur. The primary requirement of the cow is for a diet that provides adequate $\mathrm{S}$ substrate to ensure maximal microbial synthesis of the $\mathrm{S}$ containing AA. A small amount of $\mathrm{S}$ is also needed to allow synthesis of chondroitin sulfate and heparin found in connective tissue. The liver also uses sulfate in detoxification and elimination reactions. This $\mathrm{S}$ can be derived during catabolism of the S-containing AA. Diets containing $0.20 \% \mathrm{~S}$ are adequate to meet the rumen microbes' needs for S (Bouchard and Conrad, 1973).

Sulfate S is absorbed fairly efficiently (60\%) in the small intestine (Bird and Moir, 1971; Goff et al., 2004). A $2 \mathrm{Na}^{+} / \mathrm{SO}_{4}{ }^{-2}$ cotransporter moves $\mathrm{S}$ across the apical membrane. It is assumed that $\mathrm{SO}_{4}{ }^{-2}$ diffuses across the cell to the basolateral membrane. It is pumped across the basolateral membrane into the extracellular fluids in exchange for $2 \mathrm{Cl}^{-}$or $\mathrm{HCO}_{3}{ }^{-}$anions (Figure 7; Markovich, 2001). Sulfate is a strong anion that can affect acid-base balance and has been used in diets to acidify the blood to prevent milk fever (see "Macrominerals and Acid-Base Physiology").

Sulfur Toxicity. Dietary S can be reduced to sulfide, which can interfere with absorption of other elements, particularly $\mathrm{Cu}$ and $\mathrm{Se}$ (see the sections on $\mathrm{Cu}$ and $\mathrm{Se}$ ). Acute $\mathrm{S}$ toxicity causes neurological changes, including blindness, coma, muscle twitches, and recumbency (Coghlin, 1944). Acute death occurs from production of hydrogen sulfide gas within the rumen, which is inhaled during eructation (McAllister et al., 1997). Hydrogen sulfide is a potent neurotoxin. Dairy cows seem to have more tolerance to $\mathrm{S}$, probably because they consume diets with more forage than feedlot steers (Spears et al., 2011).

\section{MICROMINERALS}

\section{Cobalt}

Cobalt and Vitamin $\boldsymbol{B}_{12}$. Whereas many monogastric mammals and birds must have vitamin $B_{12}$ supplied by their diet, microbes within the rumen can generally produce the vitamin $\mathrm{B}_{12}$ required by the cow provided that adequate available $\mathrm{Co}$ is in the diet. Vitamin $\mathrm{B}_{12}$ is a cofactor of the enzyme methylmalonyl$\mathrm{CoA}$ mutase involved in gluconeogenesis. Vitamin $\mathrm{B}_{12}$ is also a cofactor of methionine synthase, the enzyme that regenerates methionine from homocysteine. Vitamin $B_{12}$ deficiency limits methionine production and nitrogen retention. Cobalt deficiency prevents the cow from obtaining adequate vitamin $\mathrm{B}_{12}$. Fortunately, the liver and kidney can store vitamin $\mathrm{B}_{12}$, so it takes weeks for $\mathrm{B}_{12}$ deficiency of animal tissues to occur in a ruminant placed on a Co-deficient diet. However, the lack of $\mathrm{Co}$ in the diet also means that the rumen microbes, particularly the anaerobes, have no ability to produce vitamin $\mathrm{B}_{12}$ to support their own metabolism (Underwood, 1981). Within days of a switch to a codeficient diet, rumen fluid, blood, and urine concentrations of methylmalonic acid increase, the result of an inability of microbes to convert methylmalonyl-CoA to succinate, which should then be converted to propionate. Rumen bacterial populations also shift toward microbes that produce succinate rather than propionate (Kennedy et al., 1996). This leads to less than optimal rumen fermentation. Early signs of Co deficiency include failure to grow, unthriftiness, and weight loss. More severe signs include fatty degeneration of the liver, anemia 


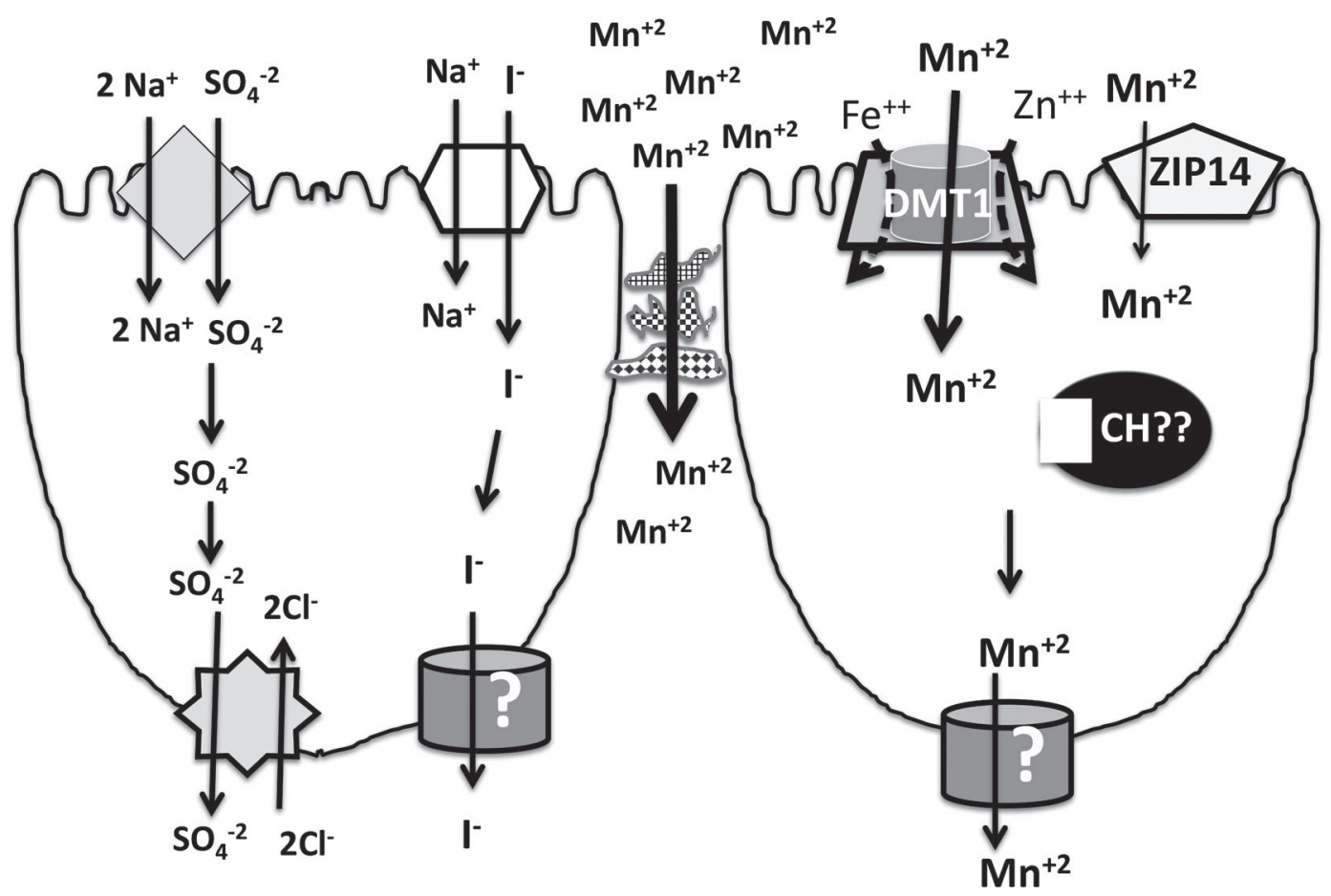

Figure 7. Sulfate, iodide, and manganese absorption in the small intestine. A $2 \mathrm{Na} / \mathrm{SO}_{4}{ }^{-2}$ cotransporter moves sulfate across the apical membrane. It diffuses across the cell and crosses the basolateral membrane using an $\mathrm{SO}_{4}^{-2} / 2 \mathrm{Cl}^{-}$exchanger. Iodide is cotransported with Na across the apical membrane. It is not known how iodide crosses the basolateral membrane. Manganese is absorbed by paracellular diffusion across the tight junctions when diet Mn is high. Transcellular absorption of $\mathrm{Mn}^{2+}$ involves use of the DMT1 to cross the apical membrane; DMT1 also moves $\mathrm{Fe}$ and $\mathrm{Zn}$ across the apical membrane. A member of the zinc transporter protein family, ZIP14, can also transport Mn ${ }^{2+}$ across the apical membrane. Chaperones $(\mathrm{CH})$ to safely carry $\mathrm{Mn}^{2+}$ across the cell and mechanisms to move $\mathrm{Mn}^{2+}$ across the basolateral membrane have yet to be discovered.

with pale mucous membranes (Underwood, 1981), and reduced resistance to infection as a result of impaired neutrophil function (Paterson and MacPherson, 1990).

Cobalt Supplementation. Cobalt chloride, nitrate, carbonate, glucoheptonate, and sulfate salts all appear to be suitable sources of Co for ruminants. Diets that are $0.11 \mathrm{mg} / \mathrm{kg}$ of Co from these sources permit rumen microbes to make adequate vitamin $\mathrm{B}_{12}$ for the cow under most circumstances. Cobaltous oxide is less soluble and less available for use by microbes (Henry, 1995). However, cobaltous oxide pellets and controlledrelease glass pellets containing Co that are retained in the rumen-reticulum have been used successfully to supply Co over extended periods of time to ruminants on pasture.

Rumen microbes of cows fed higher concentrate diets may not synthesize as much vitamin $B_{12}$ from $C o$ as cows fed higher fiber diets (Beaudet et al., 2016). Certain bacteria promoted by high-grain diets, such as Streptomyces griseus, Propionibacterium shermanii, and some E. coli strains, can take up Co and produce compounds that are similar to vitamin $\mathrm{B}_{12}$ but are incapable of functioning like $\mathrm{B}_{12}$ (Ellenbogen and Cooper, 1991). These pseudovitamin $B_{12}$ compounds divert Co in the rumen away from production of biologically active vitamin $\mathrm{B}_{12}$ (Girard et al., 2009), increasing the dietary requirement for Co.

\section{Copper}

Copper Function. Copper has the ability to act as an electron donor or acceptor as it can move between the cuprous $\left(\mathrm{Cu}^{1+}\right)$ and cupric $\left(\mathrm{Cu}^{2+}\right)$ oxidation states. This makes $\mathrm{Cu}$ an important component of enzymes such as cytochrome oxidase, necessary for electron transport during aerobic respiration; lysyl oxidase, needed for formation of bone and connective tissue collagen and elastin; hephaestin, which allows Fe to be absorbed by enterocytes; ceruloplasmin, which is essential for transport of $\mathrm{Fe}$ to reticulocytes that are producing hemoglobin; tyrosinase, necessary for production of the black pigment melanin from tyrosine; and $\mathrm{Cu} / \mathrm{Zn}$ superoxide dismutase, which protects cells from the effects of superoxide anion (see "Minerals as Pro-Oxidants and Antioxidants").

Poor $\mathrm{Cu}$ status can affect immune function before more classical signs of $\mathrm{Cu}$ deficiency are observed. Neutrophils of cows fed insufficient $\mathrm{Cu}$ have a reduced 
ability to kill invading microbes, leading to increased susceptibility to infection and more severe infections, including mastitis (Scaletti et al., 2003). The amount of dietary $\mathrm{Cu}$ required for optimal immune function may exceed the amount required to prevent the more classical signs of $\mathrm{Cu}$ deficiency. Specific pathogen-free lambs require less $\mathrm{Cu}$ than lambs exposed to pathogens, suggesting that fighting infections consumes $\mathrm{Cu}$ and increases requirements (Suttle, 2012). Of all the required minerals, the potential for toxicity is greatest with $\mathrm{Cu}$ because the amount of dietary $\mathrm{Cu}$ that can cause toxicity is only 4 - to 10 -fold greater than the amount of $\mathrm{Cu}$ required to support normal metabolism.

Copper Absorption from Diets. The PD across the tight junction, created by the high $\mathrm{Na}^{+}$content of the interstitial space, is too highly positively charged to support paracellular $\mathrm{Cu}$ absorption by diffusion. Paracellular absorption via solvent drag could contribute to $\mathrm{Cu}$ absorption. In monogastric species, $\mathrm{Cu}$ is primarily absorbed across the stomach and small intestine by a transcellular process (van den Berghe and Klomp, 2009). The acidity of the stomach promotes the presence of $\mathrm{Cu}$ ions in solution. For this review it is assumed that this is true in ruminants as well, but this is largely unexplored. Diet $\mathrm{Cu}$ is generally in the cupric form $\left(\mathrm{Cu}^{2+}\right)$, but only cuprous $\left(\mathrm{Cu}^{+}\right)$is thought to be transported across the apical membrane. Soluble $\mathrm{Cu}^{2+}$ in the fluid overlying the apical membrane of gastric and duodenal epithelia is reduced by brush border $\mathrm{Cu}$ metalloreductases to $\mathrm{Cu}^{+}$(Figure 8). The $\mathrm{Cu}^{+}$uses a specific high-affinity $\mathrm{Cu}^{+}$transport protein (CTR1) to cross the apical membrane and enter the enterocyte (Hashimoto and Kambe, 2015). This process is highly efficient: as much as 40 to $60 \%$ of the diet's freely ionized soluble $\mathrm{Cu}$ can cross the apical membrane of the stomach and upper intestinal epithelium. Although CTR1 seems to be the most important path used to cross the apical membrane, there is evidence that the divalent metal transporter 1 protein (DMT1; used for $\mathrm{Fe}, \mathrm{Zn}$, and $\mathrm{Mn}$ as well) also is a minor pathway for

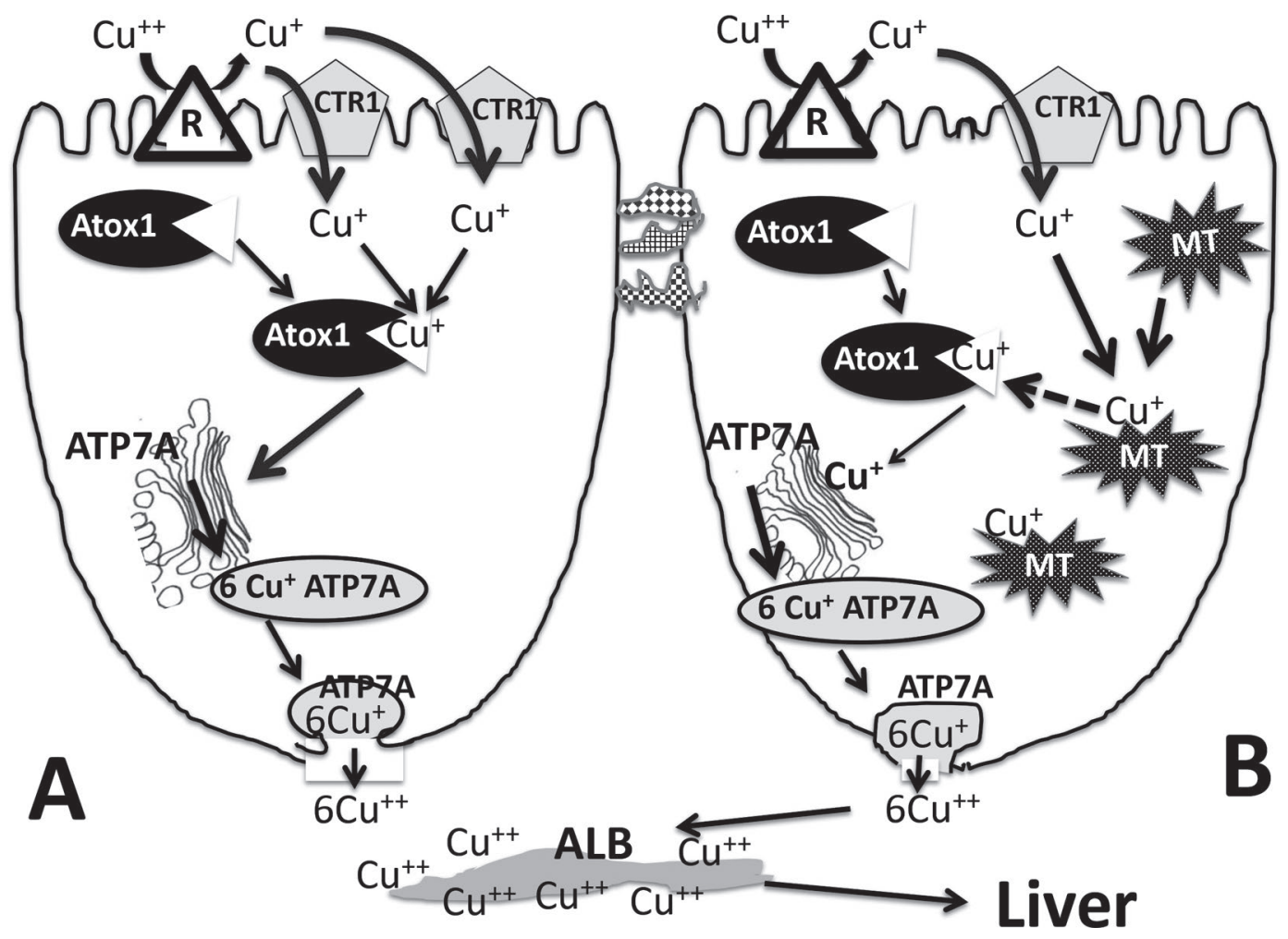

Figure 8. Enterocyte transcellular copper absorption. Brush border copper reductase (R) converts dietary $\mathrm{Cu}^{2+}$ to $\mathrm{Cu}^{+}$. (A) A copper transporter 1 protein (CTR1) facilitates diffusion of the $\mathrm{Cu}^{+}$across the apical membrane. $\mathrm{Cu}^{+}$becomes bound to a copper chaperone protein (Atox1). Atox1 shuttles the $\mathrm{Cu}^{+}$to the Golgi apparatus, where it is transferred to a copper transport protein (ATP7) capable of holding $6 \mathrm{Cu}^{+}$ions that is within the membrane of a Golgi transport vesicle. The ATP7A vesicle carries the $6 \mathrm{Cu}^{+}$safely across the cell. The transport vesicle membrane melds with the basolateral membrane releasing the $\mathrm{Cu}^{+}$into the extracellular fluid by exocytosis. The ATP7A transport vesicle membrane contains a $\mathrm{Cu}$ oxidase, which oxidizes the $\mathrm{Cu}^{+}$to $\mathrm{Cu}^{2+}$ as it is released to the interstitial space. The $\mathrm{Cu}^{2+}$ ions become bound to albumin (ALB) for transport. (B) However, if the body has adequate copper stores, the enterocytes begin to produce metallothionein (MT) in large amounts. The $\mathrm{Cu}^{+}$ions entering the cell are now more likely to be bound to MT than to the Atox1 chaperone. MT can give up $\mathrm{Cu}^{+}$to the Atox1, but only very slowly, and much of the MT-bound $\mathrm{Cu}$ may be trapped in the enterocyte when it dies and is sloughed off and is excreted with the feces. High $\mathrm{Cu}$ status also reduces the amount of CTR1 in the apical membrane. 
$\mathrm{Cu}$ movement across the apical membrane (Lutsenko et al., 2007). A Cu/Cl cotransport mechanism has been proposed in the apical membrane as well, but it is unknown whether it transports only $\mathrm{Cu}+$ or whether it can transport $\mathrm{Cu}^{2+}$ (Zimnicka et al., 2011).

All of the $\mathrm{Cu}$ crossing the apical membrane will be picked up by $\mathrm{Cu}$ chaperone proteins that will direct the $\mathrm{Cu}$ absorbed across the apical membrane to various sites for use within the epithelial cell. One $\mathrm{Cu}$ chaperone delivers $\mathrm{Cu}^{+}$to $\mathrm{Cu} / \mathrm{Zn}$-superoxide dismutase, an antioxidant enzyme. Other $\mathrm{Cu}$ chaperone proteins deliver $\mathrm{Cu}^{+}$to hephaestin, a protein needed for Fe absorption, and cytochrome c oxidase, a $\mathrm{Cu}$-dependent enzyme in the mitochondria (Markossian and Kurganov, 2003).

Transcellular absorption of $\mathrm{Cu}$ must ultimately move $\mathrm{Cu}$ out of the epithelium so cells of the rest of the body can obtain the $\mathrm{Cu}$ they might need (Figure 8). A Cu chaperone protein known as Atox1 binds the incoming $\mathrm{Cu}^{+}$and transports the $\mathrm{Cu}$ through the cytosol to the Golgi apparatus of the cell (Lutsenko et al., 2007). Here it is transferred to another protein, ATP7A, a Cutransporting ATPase protein capable of binding $6 \mathrm{Cu}^{+}$ ions. This protein is located within the Golgi membrane. The $6 \mathrm{Cu}^{+}-$ATP7A complex is incorporated into the membrane of a Golgi transport vesicle and translocated to the basolateral membrane. The vesicle membrane melds into the basolateral membrane, and the ATP7A uses the energy of an ATP molecule to release the $\mathrm{Cu}^{+}$ into the extracellular fluids (Lutsenko et al., 2008; van den Berghe and Klomp, 2009). A Cu oxidase seems to work with the ATP7A at the basolateral membrane to convert the $\mathrm{Cu}^{+}$to $\mathrm{Cu}^{2+}$ for release into the interstitial space (Lutsenko et al., 2007). The $\mathrm{Cu}^{2+}$ ions then diffuse into the plasma, where they quickly become bound to albumin and histidine molecules for transport to the liver, with a very small portion going to other tissues (Hashimoto and Kambe, 2015).

When high amounts of $\mathrm{Cu}^{+}$are entering the cell, the high levels of $\mathrm{Cu}$ within the cytosol trigger the ATP7A protein to become more active and hydrolyze more ATP to release $\mathrm{Cu}^{+}$at a higher rate into the circulation to get $\mathrm{Cu}$ out of the enterocytes. The enterocyte also increases production of a $\mathrm{Cu}$ binding protein called metallothionein (Figure 8). Metallothionein accumulates and acts as a temporary buffer of the extra $\mathrm{Cu}^{+}$, so it cannot exist in a freely ionized state within the enterocyte (van den Berghe and Klomp, 2009). The $\mathrm{Cu}$ bound to metallothionein can be transferred to ATP7A for transport out of the cell later, but any $\mathrm{Cu}$ bound to metallothionein when the intestinal cell dies and is shed will pass out in the feces. The brush border $\mathrm{Cu}$ metalloreductase is downregulated when $\mathrm{Cu}$ is not needed (Kaplan and Lutsenko, 2009). There is also evidence that production of the CTR1 transport protein needed for movement of $\mathrm{Cu}^{+}$across the apical membrane is downregulated when cytosol $\mathrm{Cu}$ levels are high (van den Berghe and Klomp, 2009).

Copper Metabolism. The bulk of the $\mathrm{Cu}^{2+}$ on histidine and albumin will then be taken up from the circulation by the hepatocytes using $\mathrm{Cu}$ reductase to reduce the $\mathrm{Cu}^{2+}$ to $\mathrm{Cu}^{+}$and $\mathrm{CTR} 1$ to move $\mathrm{Cu}^{+}$across the hepatocyte cell membrane (van den Berghe and Klomp, 2009). Copper chaperones can move $\mathrm{Cu}$ within the hepatocyte to permit production of various $\mathrm{Cu}$-containing enzymes such as $\mathrm{Cu}$, Zn-superoxide dismutase, and cytochrome c oxidase needed by the hepatocytes. To export $\mathrm{Cu}$ from hepatocytes for use by other tissues, the Atox $1 \mathrm{Cu}$ chaperone moves $\mathrm{Cu}^{+}$to the transmembrane Golgi complex, where it is transferred to another ATPase known as ATP7B. The $\mathrm{Cu}$ bound to ATP7B is then utilized to produce $\mathrm{Cu}$-containing proteins for export from the liver. The major protein produced is ceruloplasmin, which has $6 \mathrm{Cu}$ atoms incorporated into each molecule - the $\mathrm{Cu}$ is bound to His or Cys/Met residues on the protein. It is then secreted by exocytosis into the blood across the cell membrane facing the liver sinusoids. About 40 to $70 \%$ of plasma $\mathrm{Cu}$ is bound to ceruloplasmin. It can bind to receptors on cells and deliver $\mathrm{Cu}$ to them (Linder, 2016). It is also a functional enzyme. Ceruloplasmin is a ferroxidase. It removes an electron from ferrous $\mathrm{Fe}\left(\mathrm{Fe}^{2+}\right)$ to convert it to ferric iron $\left(\mathrm{Fe}^{3+}\right)$. This is vital to $\mathrm{Fe}$ transfer from liver stores to transferrin. It is also necessary for conservation of $\mathrm{Fe}$ from senescent red blood cells. Macrophages digest the red blood cells, and plasma ceruloplasmin oxidizes the $\mathrm{Fe}$ as it leaves the cell so it can be bound to transferrin (Hellman and Gitlin, 2002). Transferrin delivers the Fe to hemocytoblasts to be used to make new red blood cells.

The liver can also store large amounts of $\mathrm{Cu}$. Some is bound to metallochaperones and metallothionein that hold the $\mathrm{Cu}$ for later use. The liver is the main organ responsible for $\mathrm{Cu}$ homeostasis. Once liver $\mathrm{Cu}$ stores exceed a certain concentration, any additional $\mathrm{Cu}$ that does manage to get inside the hepatocyte is moved to the canalicular side of the hepatocyte by ATP7B and excreted into the bile. It is excreted in a complexed form that cannot be reabsorbed by the intestinal epithelium and so ends up in the feces. Regulation of $\mathrm{Cu}$ excretion in bile represents the major factor protecting the animal from copper toxicity (Lönnerdal, 2008; Roberts and Sarkar, 2008). Monogastric species rarely develop $\mathrm{Cu}$ toxicity as they have a high capacity to excrete $\mathrm{Cu}$ through the bile. However, ruminants (particularly sheep) are very limited in their ability to excrete $\mathrm{Cu}$ into the bile compared with nonruminants (Søli and Rambaek, 1978). Jersey cows are more susceptible to $\mathrm{Cu}$ intoxication than are Holsteins, and this may be 
due to a lower ability to excrete $\mathrm{Cu}$ in their bile $(\mathrm{Du}$ et al., 1996).

Dietary Substances that Interfere with Copper Absorption. As discussed above, free ionized $\mathrm{Cu}$ overlying the brush border is readily transported across the apical membrane of enterocytes. The largest problems revolve around factors that reduce the amount of free ionized $\mathrm{Cu}$ in the fluid over the brush border of the villus enterocytes. For adult ruminants, the NRC (2001) model estimated that $4 \%$ of diet $\mathrm{Cu}$ derived from forages and grains and $5 \%$ of $\mathrm{Cu}$ from supplemental $\mathrm{CuSO}_{4}$ was absorbed. These coefficients of absorption for $\mathrm{Cu}$ were based on apparent absorption in ruminants. Apparent absorption is lower than true $\mathrm{Cu}$ absorption because a large amount of absorbed $\mathrm{Cu}$ is typically excreted in the bile each day. The coefficients of absorption are reasonably valid for typical situations - that is, when there are not unusual amounts or types of substance in the diet that might interfere with $\mathrm{Cu}$ absorption. Several factors that can interfere with $\mathrm{Cu}$ absorption are known, and several more factors that have not been fully identified likely exist.

Molybdenum and Sulfur. The absorption of dietary $\mathrm{Cu}$ is reduced by the presence of Mo and $\mathrm{S}$ in the diet. Diet Mo and sulfide formed within the rumen combine to form tetrathiomolybdate in the rumen. Tetrathiomolybdate binds $\mathrm{Cu}$ ions that are in solution in the rumen fluid to form a highly insoluble and very stable complex. Suttle and McLauchlan (1976) developed a nomogram that models the effect of dietary $\mathrm{S}$ and $\mathrm{Mo}$ on the apparent absorption of dietary $\mathrm{Cu}$. As diet Mo increases from 1 to $20 \mathrm{mg} / \mathrm{kg}$, the Cu absorption coefficient goes from 0.042 to 0.01 - that is, 4 times as much $\mathrm{Cu}$ would need to be fed to meet the requirements of the animal. Sulfur, even in the absence of Mo, can be detrimental to $\mathrm{Cu}$ absorption. Sulfates may be reduced to sulfides in the anaerobic, highly reducing environment in the rumen. Free $\mathrm{Cu}$ ions may become bound to sulfide-forming $\mathrm{Cu}$ sulfides $\left(\mathrm{Cu}_{2} \mathrm{~S}\right.$ and $\left.\mathrm{CuS}\right)$, which are very stable and insoluble in water. The NRC (2001) model assumed that normal diets contain $1 \mathrm{mg} /$ $\mathrm{kg}$ of Mo and $0.25 \% \mathrm{~S}$.

Soil Ingestion. Up to $10 \%$ of the DMI of pastured animals can be soil ingested as they graze - especially if pastures are short (Thornton and Alloway, 1974). Suttle (1975) found that inclusion of soil at 10\% of DM reduced $\mathrm{Cu}$ absorption by $50 \%$ across several different soil types. Silicates and other anions in clay form insoluble complexes with $\mathrm{Cu}$ ions.

High Dietary Zinc. Although adequate liver $\mathrm{Cu}$ stores can induce metallothionein synthesis within the enterocytes, it is $\mathrm{Zn}$ that is the primary regulator of metallothionein synthesis; $\mathrm{Cu}$ is the secondary stimulus (Taylor et al., 1991). Metallothionein binds Zn so it is not in a free ionized state within the cell, just as it does with $\mathrm{Cu}^{+}$. Unfortunately, the metallothionein induced by excess diet $\mathrm{Zn}$ also sequesters $\mathrm{Cu}$ inside the enterocytes. Any $\mathrm{Cu}$ (and $\mathrm{Zn}$ ) bound to the metallothionein when the villus enterocyte dies and sloughs off would be lost to the feces. In addition, Zn would compete for use of the DMT1 path for moving divalent metals across the apical membrane of the enterocytes (Lutsenko et al., 2007). Under practical conditions, $\mathrm{Zn}$ is not a major factor affecting $\mathrm{Cu}$ absorption in cows unless the diet has at least 2-fold more $\mathrm{Zn}$ than is recommended in the diet (Miller et al., 1989).

High Dietary Iron. High dietary Fe can cause $\mathrm{Cu}$ deficiency in man and animals. It has been theorized that high-Fe diets interfere with intestinal $\mathrm{Cu}$ absorption. Iron would be expected to compete with $\mathrm{Cu}$ for use of the DMT1 path for moving $\mathrm{Cu}$ across the apical membrane of the enterocytes, even though this is considered a minor pathway for $\mathrm{Cu}$ to use for absorption across the apical membrane of enterocytes (Lutsenko et al., 2007). However, it has recently been demonstrated in mice that high-Fe diets do not alter intestinal $\mathrm{Cu}$ absorption appreciably. A high-Fe diet does interfere with the availability of that $\mathrm{Cu}$ for uptake by tissues such as the liver, and this results in $\mathrm{Cu}$ deficiency symptoms (Ha et al., 2017).

Under practical conditions, the effect of $\mathrm{Fe}$ on $\mathrm{Cu}$ metabolism in cattle seems to be negligible until diet Fe exceeds $500 \mathrm{mg} / \mathrm{kg}$ (Phillippo et al., 1987). Bremner et al. (1987) demonstrated that preruminant calves could be fed milk diets with iron added to $500 \mathrm{mg} /$ $\mathrm{kg}$ of DM $(9 \mathrm{mM})$ without any ill effects on $\mathrm{Cu}$ status. However, once the calves were fed a barley grain and barley straw diet, the addition of just $250 \mathrm{mg}$ of $\mathrm{Fe} / \mathrm{kg}$ of DM to their diet for $24 \mathrm{wk}$ significantly reduced liver and plasma $\mathrm{Cu}$ concentrations. Water can contain high amounts of very soluble ferrous iron, but no specific recommendations on how to adjust diet $\mathrm{Cu}$ for high $\mathrm{Fe}$ in the water can be made.

Copper Toxicity. Of all the minerals, $\mathrm{Cu}$ is the most likely to become toxic if oversupplemented. When cattle consume excessive $\mathrm{Cu}$, a portion will be taken up by the liver. The mechanisms that excrete excess $\mathrm{Cu}$ into the bile can be overwhelmed. This causes sequestration of large amounts of $\mathrm{Cu}$ in the liver. The $\mathrm{Cu}$ may stay in the liver and never cause a problem, or it can cause free radical damage to the liver. Stress or other factors (e.g., infection and inflammation) may result in the sudden liberation of large amounts of $\mathrm{Cu}$ from the liver to the blood as part of an acute phase protein response. The $\mathrm{Cu}$ released may overwhelm albumin $\mathrm{Cu}$ binding capacity. Unbound free ionized $\mathrm{Cu}$ is strongly oxidizing and is likely to cause destruction of red blood cell membranes. Copper toxicity is accompanied by 
considerable hemolysis, jaundice, methemoglobinemia, hemoglobinuria, generalized icterus, widespread cell necrosis, and often death (NRC, 2005; Johnston et al., 2014). As little as $40 \mathrm{mg}$ of $\mathrm{Cu} / \mathrm{kg}$ of diet fed long term may cause toxicity in Jersey cows; Holsteins may tolerate up to $100 \mathrm{mg}$ of $\mathrm{Cu} / \mathrm{kg}$ of DM (Du et al., 1996; NRC, 2005). However, a field report suggests even 40 $\mathrm{mg}$ of $\mathrm{Cu} / \mathrm{kg}$ may have caused toxicity in a Holstein herd (Bradley, 1993). Cows have been observed to drink $\mathrm{Cu}$ sulfate foot bath water, which may be an overlooked cause of $\mathrm{Cu}$ toxicity.

Assessing Copper Status. Forage and diet concentrations of $\mathrm{Cu}$ are of limited value in assessing adequacy of $\mathrm{Cu}$ unless concentrations of $\mathrm{Cu}$ antagonists in forage such as Mo, S, and Fe are also considered. Other antagonists to $\mathrm{Cu}$ absorption that are unidentified also seem to exist based on the response of some herds to increased $\mathrm{Cu}$ supplementation with forms of $\mathrm{Cu}$ that are able to pass through the rumen without reacting to interfering substances (see section on organic and chelated minerals). Concentrations of $\mathrm{Cu}$ in liver below 20 $\mathrm{mg} / \mathrm{kg}$ on a DM basis (6 mg/ $\mathrm{kg}$ on a wet weight basis) or plasma concentrations $<0.50 \mathrm{mg} / \mathrm{L}$ are definitive of $\mathrm{Cu}$ deficiency. Copper concentration in normal liver is between 100 and $300 \mathrm{mg} / \mathrm{kg}$ on a DM basis (Ammerman, 1970; Underwood, 1981; Puls, 1994). However, in the presence of high dietary Mo and S, animals with "normal" $\mathrm{Cu}$ levels in liver may actually be $\mathrm{Cu}$ insufficient. This is because $\mathrm{Cu}$ can exist as thiomolybdate complexes within the liver parenchyma. This $\mathrm{Cu}$ is unavailable for biochemical functions (Suttle, 1991). Liver $\mathrm{Cu}$ concentration in excess of $1,000 \mathrm{mg} / \mathrm{kg}$ of DM indicates that the cow is at risk of $\mathrm{Cu}$ intoxication. In most of these cases, $\mathrm{Cu}$ toxicity was diagnosed because animals had experienced a hemolytic crisis observed at necropsy. Recent reports suggest that liver $\mathrm{Cu}$ levels of just $500 \mathrm{mg} / \mathrm{kg}$ of $\mathrm{DM}$ can be implicated in liver damage, characterized by elevated liver enzymes and increased numbers of stellate cells in the space of Disse suggestive of liver fibrosis (Gummow, 1996; Bidewell et al., 2012; Johnston et al., 2014). This is unfortunately becoming more common than $\mathrm{Cu}$ deficiency (Kendall et al., 2015). Interestingly, several of these case reports suggest that cows died of $\mathrm{Cu}$ toxicity shortly after dryoff, suggesting that this stress caused mobilization of $\mathrm{Cu}$ from the liver.

\section{lodine}

Iodine Function. Iodine is necessary for the synthesis of the thyroid hormones thyroxine and triiodothyronine that regulate energy metabolism. The amount of I incorporated into thyroid hormones is about $0.4 \mathrm{mg}$ of I/d in calves weighing $40 \mathrm{~kg}$ and increases to $1.3 \mathrm{mg}$ of I/d in nonpregnant heifers weighing $400 \mathrm{~kg}$. Early pregnancy does not increase thyroid hormone, whereas late-gestation cows require about $1.5 \mathrm{mg}$ of I/d (Miller et al., 1988). During lactation thyroid hormone production is increased, especially in higher producing cows, and I incorporation into thyroid hormone may reach 4 to $4.5 \mathrm{mg}$ of I/d (Sorensen, 1962). Thyroid hormone production is also increased during colder weather to stimulate an increase in basal metabolic rate to allow the cow to stay warm (Goodman and Middlesworth, 1980).

Iodine Sources. Concentrations of I in forage are extremely variable and depend on soil I content. Soil near the oceans tends to provide adequate I within plants. However, in the Great Lakes regions and northwest United States, I concentrations in forages are generally low enough to result in I deficiency unless supplemented. Most I sources are readily absorbable, and though the iodides of $\mathrm{Na}, \mathrm{K}$, and Ca could be used, they tend to be easily oxidized and some of the iodide volatilizes away before the animal can ingest it. Penta$\mathrm{Ca}$ orthoperiodate and ethylenediamine dihydroiodide (EDDI) are more stable in feeds, and EDDI has become the most frequently used I source for use in diets. They are also less water soluble and are commonly used in mineral blocks and salt licks exposed to the weather.

Iodine Absorption Mechanisms. About 70 to $90 \%$ of dietary I is absorbed (Miller et al., 1975). It is normally ingested in the form of iodide. $\mathrm{A} \mathrm{Na}^{+} / \mathrm{I}^{-}$ symporter on the apical surface of the intestinal epithelium brings dietary iodide across the apical membrane (Figure 7). Increasing levels of intracellular $\mathrm{I}^{-}$are able to downregulate the posttranslational expression of the $\mathrm{Na}^{+} / \mathrm{I}^{-}$symporter, offering some small control of I absorption at the intestinal level (Nicola et al., 2015). The fate of iodide within the enterocyte and its transport across the basolateral membrane are not well described. There seem to be no great interferences with intestinal iodide absorption that result in I deficiency.

Iodine Deficiency Symptoms. Iodine deficiency reduces thyroid hormone production, slowing the rate of oxidation of all cells. Often the first indication of I deficiency in a herd is enlargement of the thyroid (goiter) of newborn calves. Calves may be born hairless, weak, or dead. Fetal death can occur at any stage of gestation. Often the cows will appear normal (Hemken, 1970). In adult cattle, I deficiency can cause enlarged thyroid glands, reduced fertility (males and females), and increased morbidity.

Factors Affecting Iodine Requirement. Goitrogens are compounds that interfere with the synthesis or secretion of thyroid hormones and cause hypothyroidism, which is sometimes accompanied by an enlarged thyroid gland, known as a goiter. Goitrogens fall into 
2 categories. The first and most common type is the cyanogenic goitrogens, which impair iodide uptake by the thyroid gland. Cyanogenic compounds release hydrogen cyanide during their metabolism. The hydrogen cyanide quickly reacts with sulfate groups to form thiocyanate. Thiocyanates have about the same molecular size as iodide and compete with iodide for binding sites on the iodide transporter protein that moves iodide across the thyroid follicular cell membrane into the cell (Pesce and Kopp, 2014). This reduces the efficiency of iodide uptake and retention by the thyroid gland. Cyanogenic plant glucosides can be found in many feeds, including raw soybeans, beet pulp, corn, sweet potato, white clover, and millet. Their effect is easily overcome by increasing diet supplemental I to outcompete the thiocyanates for iodide transport sites on the thyroid follicle cells.

The second and more detrimental type is the goitrins found in cruciferous plants (rape, kale, cabbage, turnips, mustard) and aliphatic disulfides found in plants such as onions. These compounds inhibit the enzyme thyroperoxidase. This blocks iodination of tyrosine residues on the thyroglobulin molecule. This prevents formation of mono- and diiodotyrosine, thereby blocking thyroxine production (Ermans and Bourdoux, 1989). With goitrins and aliphatic disulfides, hormone synthesis will not be readily restored to normal by additional dietary I supplementation. The offending feedstuff needs to be reduced or removed from the diet.

Iodine Toxicity. Lactation imposes the highest requirement for iodine of all stages in the cow's life; the lactating cow's requirement for I is $1.5 \mathrm{mg} / 100 \mathrm{~kg}$ of BW (NRC, 2001). The maximal tolerable concentration of $\mathrm{I}$ in the diet, as far as cow health is concerned, is reported to be $50 \mathrm{mg} / \mathrm{kg}$ of diet DM (NRC, 2005). Iodine toxicity has been reported in adult dairy cows with dietary intakes of just $500 \mathrm{mg} / \mathrm{d}$. Symptoms included excessive nasal and ocular discharge, salivation, decreased milk production, coughing, and dry, scaly coats (Olson et al., 1984). Bronchopneumonia has also been reported (Mangkoewidjojo et al., 1980). Recently, Ong et al. (2014) reported enlarged thyroid glands in dairy cattle as a result of chronic excessive intake of I. It was estimated that the cows were receiving 7.5 to $12.5 \mathrm{mg}$ of $\mathrm{I} / 100 \mathrm{~kg}$ of BW each day during lactation. Gross examination of these thyroid glands might suggest that the cows were suffering from I-deficient goiter. However, histologic examination of the thyroid glands suggested that the glands had regions of cystic nodular hyperplasia and follicular atrophy with areas of fibrosis. It was unclear whether this represented a unique pathological change that occurred when cattle that were previously deficient in I were suddenly fed supplemental I in the diet as dietary I had been increased recently in the herd. To make interpretation even more difficult, the animals had below-normal levels of free triiodothyonine in their blood. It has been suggested that excess I inhibits iodination of thyroglobulin and can inhibit thyroid hormone release from the thyroid gland by preventing colloid proteolysis in the thyroid gland (Markou et al., 2001; Sesmilo et al., 2011). Calves receiving excessive amounts of I can also develop goiter (Mangkoewidjojo et al., 1980).

Very high I diets have been used in the past to control foot rot. However, high dietary I concentrations also increase I concentrations in milk (Berg et al., 1988), and because humans are much more sensitive to I thyrotoxicosis than are cows, the danger of excess dietary I fed to cattle is essentially a public health issue (Hetzel and Welby, 1997). The US Food and Drug Administration (2000) limits EDDI use to $<50 \mathrm{mg} /$ head per day. The National Dairy Council voluntarily limits milk to $500 \mu \mathrm{g}$ of I/L. Iodine can also enter milk due to poor removal of I-based teat dip during preparation of the cow for milking (French et al., 2016).

\section{Iron}

Iron primarily functions as a component of heme found in hemoglobin and myoglobin. Enzymes of the electron transport chain, myeloperoxidase, catalase, and the cytochrome P-450 enzymes also require $\mathrm{Fe}$ as cofactors. Iron deficiency results in hypochromic microcytic anemia due to failure to produce hemoglobin. It is likely to occur only in rapidly growing calves fed milk diets. Another important aspect of Fe deficiency is greater morbidity and mortality associated with depressed immune responses (Möllerberg and MorenoLopez, 1975). Iron deficiency in adult cattle is very rare as their requirement for $\mathrm{Fe}$ is low and soil contamination of forages generally ensures that the Fe needs of the adult will be met or exceeded.

Iron in the ferric form $\left(\mathrm{Fe}^{3+}\right)$ is poorly absorbed from the intestinal tract. Much of the dietary Fe exists within feedstuffs in the ferric form. Some of the ferric Fe can be reduced to the ferrous $\left(\mathrm{Fe}^{2+}\right)$ form upon reaction with the acid of the abomasum (Wollenberg and Rummel, 1987). During digestion, ferrous Fe usually becomes bound to some chelator such as histidine, mucin, or fructose. These chelators enhance Fe absorption by solubilizing the $\mathrm{Fe}$ ion and protecting it in the ferrous state. Formation of Fe-AA complexes may allow the $\mathrm{Fe}$ to use the AA transporters to move across the intestine (see "Chelated and Organic Mineral Supplements"). Other chelators (e.g., oxalate and lignins) can form insoluble $\mathrm{Fe}$ complexes, blocking absorption. In monogastrics, a duodenal brush border enzyme, ferrireductase, reduces the bulk of the $\mathrm{Fe}^{3+}$ that will be 


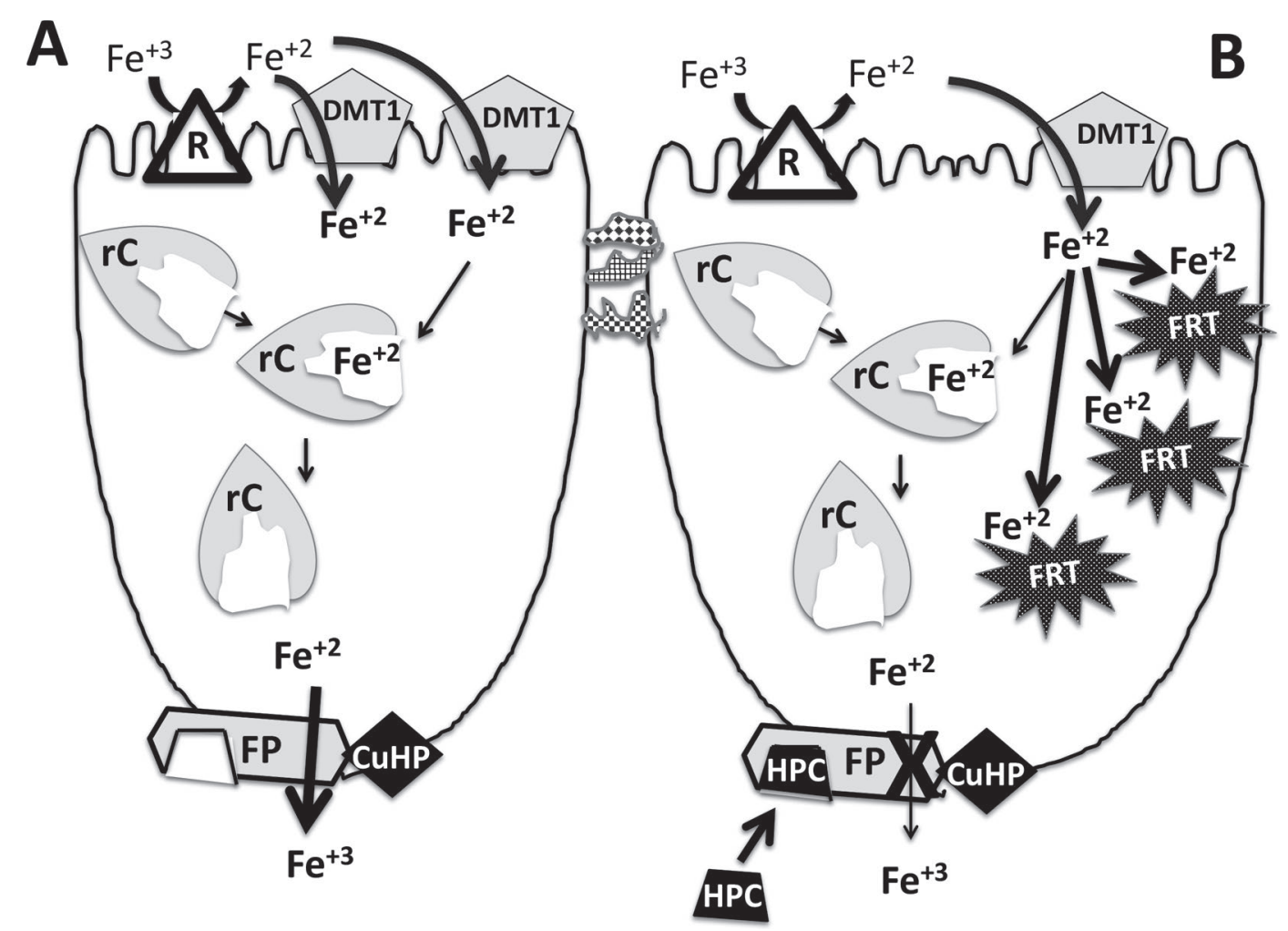

Figure 9. Enterocyte iron absorption. (A) When Fe is needed, the amount of divalent metal transporter 1 protein (DMT1) in the apical membrane is upregulated. This can move $\mathrm{Fe}^{2+}$ across the apical membrane. Ferrireductase $(\mathrm{R})$ in the apical membrane can convert diet $\mathrm{Fe}^{3+}$ to $\mathrm{Fe}^{2+}$ for absorption. Once $\mathrm{Fe}^{2+}$ crosses the apical membrane, it is picked up by a chaperone protein, poly (rC)-binding protein-1 (rC), for transport to

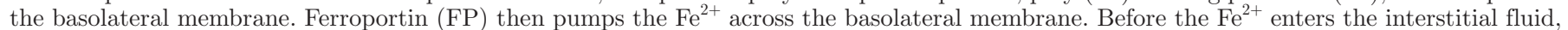
it is converted to $\mathrm{Fe}^{3+}$ by $\mathrm{Cu}$-hephaestin $(\mathrm{CuHP})$, linked to the $\mathrm{FP}$ transporter. (B) When Fe stores are adequate, the amount of DMT1 is reduced. The enterocytes begin to produce ferritin (FRT), which binds and sequesters the bulk of the $\mathrm{Fe}^{2+}$ crossing the apical membrane. Hepcidin (HPC), a hormone produced by the Fe-laden liver, binds to FP, blocking its ability to transport Fe out of the cell. Very little Fe will be absorbed.

absorbed to $\mathrm{Fe}^{2+}$ (Mackenzie and Garrick, 2005). It is assumed that this enzyme also exists in ruminants (Figure 9).

The $\mathrm{Fe}^{2+}$ binds to a protein known as divalent metal transporter 1 (DMTR1) within the brush border of the enterocyte and is transported into the cell. The effectiveness of DMTR1 is linked to the activity of the apical membrane $\mathrm{Na}^{+} / \mathrm{H}^{+}$exchanger (Shawki et al., 2016). The low-pH microclimate in the unstirred water layer created by the $\mathrm{Na}^{+} / \mathrm{H}^{+}$exchanger enhances existence of $\mathrm{Fe}$ in the free $\mathrm{Fe}^{2+}$ state to promote its absorption Once inside the cell, the $\mathrm{Fe}^{2+}$ is bound to special chaperone proteins. Some chaperones carry Fe to sites within the cell to allow synthesis of Fe-containing enzymes such as catalase. Some chaperone proteins may be better thought of as modulators of mRNA translation. Poly $(\mathrm{rC})$ binding protein- 1 is an $\mathrm{Fe}$ chaperone protein that is important to $\mathrm{Fe}$ export from the cell. It transports $\mathrm{Fe}^{2+}$ to the basolateral membrane (Shi et al., 2008). Ferroportin, a transmembrane protein within the basolateral membrane, moves $\mathrm{Fe}^{2+}$ from the inside of the cell to the extracellular fluids (Figure 9). Hephaestin is a
$\mathrm{Cu}$-containing ferroxidase found near ferroportin in the basolateral membrane. It oxidizes the $\mathrm{Fe}^{2+}$ to the less toxic $\mathrm{Fe}^{3+}$ as it is moved into the interstitial space. The $\mathrm{Fe}^{3+}$ becomes bound to transferrin for transport within the blood to tissues of the body, particularly those involved in hematopoiesis (Waldvogel-Abramowski et al., 2014).

Plant tissue can contain $\mathrm{Fe}$ bound to plant ferritin molecules. Each molecule can hold up to 3,000 to 4,500 Fe ions. Recently, it has been shown that intestinal cells can take up ferritin and the Fe bound to it by endocytosis (San Martin et al., 2008). This may be of some importance to nonruminants, where ferritin-bound Fe can reach the duodenum. It is unknown how much plant ferritin escapes digestion in the rumen and whether this contributes to Fe status of the ruminant.

Iron is needed for many biologic processes, but excess Fe can be toxic. If Fe status of the body is adequate, the amount of DMTR1 synthesized and placed into the apical cell surface of enterocytes is reduced, slowing $\mathrm{Fe}$ absorption. High dietary Fe induces production of an Fe binding protein within enterocytes called ferritin. 
The ferritin works to sequester Fe within the enterocyte, preventing Fe entering the enterocyte from being transported to the basolateral membrane (Ezquer et al., 2006; Collins et al., 2010). Once bound to ferritin, the $\mathrm{Fe}$ is excreted with the feces when the enterocyte dies and is sloughed (Beard and Dawson, 1997).

Iron absorption is the primary means of maintaining Fe homeostasis and is controlled at local and systemic levels. Locally, the presence of adequate Fe within the enterocyte affects translation of mRNA coding for ferritin and the divalent metal transporter protein. When intracellular Fe is high, Fe-responsive elements on the mRNA become bound to Fe-responsive proteins (a special type of $\mathrm{Fe}$ chaperone), which block translation and production of the DMT1. Iron response elements associated with ferritin mRNA enhance translation to stimulate ferritin synthesis. The opposite occurs when intracellular Fe is low (Kühn, 2015).

The liver regulates Fe absorption based on systemic Fe status. Liver hepatocytes have transferrin receptors on them that can sense the degree of Fe saturation of transferrin (Scheers, 2013). When the liver has adequate Fe stores, it secretes a hormone, hepcidin, which initiates synthesis of ferritin in intestinal epithelial cells and effectively inhibits absorption of Fe (Gozzelino and Arosio, 2016). More important, hepcidin binds to a site on the existing ferroportin molecules, effectively blocking Fe from exiting the enterocyte (Sangkhae and Nemeth, 2017). Inflammatory cytokines can also play a role in Fe metabolism. Interleukins 17 and 22 downregulate ferroportin levels in enterocytes, slowing $\mathrm{Fe}$ absorption. These cytokines also increase liver secretion of apo-ferritin into the serum as part of the acute phase inflammatory response. The ferritin scavenges free Fe from damaged cells, reducing the availability of Fe to bacteria, thus limiting bacterial growth (Diaz-Ochoa et al., 2014).

\section{Manganese}

Manganese deficiency can cause impaired growth, skeletal abnormalities (shortened and deformed bones), disturbed or depressed reproduction, and abnormalities of the newborn (including ataxia due to failure of the inner ear to develop; Underwood, 1977). The skeletal changes are related to loss of galactotransferase and glycosyltransferase, enzymes vital to production of cartilage and bone ground substance mucopolysaccharides and glycoproteins. Manganese superoxide dismutase is found within mitochondria, where it works to minimize accumulation of reactive forms of oxygen, which could damage cells. Manganese is found in highest concentrations within the mitochondria of cells. It also accumulates in the inorganic matrix of bone.
Manganese Absorption and Metabolism. Little work on the mechanism of absorption of Mn has been done in cattle. In broiler chicks, specific Mn transporter proteins exist within the duodenum and jejunum, but they are of limited capacity. In rats, mutation of the divalent metal transporter I protein reduces the absorption of Mn as well as Fe and Zn. This suggests that these transition metals compete with each other for binding sites on this transporter (Chua and Morgan, 1997). Additional divalent metal transporters such as ZIP14 and ZIP8 have also been shown to move Mn (and other metals) across the apical membrane (Figure 7; Jenkitkasemwong et al., 2012). A mechanism to specifically enhance the efficiency of Mn absorption during Mn deficiency does not appear to exist (Gibbons et al., 1976). The ileum of broilers is able to absorb Mn through a nonsaturable process, suggesting that the absorption is occurring paracellularly. This seems to be where the bulk of $\mathrm{Mn}$ is absorbed in broilers if they are fed a higher Mn diet (Bai et al., 2008).

The work of Van Bruwaene et al. (1984) determined that less than $1 \%$ of an orally administered tracer dose of ${ }^{54} \mathrm{Mn}$, given as very soluble $\mathrm{MnCl}_{2}$, was absorbed by lactating dairy cows. Similarly, Sansom et al. (1978) found that less than $0.75 \%$ of $\mathrm{Mn}$ ingested was absorbed. These cows were not on a high plane of $\mathrm{Mn}$ supplementation. More recent studies suggest that Mn is absorbed with higher efficiency. The apparent absorption of $\mathrm{Mn}$ in cows fed approximately $700 \mathrm{mg}$ of $\mathrm{Mn} / \mathrm{d}$ was 6 to $7 \%$ or approximately $45 \mathrm{mg} / \mathrm{d}$ (Weiss and Socha, 2005). When 1,600 $\mathrm{mg}$ of $\mathrm{Mn} / \mathrm{d}$ was fed, close to $11 \%$ of the Mn or approximately $176 \mathrm{mg} / \mathrm{d}$ was absorbed (Faulkner et al., 2017). These data suggest that a nonsaturable paracellular absorption mechanism is likely occurring in cattle at these higher Mn intakes, and, just as in broilers, it may carry more Mn across the intestinal tract than the transcellular pathway. Perhaps the earlier studies did not feed enough Mn to permit paracellular absorption. They measured active transcellular transport, which is the only method for $\mathrm{Mn}$ absorption available to the cow when diet $\mathrm{Mn}$ is lower. Again, just as in the broilers, the transcellular transporters are likely of low capacity in cattle. However, because tissue $\mathrm{Mn}$ requirements are relatively low (Sansom et al., 1978), transcellular Mn absorption seems capable of meeting tissue requirements for $\mathrm{Mn}$ under most conditions.

Absorbed Mn can exist in small amounts as the free ion in plasma, but the great bulk of absorbed $\mathrm{Mn}$ is bound to $\alpha 2$-macroglobulin and albumen. A good portion of this $\mathrm{Mn}$ entering the portal blood is removed by the hepatocytes. Some absorbed Mn is oxidized to $\mathrm{Mn}^{3+}$, which then becomes bound to transferrin and remains in the circulation (Bertinchamps et al., 1966). 
The major homeostatic control for Mn appears to be regulation of biliary and to a lesser extent pancreatic excretion of $\mathrm{Mn}$ absorbed in excess of tissue needs (Brandt and Schramm, 1986). A large proportion of absorbed $\mathrm{Mn}$ is excreted into the bile and ends up back in the feces (Sansom et al., 1978; Van Bruwaene et al., 1984). Enterohepatic circulation of Mn may also be a factor in Mn homeostasis (Miller, 1979). Very little Mn is ordinarily excreted in urine $(<2 \mathrm{mg} / \mathrm{d}$; Faulkner et al., 2017).

Most of the Mn in the body is found in the skeleton, liver, and hair. Manganese accumulates in the liver when dietary $\mathrm{Mn}$ is increased, but the increase in diet Mn has to be large to see even a small increase. Steers fed diets with $29 \mathrm{mg} / \mathrm{kg}$ of $\mathrm{Mn}$ in the growing phase and $8 \mathrm{mg} /$ $\mathrm{kg}$ of $\mathrm{Mn}$ in the finishing phase had liver Mn of 12.1 $\mathrm{mg} / \mathrm{kg}$ of DM. Supplementing the diet of steers with an additional $240 \mathrm{mg}$ of $\mathrm{Mn} / \mathrm{kg}$ of diet DM increased liver Mn to just $15.1 \mathrm{mg} / \mathrm{kg}$ of DM (Legleiter et al., 2005). Symptoms of Mn deficiency are difficult to detect, and there is no simple or accurate way to assess Mn status. Liver Mn, despite its lack of sensitivity, is still used to assess Mn status (Black et al., 1985). Adequate liver Mn concentration is reported to be 8 to $20 \mathrm{mg} / \mathrm{kg}$ on a DM basis (Puls, 1994). The liver and perhaps other tissues have some ability to mobilize stored Mn, which may satisfy needs for several weeks during times of $\mathrm{Mn}$ deficiency (Lassiter and Morton, 1968).

Antagonists to Manganese Absorption. High dietary $\mathrm{Ca}, \mathrm{K}$, or $\mathrm{P}$ increase $\mathrm{Mn}$ excretion in the feces, presumably by reducing Mn absorption (Lassiter et al., 1972; Hartmans, 1974). Excessive dietary Fe depresses Mn retention in calves (Ho et al., 1984). In pigs, a low-Fe diet enhances Mn absorption (Hansen et al., 2009), likely because it removes competition for the DMT1 in the apical membrane of enterocytes. It is also important to keep in mind that the expression of the DMT1 protein is regulated by Fe status of the cell. When Fe within enterocytes is high, the expression of the transporter is downregulated (see the section on iron). Manganese and $\mathrm{Zn}$ that use that same transporter to cross the apical surface will be blocked from using this path for transcellular transport. Fortunately, if the diet concentration of $\mathrm{Mn}$ is high enough, there is paracellular transport within the ileum of most species examined, though this is not proven in ruminants.

\section{Molybdenum}

Function and Requirement of Molybdenum. Molybdenum is a component of xanthine oxidase, sulfide oxidase, and aldehyde oxidase, enzymes found in milk and many tissues (Mills and Davis, 1987). It is al- most impossible for a dairy cow to develop a deficiency of Mo when fed practical diets.

Molybdenum Toxicity. Dietary Mo becomes a practical concern because it antagonizes the absorption of $\mathrm{Cu}$ (and to a lesser extent $\mathrm{P}$ ). Molybdenum toxicosis signs are essentially those associated with $\mathrm{Cu}$ deficiency. Molybdenum and sulfide formed within the rumen interact within the digestive tract to form a thiomolybbdate complex that has a high affinity for $\mathrm{Cu}$. Copper bound to this molybbdate is unavailable for absorption (see the section on copper). The toxicity of Mo can be overcome by increased $\mathrm{Cu}$ supplementation, and $\mathrm{Cu}$ toxicity can be reduced by Mo supplementation.

\section{Selenium}

Selenium Functions. Selenium is similar to $\mathrm{S}$ in its chemistry. Selenocysteine and selenomethionine are AA with the same structure as cysteine and methionine, except that an Se atom exists where the S atom usually is.

Selenocysteine is incorporated into several mammalian proteins during their synthesis. The resulting protein is a selenoprotein. For example, selenocysteine is a component of the antioxidant enzyme glutathione peroxidase. A selenoprotein is also a component of type I iodothyronine- 5 '-deiodinase, the enzyme that converts thyroxine $\left(\mathrm{T}_{4}\right)$ to triiodothyronine $\left(\mathrm{T}_{3}\right.$; Berry et al., 1991). An Se deficiency can cause hypothyroidism.

Selenoproteins are commonly found in muscle tissue. Their exact function is unknown, but when they are absent muscle function is disrupted and "white muscle disease" or nutritional muscular dystrophy develops (Yeh et al., 1997). The prevalence of retained placenta is higher in Se-deficient cows. Retained placenta incidence was reduced when supplemental Se was fed to or injected into late-gestation dairy cows (Harrison et al., 1984; Miller et al., 1993). Other problems that have responded to Se supplementation include metritis and cystic ovaries (Harrison et al., 1984) and udder edema (Miller et al., 1993).

The requirements for vitamin E and Se are clearly interdependent, perhaps because they both have antioxidant roles. Some symptoms of vitamin E deficiency can be overcome by addition of Se to the diet, and some symptoms of Se deficiency can be overcome by increasing vitamin $\mathrm{E}$ in the diet. However, they are not interchangeable. Each has unique roles that cannot be performed by the other nutrient, and it is critical to try to meet the dietary requirements of each one.

Selenium Sources. The concentrations of Se in plant material are highly correlated with those in the soil, and fertilization of soil with Se increases Se concen- 
trations in plants. Based on current regulations of the US Food and Drug Administration (2015), inorganic Se (as Na selenate or Na selenite) and Se incorporated into yeast are the only forms that can be added legally to diets in the United States. The amount of inorganic or yeast Se added to a diet may not exceed $0.3 \mathrm{mg} /$ $\mathrm{kg}$ of DM. Yeast Se is a product produced by growing yeast in the presence of inorganic Se. The yeast will incorporate the Se into their own protein. These selenoproteins are digested, and the selenomethionine and selenocysteine AA can have a higher coefficient of absorption than does $\mathrm{Na}$ selenate in the presence of antagonists to Se absorption.

Selenium Absorption and Metabolism. Most of what is known about Se absorption and metabolism comes from monogastric studies, often performed in rodents. It is believed that cattle metabolize Se similarly. Dietary selenocysteine and selenomethionine, the forms found in plants and yeast selenoproteins, are absorbed across the small intestine using the same transcellular transporters as their S-containing counterparts, cysteine and methionine (Nickel et al., 2009). These seleno$\mathrm{AA}$ are removed from the circulation by the liver and other tissues such as muscle and the mammary gland. Hepatocytes will occasionally incorporate selenomethionine in place of regular methionine in several proteins such as albumin. Mammary gland cells can incorporate selenomethionine in place of methionine during casein synthesis. This might be considered "accidental or random inclusion" into these proteins, as it is not vital to their function (Muñiz-Naveiro et al., 2005).

The remaining selenomethionine is converted to selenocysteine in the liver and other tissues by a transsulfuration pathway. The selenocysteine formed, or absorbed dietary selenocysteine taken up by the tissues, is then catabolized and the Se is reduced to form a hydrogen selenide $\left(\mathrm{H}_{2} \mathrm{Se}\right.$; Burk and Hill, 2015). The selenide, and only the selenide, can be used to produce the selenocysteine transfer RNA (tRNA) needed to make the functional selenoproteins the body requires (Burk et al., 2015). A series of enzymes uses selenide to form selenophosphate and then adds the Se to serine on a special serine tRNA called O-phosphoseryl-tRNA to form selenocysteyl tRNA. Other enzymes then act on the selenocysteyl-tRNA to convert it to selenocysteine tRNA (Turanov et al., 2011). The selenocysteine, bound to the tRNA upon which it was synthesized, will be used to produce selenoproteins in the various tissues of the body. Specially modified selenocysteine insertion codon sequences within the mRNA code for placement of the selenocysteine tRNA into nascent selenoproteins by the ribosomes (Burk and Hill, 2015).

Sodium selenate and $\mathrm{Na}$ selenite are 2 commonly used inorganic sources of Se added to diets. Both are quite soluble in water. Selenate ions $\left(\mathrm{SeO}_{4}{ }^{-2}\right)$ are absorbed very efficiently by a paracellular route in the lower small intestine. Once absorbed, some selenate is reduced to selenite $\left(\mathrm{SeO}_{3}{ }^{-2}\right)$ in the extracellular fluids by an ATP sulfurylase (Gammelgaard et al., 2012). Dietary selenite ion absorption is more complex, and very little is absorbed as the selenite ion. If reduced glutathione has been secreted into the brush border of the apical membrane by the epithelial cells, the $\mathrm{SeO}_{3}{ }^{-2}$ can react with the glutathione to form selenoglutathione. A portion of the selenoglutathione is absorbed transcellularly by processes that are not well defined (Roman et al., 2014). Glutathione reductase converts selenoglutathione to $\mathrm{H}_{2} \mathrm{Se}$ in liver and other tissues (Bedwal et al., 1993). The selenide can be used to make selenocysteine tRNA. Blood selenate and selenite can be taken up by liver, muscle, and other tissues and reduced to form selenide. This also allows synthesis of the selenocysteine tRNA needed to produce selenoproteins in those tissues.

The efficiency of absorption of Se from different sources is not well known for ruminants. It can also vary considerably depending on metabolism of Se within the rumen. The Se in Na-selenate, Na-selenite, and Se-enriched yeast had similar apparent digestibilities in the range of 40 to $50 \%$ in cows (Harrison and Conrad, 1984a; Koenig et al., 1997). However, one study (Koenig et al., 1991) found that the true digestibility of Se from Na-selenite fed to dairy cows was just $11 \%$.

Some of the Se from dietary selenate or selenite can be taken up by rumen bacteria and incorporated into seleno-AA and rumen microbial protein, Dietary selenomethionine and selenocysteine are incorporated into rumen microbial protein with greater efficiency than is selenite or selenate, which may also account for the higher coefficient of absorption of yeast Se supplements under some situations (Galbraith et al., 2016).

Antagonists to Selenium Absorption. Certain nutrients affect the absorption and metabolism of Se and can alter the dietary Se requirement. The apparent digestibility of Se is reduced when cows are fed diets with high $\mathrm{Ca}$ or high $\mathrm{S}$, although the effects are relatively small (Harrison and Conrad, 1984b; Ivancic, 1999). Supplementation of sulfates from anionic salts for the last 3 wk of gestation did not influence Se status of dry cows (Gant et al., 1998).

Ruminants as a rule absorb less of their dietary intake of Se than do monogastrics. Almost $85 \%$ of an orally administered Se dose was absorbed by pigs, but only $35 \%$ was absorbed by ewes (Wright and Bell, 1966). How the rumen interferes with Se absorption is unknown.

Cyanogenic glycosides of soybean meal, beet pulp, millet, and a variety of legumes interfere with Se status 
of ruminants (Gutzwiller, 1993). However, just as with I (discussed in the section on iodine), the cyanogenic glycosides may not interfere with absorption as much as they do the use of the Se by the body. In rats, feeding cyanogenic glycosides did not affect absorption but greatly increased urinary Se excretion (Beilstein and Whanger, 1984).

Diagnosis of Selenium Deficiency. Diagnosis of Se insufficiency can be challenging. In theory, glutathione peroxidase activity in whole blood should be a sensitive indicator, but availability of the test, delays in transport of blood to the laboratory, and laboratory variation in determination of enzyme activity can be frustrating. Whole-blood Se content is preferred for diagnosing a herd's status to see whether they have been properly supplemented in the preceding months. The Se is incorporated into the red blood cells at the time of erythropoiesis, so Se status for approximately the last $100 \mathrm{~d}$ is assessed (Puls, 1994). Plasma and serum Se concentration is also useful, particularly as an indicator of short-term Se status. It is the better sample to collect when a response to supplement addition is being examined because it will change more quickly. Whole-blood Se may not improve significantly for weeks to months following supplementation, as it is dependent on erythropoiesis to produce and release new Se-sufficient red blood cells into the circulation (Waldner et al., 1998).

\section{Zinc}

Zinc Function. Zinc is a component of many metalloenzymes involved in almost every metabolic pathway of the body (Salgueiro et al., 2000). Zinc deficiency alters prostaglandin synthesis, which may affect luteal function (Graham, 1991). Zinc is a component of thymosin, a hormone produced by cells in the thymus gland to regulate lymphocyte maturation, vital to competent cell-mediated immunity.

Zinc Absorption. Intestinal Zn absorption occurs primarily in the small intestine by a transcellular transport process (Figure 10). The transporters required for Zn absorption are also present in the colon (Gopalsamy et al., 2015). A Zn transporting protein (ZIP4) in the apical membrane transports $\mathrm{Zn}$ ions into the cell. The amount of ZIP4 on the apical membrane is upregulated when the animal needs $\mathrm{Zn}$ and downregulated when the animal is Zn replete (Mao et al., 2007). Other ZIP transporters have been identified (ZIP 11 and ZIP 14) that may also play a minor role in bringing Zn across the apical membrane (Cousins, 2010). Zinc can also use DMT1 to cross the apical membrane, though it must compete for binding sites on this transporter with $\mathrm{Fe}$ and Mn. Again, it is the Fe status of the animal that causes up- or downregulation of expression of this protein on the apical surface (see the section on Fe). It is considered a minor pathway for Zn absorption across the apical membrane.

Once inside the cell, the $\mathrm{Zn}$ needs to be chaperoned to sites within the cell for use by that cell, or it can be transported to the basolateral membrane for export into the interstitial space. Zinc transporter proteins $(\mathrm{ZnT})$ regulate the movement within the cell and keep the $\mathrm{Zn}^{2+}$ in a bound state so it cannot act as a pro-oxidant. Zinc transporter proteins 2 and 4 to 7 (especially 7) move $\mathrm{Zn}^{2+}$ to the basolateral membrane (Cousins, 2010). Zinc transporter 1 (ZnT1) is the primary path used to move Zn from the transport vesicles through the basolateral membrane (Figure 10). The activity of $\mathrm{ZnT} 1$ does not seem to be regulated by $\mathrm{Zn}$ status (Cousins et al., 2006). This transporter releases the $\mathrm{Zn}^{2+}$ into the portal circulation to be carried in the blood bound to albumin $(\sim 70 \%)$ and transferrin for release to the liver and other tissues for their use or for storage (Evans and Winter, 1975).

When animals are $\mathrm{Zn}$ replete, the enterocytes begin synthesizing metallothionein, a protein that binds $\mathrm{Zn}$ (as well as $\mathrm{Cu}$ and $\mathrm{Cd}$ ) atoms very tightly. The metallothionein acts as a buffer to hold the excess $\mathrm{Zn}$ and prevent the appearance of free $\mathrm{Zn}^{2+}$ ions within the cytosol. Metallothionein can be thought of as a special ZnT protein. However, it only slowly gives up $\mathrm{Zn}$ to other $\mathrm{ZnT}$ proteins for use in the enterocyte or for export from the enterocyte (Petering and Mahim, 2017). Any Zn bound to metallothionein at the time the enterocyte dies and is sloughed off will be excreted with the feces (Chesters, 1997). Upregulating or downregulating enterocyte metallothionein content can help control the amount of dietary $\mathrm{Zn}$ that is absorbed. Metallothionein and the transporter ZnT1 at the basolateral membrane regulate the amount of $\mathrm{Zn}$ released to the portal circulation for systemic distribution (Cousins, 2010). How Zn status regulates intestinal metallothionein concentration is unknown, but it requires days to weeks to decrease metallothionein concentration in the intestine to adjust to a low-Zn diet (Taylor et al., 1991).

Paracellular absorption of $\mathrm{Zn}$ is also known to occur (rodent studies), but as with all paracellular absorption it requires higher dietary $\mathrm{Zn}$ be present to achieve the higher lumen-soluble Zn concentration needed to drive paracellular absorption (Condomina et al., 2002). How much it contributes to normal bovine nutrition is unknown. However, some humans, Holstein-Friesian cows, and Siberian husky and Malamute dogs with a mutation in the ZIP4 gene have lost the major transcellular pathway for moving $\mathrm{Zn}$ across the apical membrane of enterocytes (Yuzbasiyan-Gurkan and Bartlett, 2006). They can be rescued by placing them on a higher Zn 


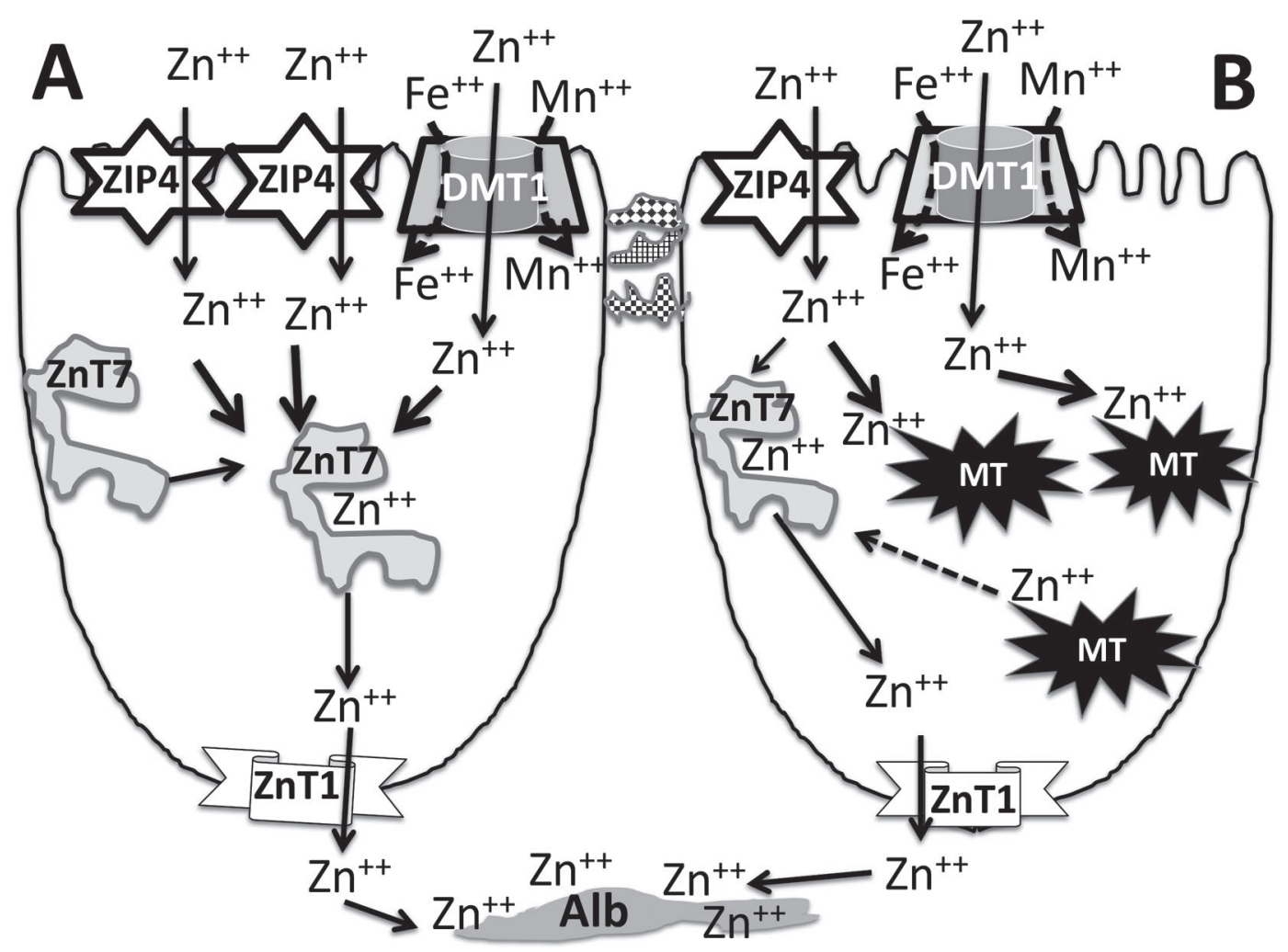

Figure 10. Enterocyte transcellular zinc absorption. (A) When $\mathrm{Zn}$ is needed, $\mathrm{Zn}^{2+}$ is moved across the apical membrane by zinc transporter 4 protein (ZIP4). Zinc can also compete with Fe and Mn for transport across the apical membrane via the divalent metal transport 1 protein (DMT1). A Zn chaperone protein, ZnT7, captures $\mathrm{Zn}^{2+}$ that has crossed the apical membrane and carries it to the basolateral membrane, where it hands the $\mathrm{Zn}^{2+}$ off to $\mathrm{Zn}$ intestinal transporter 1 ( $\mathrm{ZnT1}$ ), which moves the $\mathrm{Zn}^{2+}$ into the interstitial fluid, where it is bound to albumin (Alb). (B) When the body has enough Zn, the amount of ZIP4 in the apical membrane is downregulated. The enterocytes also begin to produce high amounts of metallothionein (MT), which will bind the bulk of any further $\mathrm{Zn}^{2+}$ that crosses the apical membrane. The MT can give up $\mathrm{Zn}^{2+}$ to the ZnT7 chaperone for export, but does this very slowly. This greatly slows the rate of Zn absorption. Zn bound to MT when the cell dies and is sloughed off will be excreted in the feces.

diet (typically 5 -fold more than typical supplementation rate; Chesters, 1983; Maverakis et al., 2007), which may be high enough to support paracellular absorption. These animals also respond well to supplementation with $\mathrm{Zn}-\mathrm{AA}$ complexes. This suggests that the $\mathrm{Zn}-\mathrm{AA}$ complexes are transported by the $\mathrm{Na}^{+} / \mathrm{AA}$ symporters of the enterocytes, though it is also possible that these Zn-AA complexes are being absorbed paracellularly with the bulk flow of water (White et al., 2001; see "Chelated and Organic Mineral Supplements").

Factors Affecting Zinc Absorption. Two major dietary factors that can modify the efficiency of absorption of dietary $\mathrm{Zn}$ are interactions of $\mathrm{Zn}$ with other metal ions and the presence of organic chelating agents in the diet. Zinc and $\mathrm{Cu}$ are antagonistic to one another. In most cases, $\mathrm{Zn}$ interferes with $\mathrm{Cu}$ absorption by upregulating synthesis of metallothionein within enterocytes, which can cause $\mathrm{Cu}$ deficiency if $\mathrm{Cu}$ is marginal. But when dietary $\mathrm{Cu}: \mathrm{Zn}$ ratios are very high (50:1), Cu could interfere with Zn absorption by inducing metallothionein within enterocytes (Van Campen,
1969). This is unlikely in cattle as they would likely die of $\mathrm{Cu}$ intoxication before they became $\mathrm{Zn}$ deficient. Excessive dietary $\mathrm{Fe}$ can interfere with $\mathrm{Zn}$ absorption in humans and other species (Flanagan et al., 1980). The Fe can out-compete the $\mathrm{Zn}$ for binding sites on the apical membrane DMT1. Again, the DMT1 path is only a minor mechanism for Zn absorption.

Cadmium interferes with the absorption of both $\mathrm{Zn}$ and $\mathrm{Cu}$. It also interferes with tissue metabolism of $\mathrm{Zn}$ and $\mathrm{Cu}$ in the liver and kidneys. Lead competitively inhibits $\mathrm{Zn}$ absorption and interferes with the function of Zn enzymes during heme synthesis (Finelli et al., 1975).

High-S diets interfere with Zn absorption (as well as $\mathrm{Cu}$ and Mn; Pogge et al., 2014). Sulfate can be reduced to sulfide in the rumen. One possibility is that the sulfide can interact with $\mathrm{Zn}$ to form insoluble zinc sulfide ( $\mathrm{ZnS}$; Rickard and Luther, 2006). This ZnS may be unavailable for absorption by the small intestine. However, this is not a fully satisfying explanation for the results of Pogge et al. (2014) because $\mathrm{Zn}$ of $\mathrm{ZnS}$ can interact with the $\mathrm{HCl}$ of the abomasum to release soluble and ion- 
ized $\mathrm{Zn}^{2+}$ for absorption in the small intestine. Organic chelators of Zn can increase or decrease efficiency of absorption of Zn. Those that form insoluble complexes with $\mathrm{Zn}$ tend to interfere with $\mathrm{Zn}$ absorption. Phytate commonly binds $\mathrm{Zn}$ in plants and greatly diminishes $\mathrm{Zn}$ absorption in nonruminating calves. However, rumen microbes metabolize most of the dietary phytate, so it is not a factor affecting $\mathrm{Zn}$ absorption in ruminating animals (Pond and Oltjen, 1988). It is likely that other organic and inorganic Zn chelators exist in diets, but few are identified (Demertzis, 1973; see "Chelated and Organic Mineral Supplements").

Zinc Status. Serum Zn concentrations are normally between 0.7 and $1.3 \mu \mathrm{g} / \mathrm{mL}$. Serum Zn concentrations below $0.4 \mu \mathrm{g} / \mathrm{mL}$ are often considered deficient. However, stress or disease can cause a rapid redistribution of $\mathrm{Zn}$ out of extracellular fluids into the liver and other soft tissue cells, causing serum Zn concentrations to fall into the deficient range even when dietary $\mathrm{Zn}$ is adequate (Hambridge et al., 1986; Goff and Stabel, 1990). The unused capacity of plasma to bind Zn may offer another means of assessing Zn status. Calves fed 20 or $70 \mathrm{mg} / \mathrm{kg}$ of $\mathrm{Zn}$ exhibited no difference in plasma $\mathrm{Zn}$ concentrations. However, the percentage of unsaturated plasma Zn binding capacity accurately reflected Zn intakes (Kincaid and Cronrath, 1979).

Normal concentrations of $\mathrm{Zn}$ in the liver are reported to be 75 to $300 \mathrm{mg}$ of $\mathrm{Zn} / \mathrm{kg}$ on a dry weight basis (Puls, 1994). However, Zn-responsive conditions have been seen in cattle with concentrations of $\mathrm{Zn}$ in liver above $100 \mathrm{mg} / \mathrm{kg}$ of $\mathrm{DM}$ because $\mathrm{Zn}$ in liver does not serve as a readily mobilizable source of $\mathrm{Zn}$ during times of dietary Zn insufficiency (Miller, 1979). This makes it difficult to certify Zn adequacy by Zn concentration in liver, but a presumptive diagnosis of $\mathrm{Zn}$ deficiency can be made when $\mathrm{Zn}$ in liver is below $75 \mathrm{mg} / \mathrm{kg}$ of dry weight.

\section{Chromium}

Chromium can exist in several valences. The +3 valence is generally considered an essential nutrient that helps potentiate the action of insulin on tissues (Spears et al., 2012). How this is done remains unclear. Earlier studies suggested that $\mathrm{Cr}$ stabilized the insulin molecule (Govindaraju et al., 1989) or that $\mathrm{Cr}^{3+}$ facilitated the interaction of insulin with its receptor in tissues (Mertz, 1993). Much of the focus was on a circulating molecule that became known as glucose tolerance factor (Toepfer et al., 1976). Unfortunately, current research suggests that the putative glucose tolerance factor - a complex containing $\mathrm{Cr}^{3+}$ originally isolated from brewer's yeast - was an artifact and not biologically relevant. A current hypothesis on the mechanism of action of $\mathrm{Cr}^{3+}$, as put forth by Vincent (2015), is outlined below.

A large portion of dietary $\mathrm{Cr}^{3+}$ that is absorbed across the digestive tract is carried through the blood on transferrin molecules. Insulin, secreted in response to elevated blood glucose, interacts with its receptor on the surface of target cells (e.g., adipose, muscle). Those receptors, upon binding to insulin, become active enzymes known as tyrosine kinases. One of the responses to insulin activation of the tyrosine kinase is to stimulate the movement of transferrin receptors to the cell membrane. The transferrin receptors on the cell surface allow $\mathrm{Cr}^{3+}$ bound to transferrin to be endocytosed across the cell membrane into the cytosol. The $\mathrm{Cr}^{3+}$ is then transferred to a cytosolic protein called apochromodulin (without $\mathrm{Cr}^{3+}$ ). Once it has bound $4 \mathrm{Cr}^{3+}$ ions, the apo-chromodulin becomes holo-chromodulin (with $\mathrm{Cr}^{3+}$ ). This molecule then binds to the insulin receptor, greatly increasing the tyrosine kinase activity of the receptor. The apo-chromodulin will not bind to the insulin receptor. Once insulin secretion ceases, the holo-chromodulin is released from the insulin receptor tyrosine kinase and is secreted from the cell into the blood. From there it passes out into the urine (Vincent, 2015).

Some research suggests that $\mathrm{Cr}^{3+}$ is not necessary for normal glucose tolerance (Di Bona et al., 2011). Rats fed a diet with very low $\mathrm{Cr}^{3+}$ content had the same glucose tolerance response to an intravenous glucose dose that rats on a more traditional diet had. However, when large amounts of $\mathrm{Cr}^{3+}$ were added to the "normal" diets, the glucose tolerance curve indicated faster clearance of glucose from the blood. This has led some to suggest that the action of supplementing diets with $\mathrm{Cr}^{3+}$ could be considered a supranutritional or pharmacologic action rather than correcting a deficiency of $\mathrm{Cr}^{3+}$ (Yoshida, 2012; Vincent, 2014). This argument has been controversial. It assumes that there is no requirement for dietary $\mathrm{Cr}^{3+}$.

When diets are supplemented with relatively high doses of $\mathrm{Cr}^{3+}$ it does improve glucose tolerance. It also affects lipid and cholesterol metabolism, causing reduced fat accumulation in carcasses, and lowers serum lipid concentrations (Sales and Jancík, 2011). How $\mathrm{Cr}^{3+}$ alters metabolism of lipids and cholesterol is largely unknown. If $\mathrm{Cr}^{3+}$ can act as a second messenger through chromodulin to affect the insulin receptor tyrosine kinases, as Vincent (2015) suggests, what other hormones and cytokines that also work through receptor tyrosine kinases may be modulated by $\mathrm{Cr}^{3+}$ and holo-chromodulin?

Intestinal Absorption of Chromium. Chromium exists in the diet as inorganic $\mathrm{Cr}^{3+}$ and $\mathrm{Cr}^{3+}$ complexed to organic compounds. The mechanism for its absorp- 
tion is essentially unknown but is believed to be passive paracellular absorption across the digestive tract (Dowling et al., 1989). Soluble inorganic forms of $\mathrm{Cr}^{3+}$ such as $\mathrm{CrCl}_{3}$ are well absorbed (around $2 \%$ absorption). However, insoluble forms of $\mathrm{Cr}^{3+}$ such as chromic oxide are not. Chromium (III) oxide was often used as a marker in digestibility studies because of this fact. Organic forms of $\mathrm{Cr}^{3+}$ (e.g., Cr nicotinate, $\mathrm{Cr}$ propionate, $\mathrm{Cr}$ methionine, $\mathrm{Cr}$ picolinate, and $\mathrm{Cr}$ from naturally occurring sources such as brewer's yeast) are usually considered more available sources of $\mathrm{Cr}$ than inorganic $\mathrm{Cr}$ used for diet supplementation, but the amount absorbed is generally well below $5 \%$ of that fed (Underwood, 1977; Mertz, 1993). Because organically bound forms of $\mathrm{Cr}^{3+}$ would not be in an ionized form, it seems likely, in this author's opinion, that some of these forms are absorbed by solvent drag in the bulk flow of water through the tight junctions between enterocytes. Only Cr propionate is currently permitted to be used as a source of supplemental $\mathrm{Cr}$ in cattle diets in the United States. It can be fed at levels up to $0.5 \mathrm{mg}$ of $\mathrm{Cr} / \mathrm{kg}$ of diet DM. Fortunately, just a few hundred micrograms to a milligram of $\mathrm{Cr}^{3+}$ needs to be absorbed to fulfill the cow's requirement. Absorbed Cr circulates in the blood as free $\mathrm{Cr}^{3+}$ ions or becomes bound to transferrin and albumin.

The NRC (2001) did not list a requirement for Cr. This was in part due to a lack of data and in part because most dairy cow diets were considered to have levels of $\mathrm{Cr}$ in them that exceeded levels found to reverse experimentally induced $\mathrm{Cr}$ deficiency. More recent studies have been published that demonstrate benefits in milk production and cow health when $\mathrm{Cr}^{3+}$ was added to diets (McNamara and Valdez, 2005; Yasui et al., 2014). These studies supplied 8 to $10 \mathrm{mg}$ of supplemental Cr/ cow per day, with the greatest effects seen when the $\mathrm{Cr}$ was added to the diet during the transition period. The belief that typical diets contained much more than 8 to $10 \mathrm{mg}$ of total $\mathrm{Cr}$ has recently come into question. Evidence suggests that forage and other samples are often contaminated with elemental $\mathrm{Cr}$ during processing at the analytical laboratory. The steel knives used to grind and mince samples contain $\mathrm{Cr}$ that may have contaminated samples to give falsely elevated $\mathrm{Cr}$ content (Spears et al., 2017).

Toxicity of Chromium. Hexavalent $\mathrm{Cr}^{6+}$ (as chromate, $\mathrm{CrO}_{4}^{-2}$ ) is readily absorbed; unfortunately, it is highly toxic as well (NRC, 2005). This is essentially a manmade valence form of $\mathrm{Cr}$ that is not naturally found in nature. There is no evidence that $\mathrm{Cr}^{3+}$ can be converted to $\mathrm{Cr}^{6+}$ in the body. One form of organic $\mathrm{Cr}^{3+}$, $\mathrm{Cr}$ picolinate, has been reported to have some unique toxicity associated with it that has not been observed with other forms of $\mathrm{Cr}^{3+}$ to date. Chromium picolinate added to cell cultures was found to induce damage to the DNA of the cells, though this has not been shown to occur in vivo (Stearns et al., 1995). Feeding high doses of $\mathrm{Cr}$ picolinate to pregnant mice induced skeletal changes in some of the offspring (Bailey et al., 2006). These studies have caused some concern from the US Food and Drug Administration and other bodies that regulate nutritional supplements. In contrast, another study fed 10 to 20 times the amount of $\mathrm{Cr}$ picolinate used in the Bailey et al. (2006) study to nonpregnant rats for extended periods of time and observed no ill effects (Anderson et al., 1997).

\section{CHELATED AND ORGANIC MINERAL SUPPLEMENTS}

During the passage of a mineral from the mouth to its site of absorption, which is typically the small intestine, several fates may beset a mineral that affect its solubility - for better or worse - and therefore its opportunity for absorption. The rumen adds a large obstacle to mineral absorption that monogastrics do not have to contend with. Ruminating calves fed semisynthetic rations containing as little as $8 \mathrm{mg}$ of $\mathrm{Zn} / \mathrm{kg}$ of DM did not have any symptoms of Zn deficiency (Mills et al., 1967). However, Zn deficiency has been reported numerous times in calves of similar age fed natural, forage-based diets supplying as much as $30 \mathrm{mg}$ of $\mathrm{Zn} /$ $\mathrm{kg}$ of diet (Agricultural Research Council, 1980, Table 6.16, p. 261). The percentage of dietary Se (Wright and Bell, 1966) and $\mathrm{Cu}$ (Suttle, 1975) absorbed is much lower in ruminants than in nonruminants, suggesting that rumen modification of the minerals depresses absorbability of these minerals (Spears, 2003).

Other studies indicate that diets may include some naturally occurring Zn chelators that improve Zn absorption. Scott and Ziegler (1963) demonstrated with chicks that adding distillers dried solubles and liver extract to soybean protein-based diets improved the efficiency of absorption of the dietary Zn. The factor involved was not identified. Peptides and AA can form complexes with $\mathrm{Zn}$, and both cysteine and histidine bind $\mathrm{Zn}$ strongly and improve efficiency of absorption of $\mathrm{Zn}$ in chicks (Nielsen et al., 1966; Johnson and Evans, 1984; Hortin et al., 1991). A study in humans observed a 2-fold increase in absorption of $\mathrm{Cu}$ when diet methionine was increased (Kies and Fox, 1989), suggesting that the extra methionine may have increased the opportunity for $\mathrm{Cu}$ leaving the stomach to form a soluble methionine complex instead of an insoluble complex. It may also have allowed the $\mathrm{Cu}$ to utilize an alternative pathway for absorption by the enterocytes. This may have involved use of $\mathrm{Na}^{+} / \mathrm{AA}$ symporters or paracellular solvent drag. 
Many factors might affect the ability of a dietary mineral to reach its site of absorption in a form that permits absorption. This author uses the scientific literature plus much of his own opinion to take a mechanistic view of the fate of a mineral as it passes through the digestive tract to inspire further research. It is hoped the reader will forgive the author for some speculation. The discussion uses $\mathrm{Cu}$ fed in the form of cupric sulfate. $5 \mathrm{H}_{2} \mathrm{O}$ as an example. Cupric sulfate is quite soluble in water (providing up to $95 \mathrm{~g}$ of $\mathrm{Cu} / \mathrm{L}$ at $30^{\circ} \mathrm{C}$ and $\mathrm{pH} 7$ ). Essentially all the dietary cupric sulfate entering the rumen goes into solution, resulting in free $\mathrm{Cu}^{2+}$ ions and sulfate ions in the rumen fluid. Unfortunately, these free ions in solution have an opportunity to interact with other atoms and molecules in the rumen fluid. For example, one well-described possibility is the interaction of $\mathrm{Cu}^{2+}$ ions with thiomolybdate molecules to form an insoluble complex that is incapable of being absorbed. Diet sulfates, which have increased in recent years due to increased use of distillers grains in rations, may be reduced to sulfides in the anaerobic, highly reducing rumen environment. The sulfides may form bonds with the free $\mathrm{Cu}^{2+}$ ions. Copper sulfides (cuprous sulfide, $\mathrm{Cu}_{2} \mathrm{~S}$, and cupric sulfide, $\mathrm{CuS})$ are insoluble in water.

The lower molecular mass $\mathrm{Cu}$ ligands that form at $\mathrm{pH}$ 6 in the rumen are primarily $\mathrm{Cu}\left(\mathrm{NH}_{3}\right)_{4}, \mathrm{Cu}\left(\mathrm{NH}_{3}\right)_{3}$, and $\mathrm{Cu}\left(\mathrm{NH}_{3}\right)_{2}$. Copper can also bind to the various VFA, and these can remain relatively soluble in water (Reid and Attaelmannan, 1998). Copper ions might also interact with soluble carbonate, hydroxide, or phosphate anions found in rumen fluid. However, only very small amounts of insoluble $\mathrm{Cu}_{2} \mathrm{CO}_{3}(\mathrm{OH})_{2}, \mathrm{Cu}(\mathrm{OH})_{2}$, and $\mathrm{Cu}_{3}\left(\mathrm{PO}_{4}\right)_{2}$ have been found in rumen fluid (Reid and Attaelmannan, 1998).

Forages and feedstuffs may bind minerals by electrostatic binding or trapping of minerals within fiber particles, leading to the formation of stable mineral complexes that prevent the mineral from being absorbed (Kabaija and Smith, 1988; Laszlo, 1989). Although cellulose and hemicellulose in the diet can be broken down in the rumen, some does escape digestion, especially if it is intertwined with lignin. Lignin itself has been demonstrated to have much higher affinity binding sites for $\mathrm{Cu}, \mathrm{Zn}$, and Fe than does cellulose (Ghodrat et al., 2015). Clay and soil are common contaminants of forages. Clay contains large amounts of various silicates that are complex anions consisting of a tetrahedron of 4 oxygen atoms around a silica atom. In soil, they often exist bound to aluminum (aluminosilicates). It is known that some silicates can bind Ca (Thilsing et al., 2006) and other positively charged minerals, making them less available for absorption. However, clays and silicates cannot be lumped into a category that suggests they will bind minerals and make them unavailable. For example, adding Ca montmorrilinite to rat diets had no effect on mineral status of the animals (Wiles et al., 2004).

Microbial protein, particularly the proteins associated with the ciliated protozoa, seems to have a special affinity for some minerals, in particular $\mathrm{Cu}$ (Ivan et al., 1986). Copper bound to these proteins is insoluble in rumen fluid and may not be liberated during passage through the more distal portions of the digestive tract.

The $\mathrm{Cu}^{2+}$ could also become complexed with AA, polysaccharides, and gluconates within the rumen fluid. In this case, the complexes may remain soluble in the rumen fluid. These bonds are electrostatic in nature; electrons are not shared as in covalent bonds, and therefore they are readily reversible (Attaelmannan and Reid, 1996). Except for the well-known effect of high diet Mo and S impairing Cu solubility and absorption, the extent of formation of soluble versus permanently insoluble complexes within the rumen caused by these and other factors is largely unknown. However, it is almost a certainty that some of the soluble $\mathrm{Cu}^{2+}$ ions of the dietary cupric sulfate will become complexed with various dietary components in an irreversible fashion during their time in the rumen that renders them unavailable for absorption.

From the forestomachs, the "rumen fluid" enters the abomasum where the $\mathrm{pH}$ is generally 2.3 to 3.2 (Van Winden et al., 2002; Antanaitis et al., 2016). Some insoluble forms of $\mathrm{Cu}$, such as $\mathrm{Cu}$ sulfide, that were formed in the rumen will remain insoluble in the abomasum because it is largely unreactive in hydrochloric acid (Kale et al., 1979). The $\mathrm{HCl}$ within the abomasum will help solubilize, to varying degrees, the carbonate, hydroxide, and oxide forms of most of the macro- and trace minerals. A portion of some of the forms of $\mathrm{Cu}$ that were not soluble in rumen fluid, such as $\mathrm{Cu}$ oxide and $\mathrm{Cu}$ hydroxide, can dissociate upon exposure to the abomasal acids. As a rule, the liberation of $\mathrm{Cu}^{2+}$ ions from dietary $\mathrm{Cu}$ oxides and hydroxides within the abomasum is far from complete as their complete dissolution in abomasal acids would take more time than they generally spend in the abomasum before being flushed out into the small intestine. This is one reason these forms of $\mathrm{Cu}$ are considered inferior supplements for animal diets. This does not mean they are useless; copper oxide wire particles are administered to cattle at pasture to provide long-term supplementation (Yost et al., 2002). The copper oxide wire particles sink into the rumen, and a small portion of the wire particles administered will move into the abomasum each day. Because they are wire particles, their density and size keeps them retained in the abomasum for a longer time than fine ground dietary $\mathrm{Cu}$ oxide particles. The acid 
of the abomasum slowly solubilizes the $\mathrm{Cu}$ oxide wires, and enough $\mathrm{Cu}^{2+}$ is liberated to meet the needs of the cow. It has the added benefit of acting as an antihelminthic agent that is particularly useful against Haemonchus species, known as stomach worms (Kearney et al., 2016). A portion of any $\mathrm{Cu}$ hydroxide that might have formed in the rumen will decompose to liberate $\mathrm{Cu}$ ions upon reaction with abomasal acid (Hidmi and Edwards, 1999). Some of the types of silicates that bind minerals in the rumen may liberate the bound minerals when they are in an acidic environment; others will not.

Most minerals entering the abomasum in a freely ionized state will remain in a freely ionized form while within the abomasal fluids (Bremner, 1970). However, a major exception is $\mathrm{Cu}$. Those $\mathrm{Cu}$ ions that were soluble in the rumen fluids and those $\mathrm{Cu}$ ions that may be liberated from $\mathrm{Cu}$ carbonate, $\mathrm{Cu}$ hydroxide, and $\mathrm{Cu}$ oxide upon reaction with $\mathrm{HCl}$ tend not to remain soluble in the fluids of the abomasum (Bremner, 1970; Ward and Spears, 1993). Dietary protein and microbial protein entering the rumen become denatured by the $\mathrm{HCl}$ of the abomasum. These denatured proteins seem to have a special affinity for $\mathrm{Cu}^{2+}$ ions and form denatured protein- $\mathrm{Cu}$ complexes that are insoluble (Ivan et al., 1986). Iron may follow a similar fate in the rumen (Waghorn et al., 1990).

Upon leaving the abomasum, the low-pH chyme, carrying $\mathrm{Cu}$ bound to denatured proteins, enters the duodenum. Paracellular absorption of $\mathrm{Cl}^{-}$ions back into the blood and the secretion of alkaline pancreatic and intestinal Brunner's gland secretions cause the chyme $\mathrm{pH}$ to increase to about 7 to 7.3 in the small intestine beyond the pancreatic duct (Ewoldt and Anderson, 2005). The higher $\mathrm{pH}$ causes the denatured proteins leaving the abomasum to change conformation, and a portion of the $\mathrm{Cu}$ ions that were bound to those proteins is released within the duodenal contents (Bremner, 1970: Ward and Spears, 1993). At pH 7.3, there are approximately 100,000-fold more $\mathrm{OH}^{-}$in the chyme than at abomasal $\mathrm{pH}$ of 2.3 . Although $\mathrm{Cu}$ ions have the opportunity to combine with the $\mathrm{OH}^{-}$in the solution and precipitate, there is still only about $1 \times 10^{-7} \mathrm{M} \mathrm{OH}^{-}$in the chyme at $\mathrm{pH} 7$. Formation of $\mathrm{Cu}(\mathrm{OH})_{2}$ would accelerate greatly only if the $\mathrm{pH}$ of the chyme exceeded 8 (Hidmi and Edwards, 1999). Lignin, silicates, oxalate, and sulfides that have also exited the abomasum could interact with and chelate the $\mathrm{Cu}^{2+}$ ions, rendering them insoluble and unavailable (Andrieu, 2008). However, all is not lost. A portion of the $\mathrm{Cu}^{2+}$ will remain freely ionized within the chyme of the small intestine. Some of the $\mathrm{Cu}^{2+}$ will have the good fortune to interact with $\mathrm{AA}$, propionate, acetate, and other organic compounds. The nature of these bonds is noncovalent bonding, which means that they are readily reversible and typically are examples of "electrostatic bonding." Using metal complexes formed with AA as an example, 1 or more electronegative nitrogen or oxygen atoms on the AA or even small peptides interact with a positively charged metal atom through an electrostatic interaction (Yamashita et al., 1990). These $\mathrm{Cu}$ complexes remain soluble in the intestinal fluids (Evans and Johnson, 1980). These complexes can then diffuse through the glycocalyx to reach the apical membrane of an enterocyte of the small intestine. If the forces holding the $\mathrm{Cu}$-chelator complexes together are weak, such as with the complexes formed with the VFA or the electrostatic bonds formed with various AA, an equilibrium can be established, whereby some portion of the complex will dissociate liberating ionized $\mathrm{Cu}^{2+}$ in the unstirred water layer over the apical membrane. This may be aided by the actions of the $\mathrm{Na}^{+} / \mathrm{H}^{+}$exchanger in the apical membrane of enterocytes that creates a slightly lower $\mathrm{pH}$ in the unstirred water layer overlying the enterocytes (Lucas et al., 1975). The $\mathrm{Cu}^{2+}$ ions are then able to reach specific $\mathrm{Cu}$ transporters in the apical membrane and enter the intestinal cell. If the $\mathrm{Cu}$-chelator bonds are strong and do not permit release of the $\mathrm{Cu}^{2+}$ ion at the apical membrane of the absorptive cell, the ion-specific transporters, such as the CTR-1 and the DMT1, cannot be used to absorb the $\mathrm{Cu}$.

The interferences that will be problematic differ from mineral to mineral. As a rule, the monovalent cations $(\mathrm{Na}, \mathrm{K})$ and monovalent anions $(\mathrm{Cl}$, iodide) have no problems maintaining solubility throughout the GI tract. However, divalent and trivalent cations and anions are subject to many reactions that could render them insoluble and unavailable for absorption. Insoluble complexes form in the rumen more easily than they do in the duodenum, perhaps because they have a longer residence time in that environment.

Prechelated or complexed microminerals have been developed for use in animal nutrition. Minerals, primarily the di- and trivalent metals, have been chelated or complexed to AA and peptides, propionate, acetate, polysaccharides, and picolinate (these are sometimes referred to as organic mineral complexes). There are also inorganic forms prepared for nutritional use, such as the basic hydroxy trace minerals. When compared with the sulfated forms of the minerals, these mineral forms may be absorbed with an efficiency that is 1.1 to 2 times better than the sulfated forms (Spears and Kegley, 2002; Wrightt and Spears, 2004; Pal et al., 2010). There are also studies that found no absorption advantage to using chelated minerals over sulfate forms of the minerals (Kegley and Spears, 1994; Rojas et al., 1996). Alone, this small advantage in absorption would not warrant their inclusion because they are consider- 
ably more than 2-fold the expense of sulfate forms of the same minerals. However, when added to diets that are known to have substances such as Mo and $\mathrm{S}$ that will ordinarily interfere with mineral absorption, absorption of these chelated mineral sources can be much less affected and absorption of adequate amounts of the mineral is more ensured (Hansen et al., 2008). They have gained popularity in animal nutrition because there are likely to be substances within the rumen (and to a lesser extent the small intestine) that form insoluble complexes with some of the free ions in many diets. Research has yet to definitively determine the characteristics of a diet that is likely to pose an increased risk of forming bad complexes that would prevent mineral absorption. Because nutritionists have little ability to predict which diets are most likely to have detrimental levels of bad chelators in them, it is increasingly common to meet some of the mineral requirement of the animal by adding these organic or chelated minerals to the diet as insurance against mineral deficiency.

If these forms of mineral supplements are to be more useful than the traditional $\mathrm{SO}_{4}$ forms of the same minerals, they would have, in this author's opinion, at least some of the following attributes.

1. They need to have the ability to remain complexed or chelated as they enter and pass out of the rumen. Being complexed and in a neutral, uncharged (nonionized) state while they are in the rumen (whether or not they are soluble in rumen fluid) prevents them from forming an irreversible and insoluble complex with some other substance in the rumen fluid. This attribute is of utmost importance to the ruminant.

2. The mineral complex dissociates in the acids of the abomasum to release freely soluble mineral ions into the duodenum. For example, the basic hydroxy trace minerals such as zinc hydroxychloride are insoluble in rumen fluid, restricting their ability to react with antagonists to absorption, but they react with the acid of the abomasum to liberate $\mathrm{Zn}$ ions for absorption in the small intestine.

3. The complex that protected the mineral while in the rumen is digested within the small intestine to liberate ionized mineral. In monogastric species, chelating a mineral within a polysaccharide complex allows it to reach the intestine, where the polysaccharide is digested, releasing free mineral ions in the small intestine for absorption (Carlson et al., 2004). The effectiveness of the strategy of using polysaccharide mineral complexes in ruminant diets is less clear (Salyer et al., 2004). Little research has been done on how these compounds react in the digestive tract of the ruminant. Polysaccharide-mineral complexes can increase soluble mineral content in rumen fluids (Kennedy et al., 1993), but do they pass through the rumen intact to avoid interactions with antagonists in the rumen?

4. The complex remains intact as the mineral-chelate passes through the acid environment of the abomasum and moves into the small intestine. Being complexed and nonionized in the duodenal chyme reduces the possibility of forming an irreversible and insoluble complex with some other substance in the small intestine lumen fluids. However, it may be such a stable bond that it prevents the mineral from existing in the ionized, free state. For these complexes, an alternative to the use of the ion-specific transporters for absorption would have to be used. The complex must also still be soluble enough at this point to diffuse into the unstirred water layer over the absorptive surface of the apical membranes.

5. The forces holding the mineral to the organic compound must allow the mineral to become separated from the complex, liberating ionized mineral in the unstirred water layer and glycocalyx. This allows the mineral ions to interact with the ion-specific mineral transporter proteins on the apical membrane for entry into the cell. The ion-specific transporters do not seem capable of moving chelated, uncharged minerals across the apical membrane (Sauer et al., 2017).

6. An alternative possibility to release of free ions in the small intestine and use of ion-specific transporters in the apical membrane of enterocytes is that the mineral crosses the apical membrane or tight junctions while still complexed. This is the case for selenomethionine and selenocysteine, which serve as Se supplements (Große Ruse et al., 2015), and is suggested to be the case for AA-mineral complexes that are on the market, assuming they reach the small intestine intact. There is evidence, primarily from in vitro studies, that minerals complexed to single AA use the specific $\mathrm{Na}^{+} / \mathrm{AA}$ symporters to move across the apical membrane (Gao et al., 2014; Sauer et al., 2017).

Many of the organic minerals and complexed minerals on the market fulfill, to some degree, the ability to remain intact in the rumen fluids. It is clear that not all mineral complexes behave similarly in in vitro tests of solubility. Experiments have been done to assess the stability of various organic minerals available commercially for use in animal nutrition (Cao et al., 2000; Guo 
et al., 2001). The organic sources included a $\mathrm{Cu}$ lysine complex, a $\mathrm{Cu}$ AA chelate, 3 forms of $\mathrm{Cu}$ proteinate, 2 forms of $\mathrm{Zn}$ methionine complex, a Zn polysaccharide complex, a Zn lysine complex, a Zn AA chelate, and 3 different $\mathrm{Zn}$ proteinates. These studies found that a portion of many of the chelates tested dissociated in distilled deionized water, which would reduce their effectiveness in the rumen. However, as noted by the authors, the use of ion-specific electrodes in a beaker of mineral does not simulate the complex nature of rumen fluid very well, and it is difficult to determine actual rates of dissociation of these molecules in the rumen environment.

It is beyond the scope of this review to compare and contrast all the types of chelated minerals that are commercially available. However, it is hoped that a better conceptual understanding of how they might promote more reliable absorption of minerals will allow the nutritionist to better meet the mineral requirements of the cow.

\section{CONCLUSIONS}

Two pathways exist for the absorption of most minerals. When fed in high concentrations, many minerals can utilize paracellular absorption, where the mineral diffuses across the tight junction or moves with the bulk flow of water between intestinal epithelial cells to enter the blood. At lower dietary concentrations, the body relies on transcellular absorption to meet its mineral needs. Transcellular absorption requires special transporters to move the mineral from the chyme across the apical membrane of the enterocyte, a method to move the mineral across the cell, and another transporter that will move the mineral across the basolateral membrane of the enterocyte. These mechanisms are described for each mineral, with some discussion of the factors that can interfere with these processes. A primary obstacle to mineral absorption is the ability of the diet to present enough mineral in an ionized form to the apical membrane of enterocytes for transcellular absorption. As a general rule, transcellular absorption is critical to allowing the animal to meet its mineral needs when diet mineral concentrations are marginal. Minerals can be rendered insoluble and nonionizable in the rumen and to a lesser extent in the intestine, rendering them useless to the animal. Some of the factors that inhibit or promote solubility of minerals were identified. Minerals can be categorized as positively charged cations and negatively charged anions. The relative amount of cations versus anions absorbed helps determine the acid-base status of the animal. Several minerals play prominent roles as cofactors of antioxidants and help mitigate oxidative stress. However, when fed in excess, these same minerals can actually contribute to formation of free radicals that promote oxidative stress.

\section{ACKNOWLEDGMENTS}

As a disclaimer, I was research director at the West Central Farmer's Cooperative and developed the commercial anion product Soychlor, which is used to reduce hypocalcemia in dairy cows. I continue to consult with the cooperative, now known as Landus. I owe a large debt of gratitude to the reviewers of this article, who found many instances where I was out of date in my thinking, and with their helpful comments and critique this review is tremendously improved. I also thank David Beede for urging me to cover this field in a review article. Finally, a special thank you to Sandy Stokes Goff, who edited and helped prepare the manuscript for me as I still type with only two fingers.

\section{REFERENCES}

Abdoun, K., F. Stumpff, K. Wolf, and H. Martens. 2005. Modulation of electroneutral $\mathrm{Na}$ transport in sheep rumen epithelium by luminal ammonia. Am. J. Physiol. Gastrointest. Liver Physiol. 289:G508-G520.

Agricultural Research Council. 1980. The Nutrient Requirements of Ruminant Livestock. Commonwealth Agricultural Bureaux, Slough, UK.

Ammerman, C. B. 1970. Recent developments in cobalt and copper in ruminant nutrition: A review. J. Dairy Sci. 53:1097-1107.

Ammerman, C. B., C. F. Chicco, J. E. Moore, P. A. Van Walleghem, and L. R. Arrington. 1971. Effect of dietary magnesium on voluntary feed intake and rumen fermentations. J. Dairy Sci. 54:12881293.

Anderson, R. A., N. A. Bryden, and M. M. Polansky. 1997. Lack of toxicity of chromium chloride and chromium picolinate in rats. J. Am. Coll. Nutr. 16:273-279.

Andrieu, S. 2008. Is there a role for organic trace element supplements in transition cow health? Vet. J. 176:77-83.

Antanaitis, R., V. Žilaitis, V. Juozaitiene, and R. Stoškus. 2016. Usefulness of acidity and temperature of the rumen and abomasum in diagnosing SARA in dairy cows after calving. Pol. J. Vet. Sci. 19:553-558

Argenzio, R. A., N. Miller, and W. von Engelhardt. 1975. Effect of volatile fatty acids on water and ion absorption from the goat colon. Am. J. Physiol. 229:997-1002.

Arrhenius, S. 1912. Electrolytic dissociation. J. Am. Chem. Soc. 34:353-364.

Aschenbach, J. R., G. B. Penner, F. Stumpff, and G. Gäbel. 2011. Ruminant Nutrition Symposium: Role of fermentation acid absorption in the regulation of ruminal pH. J. Anim. Sci. 89:1092-1107. https://doi.org/10.2527/jas.2010-3301.

Attaelmannan, M. A., and R. S. Reid. 1996. The speciation of lysinecomplexed copper as a bovine nutritional supplement. J. Inorg. Biochem. 64:215-224.

Bai, S. P., L. Lu, X. G. Luo, and B. Liu. 2008. Kinetics of manganese absorption in ligated small intestinal segments of broilers. Poult. Sci. 87:2596-2604.

Bailey, M. M., J. G. Boohaker, R. D. Sawyer, J. E. Behling, J. F. Rasco, J. J. Jernigan, R. D. Hood, and J. B. Vincent. 2006. Exposure of pregnant mice to chromium picolinate results in skeletal defects in their offspring. Birth Defects Res. B Dev. Reprod. Toxicol. $77: 244-249$.

Barber, D. M., X. L. Wright, and W. MacLennan. 1983. Hypomagnesaemia in periparturient dairy cows. Vet. Rec. 112:35-36. 
Barrett, K. E., and S. J. Keely. 2000. Chloride secretion by the intestinal epithelium: Molecular basis and regulatory aspects. Annu. Rev. Physiol. 62:535-572.

Beard, J. L., and H. D. Dawson. 1997. Iron. Pages 278-284 in Handbook of Nutritionally Essential Mineral Elements. B. L. O'Dell and R. A. Sunde, ed. Marcel Dekker, New York, NY.

Beaudet, V., R. Gervais, B. Graulet, P. Nozière, M. Doreau, A. Fanchone, D. D. Castagnino, and C. L. Girard. 2016. Effects of dietary nitrogen levels and carbohydrate sources on apparent ruminal synthesis of some B vitamins in dairy cows. J. Dairy Sci. 99:2730-2739.

Bedwal, R. S., N. Nair, M. P. Sharma, and R. S. Mathur. 1993. Selenium-Its biological perspectives. Med. Hypotheses 41:150-159.

Beede, D. K., and R. J. Collier. 1986. Potential nutritional strategies for intensively managed cattle during thermal stress. J. Anim. Sci. 62:543-554.

Beede, D. K., and J. K. Shearer. 1991. Nutritional management of dairy cattle during hot weather. Agric. Prac. 12:5-12.

Beilstein, M. A., and P. D. Whanger. 1984. Effects of cyanide on selenium metabolism in rats. J. Nutr. 114:929-937.

Berg, J. M., J. L. Tymoczko, and L. Stryer. 2002. Chemical bonds in biochemistry. Pages 11-14 in Biochemistry. 5th ed. Freeman, New York, NY

Berg, J. N., D. Padgitt, and B. McCarthy. 1988. Iodine concentrations in milk of dairy cattle fed various amounts of iodine as ethylenediamine dihytroiodide. J. Dairy Sci. 71:3283-3291.

Berry, M. J., L. Banu, and P. R. Larsen. 1991. Type I iodothyronine deiodinase is a selenocysteine-containing enzyme. Nature 349:438 440.

Bertinchamps, A. J., S. T. Miller, and G. C. Cotzias. 1966. Interdependence of routes excreting manganese. Am. J. Physiol. 211:217-224.

Bidewell, C. A., J. R. Drew, J. H. Payne, A. R. Sayers, R. J. Higgins, and C. T. Livesey. 2012. Case study of copper poisoning in a British dairy herd. Vet. Rec. 170:464.

Bird, P. R., and R. J. Moir. 1971. Sulphur metabolism and excretion studies in ruminants. I. The absorption of sulphate in sheep after intraruminal or intraduodenal infusions of sodium sulphate. Aust. J. Biol. Sci. 24:1319-1328.

Black, J. R., C. B. Ammerman, and P. R. Henry. 1985. Effects of high dietary manganese as manganese oxide or manganese carbonate in sheep. J. Anim. Sci. 60:861-866.

Bouchard, R., and H. R. Conrad. 1973. Sulfur requirement of lactating dairy cows. I. Sulfur balance and dietary supplementation. J. Dairy Sci. 56:1276-1282.

Bradley, C. H. 1993. Copper poisoning in a dairy herd fed a mineral supplement. Can. Vet. J. 34:287-292.

Brandt, M., and V. L. Schramm. 1986. Mammalian manganese metabolism and manganese uptake and distribution in rat hepatocytes. Pages 3-16 in Manganese in Metabolism and Enzyme Function. V. L. Scramm and F. C. Wedler, ed. Academic Press, Orlando, FL.

Bremner, I. 1970. Zinc, copper and manganese in the alimentary tract of sheep. Br. J. Nutr. 24:769-783.

Bremner, I., W. R. Humphries, M. Phillippo, M. J. Walker, and P. C. Morrice. 1987. Iron-induced copper deficiency in calves: Dose-response relationships and interactions with molybdenum and sulfur. Anim. Prod. 45:403-414.

Breves, G., and B. Schroder. 1991. Comparative aspects of gastrointestinal phosphorus metabolism. Nutr. Res. Rev. 4:125-140.

Bronner, F. 1987. Intestinal calcium absorption: Mechanisms and applications. J. Nutr. 117:1347-1352.

Bugaut, M. 1987. Occurrence, absorption and metabolism of short chain fatty acids in the digestive tract of mammals. Comp. Biochem. Physiol. B. 86:439-472.

Burk, R. F., and K. E. Hill. 2015. Regulation of selenium metabolism and transport. Annu. Rev. Nutr. 35:109-134.

Burk, R. F., K. E. Hill, A. K. Motley, D. W. Byrne, and B. K. Norsworthy. 2015. Selenium deficiency occurs in some patients with moderate-to-severe cirrhosis and can be corrected by administration of selenate but not selenomethionine: A randomized controlled trial. Am. J. Clin. Nutr. 102:1126-1133.
Burns, T. W., J. R. Mathias, G. M. Carlson, J. L. Martin, and R. P. Shields. 1978. Effect of toxigenic Escherichia coli on myoelectric activity of small intestine. Am. J. Physiol. 235:E311-E315.

Cao, J., P. R. Henry, R. Guo, R. A. Holwerda, J. P. Toth, R. C. Littell, R. D. Miles, and C. B. Ammerman. 2000. Chemical characteristics and relative bioavailability of supplemental organic zinc sources for poultry and ruminants. J. Anim. Sci. 78:2039-2054.

Care, A. D., J. P. Bartlet, and H. M. Abdel-Hafeez. 1980. Calcium and phosphate homeostasis in ruminants and its relationship to the aetiology and prevention of parturient paresis. Pages 429-446 in Digestive Physiology and Metabolism in Ruminants. Y. Ruckebusch and P. Thivend, ed. MTP Press, Lancaster, UK.

Care, A. D.. L. J. Beardsworth, P. M. Beardsworth, and G. Breves. 1989. The absorption of calcium and phosphate from the rumen. Acta Vet. Scand. Suppl. 86:152-158.

Carlson, M. S., C. A. Boren, C. Wu, C. E. Huntington, D. W. Bollinger, and T. L. Veum. 2004. Evaluation of various inclusion rates of organic zinc either as polysaccharide or proteinate complex on the growth performance, plasma, and excretion of nursery pigs. J. Anim. Sci. 82:1359-1366.

Castillo, J. P., H. Rui, D. Basilio, A. Das, B. Roux, R. Latorre, F. Bezanilla, and M. Holmgren. 2015. Mechanism of potassium ion uptake by the $\mathrm{Na}(+) / \mathrm{K}(+)$-ATPase. Nat. Commun. 6:7622.

Chesters, J. 1997. Zinc. Pages 185-231 in Handbook of Nutritionally Essential Mineral Elements. B. L. O'Dell and R. Sunde, ed. Marcel Dekker, New York, NY.

Chesters, J. K. 1983. Zinc metabolism in animals: Pathology, immunology and genetics. J. Inherit. Metab. Dis. 6(Suppl. 1):34-38.

Christakos, S., P. Dhawin, A. Porta, L. J. Mady, and T. Seth. 2011 Vitamin D and intestinal calcium absorption. Mol. Cell. Endocrinol. 347:25-29.

Chua, A. C., and E. H. Morgan. 1997. Manganese metabolism is impaired in the Belgrade laboratory rat. J. Comp. Physiol. B 167:361-369.

Coghlin, C. L. 1944. Hydrogen sulfide poisoning in cattle. Can. J. Comp. Med. 8:111-113.

Collins, J. F., J. R. Prohaska, and M. D. Knutson. 2010. Metabolic crossroads of iron and copper. Nutr. Rev. 68:133-147.

Condomina, J., T. Zornoza-Sabina, L. Granero, and A. Polache. 2002. Kinetics of zinc transport in vitro in rat small intestine and colon: Interaction with copper. Eur. J. Pharm. Sci. 16:289-295.

Constable, P. D. 2014. Acid-base assessment: When and how to apply the Henderson-Hasselbalch equation and strong ion difference theory. Vet. Clin. North Am. Food Anim. Pract. 30:295-316.

Cousins, R. J. 2010. Gastrointestinal factors influencing zinc absorption and homeostasis. Int. J. Vitam. Nutr. Res. 80:243-248.

Cousins, R. J., J. P. Liuzzi, and L. A. Lichten. 2006. Mammalian zinc transport, trafficking, and signals. J. Biol. Chem. 281:24085-24089.

Curran, P. F., and J. R. Macintosh. 1962. A model system for biological water transport. Nature 193:347-348.

Demertzis, P. N. 1973. Oral zinc therapy in the control of infectious pododermatitis in young bulls. Vet. Rec. 93:219-222.

Di Bona, K. R., S. Love, N. R. Rhodes, D. McAdory, S. H. Sinha, N. Kern, J. Kent, J. Strickland, A. Wilson, J. Beaird, J. Ramage, J. F. Rasco, and J. B. Vincent. 2011. Chromium is not an essential element for mammals: Effects of a "low-chromium" diet. J. Biol Inorg. Chem. 16:381-390.

Diaz-Ochoa, V. E., S. Jellbauer, S. Klaus, and M. Raffatellu. 2014 Transition metal ions at the crossroads of mucosal immunity and microbial pathogenesis. Front. Cell. Infect. Microbiol. 4:2-10.

Dizdaroglu, M., and P. Jaruga. 2012. Mechanisms of free radical-induced damage to DNA. Free Radic. Res. 46:382-419.

Dobson, A. 1959. Active transport through the epithelium of the reticulo-rumen sac. J. Physiol. 146:235-251.

Dowling, H. J., E. G. Offenbacher, and F. X. Pi-Sunyer. 1989. Absorption of inorganic, trivalent chromium from the vascularly perfused rat small intestine. J. Nutr. 119:1138-1145.

Du, Z., R. W. Hemken, and R. J. Harmon. 1996. Copper metabolism of Holstein and Jersey cows and heifers fed diets high in cupric sulfate or copper proteinate. J. Dairy Sci. 79:1873-1880. 
Edrise, B. M., R. H. Smith, and D. Hewitt. 1986. Exchanges of water and certain water-soluble minerals during passage of digesta through the stomach compartments of young ruminating bovines. Br. J. Nutr. 55:157-168.

Elfers, K., I. Marr, M. R. Wilkens, G. Breves, M. Langeheine, R. Brehm, and A. S. Muscher-Banse. 2016. Expression of tight junction proteins and cadherin 17 in the small intestine of young goats offered a reduced N and/or Ca diet. PLoS One 11:e0154311. https://doi.org/10.1371/journal.pone.0154311.

Ellenbogen, L., and B. A. Cooper. 1991. Vitamin B12. Pages 491-536 in Handbook of Vitamins. L. J. Machlin, ed. Marcel Dekker, New York, NY.

Ender, F., I. W. Dishington, and A. Helgebostad. 1971. Calcium balance studies in dairy cows under experimental induction and prevention of hypocalcaemic paresis puerperalis. The solution of the aetiology and the prevention of milk fever by dietary means. Z. Tierphysiol. Tierernahr. Futtermittelkd. 28:233-256.

Erben, R. G. 2016. Update on FGF23 and Klotho signaling. Mol. Cell. Endocrinol. 432:56-65.

Ermans, A. M., and P. Bourdoux. 1989. Antithyroid sulfurated compounds. Pages 15-31 in Environmental Goitrogenesis. E. Gaitan, ed. CRC Press, Boca Raton, FL.

Evans, G. W., and T. Winter. 1975. Zinc transport by transferrin in rat portal blood plasma. Biochem. Biophys. Res. Commun. 66:1218-1224.

Evans, G. W., and E. C. Johnson. 1980. Growth stimulating effect of picolinic acid added to rat diets. Proc. Soc. Exp. Biol. Med. 165:457-461.

Ewoldt, J. M., and D. E. Anderson. 2005. Determination of the effect of single abomasal or jejunal inoculation of Clostridium perfringens Type A in dairy cows. Can. Vet. J. 46:821-824.

Ezquer, F., M. T. Núñez, A. Rojas, J. Asenjo, and Y. Israel. 2006. Hereditary hemochromatosis: An opportunity for gene therapy. Biol. Res. 39:113-124.

Faulkner, M. J., N. R. St-Pierre, and W. P. Weiss. 2017. Effect of source of trace minerals in either forage- or by-product-based diets fed to dairy cows: 2. Apparent absorption and retention of minerals. J. Dairy Sci. 100:5368-5377.

Feng, X., J. P. Jarrett, K. F. Knowlton, R. E. James, and M. D. Hanigan. 2016. Short communication: Comparison of predicted dietary phosphorus balance using bioavailabilities from the NRC (2001) and Virginia Tech model. J. Dairy Sci. 99:1237-1241.

Field, M. 2003. Intestinal ion transport and the pathophysiology of diarrhea. J. Clin. Invest. 111:931-943.

Finelli, V. N., D. S. Klauder, M. A. Karaffa, and H. G. Petering. 1975. Interaction of zinc and lead on delta-aminolevulinate deydratase. Biochem. Biophys. Res. Commun. 65:303-312.

Flanagan, P. R., J. Haist, and L. S. Valberg. 1980. Comparative effects of iron deficiency induced by bleeding and a low-iron diet on the intestinal absorptive interactions of iron, cobalt, manganese, zinc, lead, and cadmium. J. Nutr. 110:1754-1763.

Fleet, J. C., and R. D. Schoch. 2010. Molecular mechanisms for regulation of intestinal calcium absorption by vitamin D and other factors. Crit. Rev. Clin. Lab. Sci. 47:181-195.

Fordtran, J. S., F. C. Rector Jr., and N. W. Carter. 1968. The mechanisms of sodium absorption in the human small intestine. J. Clin. Invest. 47:884-900.

French, E. A., M. Mukai, M. Zurakowski, B. Rauch, G. Gioia, J. R. Hillebrandt, M. Henderson, Y. H. Schukken, and T. C. Hemling. 2016. Iodide residues in milk vary between iodine-based teat disinfectants. J. Food Sci. 81:T1864-T1870.

Fujita, H., K. Sugimoto, S. Inatomi, T. Maeda, M. Osanai, Y. Uchiyama, Y. Yamamoto, T. Wada, T. Kojima, H. Yokozaki, T. Yamashita, S. Kato, N. Sawada, and H. Chiba. 2008. Tight junction proteins claudin-2 and -12 are critical for vitamin D-dependent Ca2+ absorption between enterocytes. Mol. Biol. Cell 19:19121921.

Furuse, M., M. Hata, K. Furuse, Y. Yoshida, A. Haratake, Y. Sugitani, T. Noda, A. Kubo, and S. Tsukita. 2002. Claudin-based tight junctions are crucial for the mammalian epidermal barrier: A lesson from claudin-1-deficient mice. J. Cell Biol. 156:1099-1111.
Galbraith, M. L., W. R. Vorachek, C. T. Estill, P. D. Whanger, G. Bobe, T. Z. Davis, and J. A. Hall. 2016. Rumen microorganisms decrease bioavailability of inorganic selenium supplements. Biol. Trace Elem. Res. 171:338-343.

Gammelgaard, B., L. H. Rasmussen, C. Gabel-Jensen, and B. Steffansen. 2012. Estimating intestinal absorption of inorganic and organic selenium compounds by in vitro flux and biotransformation studies in Caco-2 cells and ICP-MS detection. Biol. Trace Elem. Res. 145:248-256.

Gant, R. G., W. Sanchez, and R. L. Kincaid. 1998. Effect of anionic salts on selenium metabolism in nonlactating, pregnant dairy cows. J. Dairy Sci. 81:1637-1642.

Gao, S., T. Yin, B. Xu, Y. Ma, and M. Hu. 2014. Amino acid facilitates absorption of copper in the Caco-2 cell culture model. Life Sci. 109:50-56.

Garberg, P., A. Ståhl, M. Warholm, and J. Högberg. 1988. Studies of the role of DNA fragmentation in selenium toxicity. Biochem. Pharmacol. 37:3401-3406.

Georgi, M. I., J. Rosendahl, F. Ernst, D. Günzel, J. R. Aschenbach, H. Martens, and F. Stumpff. 2014. Epithelia of the ovine and bovine forestomach express basolateral maxi-anion channels permeable to the anions of short-chain fatty acids. Pflugers Arch. 466:1689 1712. https://doi.org/10.1007/s00424-013-1386-x.

Ghodrat, A., A. Yaghobfar, Y. Ebrahimnezhad, H. A. Shahryar, and A. Ghorbani. 2015. In vitro binding capacity of organic (wheat bran and rice bran) and inorganic (perlite) sources for $\mathrm{Mn}, \mathrm{Zn}, \mathrm{Cu}$, and Fe. J. Appl. Anim. Res. 45:80-84.

Gibbons, R. A., S. N. Dixon, K. Hallis, A. M. Russell, B. F. Sansom, and H. W. Symonds. 1976. Manganese metabolism in cows and goats. Biochim. Biophys. Acta 444:1-10.

Girard, C. L., D. E. Santschi, S. P. Stabler, and R. H. Allen. 2009. Apparent ruminal synthesis and intestinal disappearance of vitamin B12 and its analogs in dairy cows. J. Dairy Sci. 92:4524-4529.

Gleeson, D. 1992. Acid-base transport systems in gastrointestinal epithelia. Gut 33:1134-1145.

Goff, J. P. 2014. Calcium and magnesium disorders. Vet. Clin. North Am. Food Anim. Pract. 30:359-381.

Goff, J. P. 2015. Digestion and absorption of nutrients. Pages 502521 in Dukes Physiology of Domestic Animals. W. O. Reece, H H. Erickson, J. P. Goff, and E. E. Uemura, ed. Wiley-Blackwell, Hoboken, NJ.

Goff, J. P., and R. L. Horst. 1993. Oral administration of calcium salts for treatment of hypocalcemia in cattle. J. Dairy Sci. 76:101-108.

Goff, J. P., R. Ruiz, and R. L. Horst. 2004. Relative acidifying activity of anionic salts commonly used to prevent milk fever. J. Dairy Sci. $87: 1245-1255$.

Goff, J. P., and J. R. Stabel. 1990. Decreased plasma retinol, alpha-tocopherol, and zinc concentration during the periparturient period: Effect of milk fever. J. Dairy Sci. 73:3195-3199.

Gonciulea, A. R., and S. M. Jan De Beur. 2017. Fibroblast growth factor 23-mediated bone disease. Endocrinol. Metab. Clin. North Am. 46:19-39.

Goodman, H., and L. Middlesworth. 1980. The thyroid gland. Pages 1495-1518 in Medical Physiology. Vol. 2. V. Mountcastle, ed. Mosby, St. Louis, MO.

Gopalsamy, G. L., D. H. Alpers, H. J. Binder, C. D. Tran, B. S. Ramakrishna, I. Brown, M. Manary, E. Mortimer, and G. P. Young. 2015. The relevance of the colon to zinc nutrition. Nutrients 7:572583.

Govindaraju, K., T. Ramasami, and D. Ramaswamy. 1989. Chromium (III)-insulin derivatives and their implication in glucose metabolism. J. Inorg. Biochem. 35:137-147.

Gozzelino, R., and P. Arosio. 2016. Iron homeostasis in health and disease. Int. J. Mol. Sci. 17:E130.

Grace, N. D., M. J. Ulyatt, and J. C. MacRae. 1974. Quantitative digestion of fresh herbage by sheep. III. The movement of $\mathrm{Mg}, \mathrm{Ca}$, $\mathrm{P}, \mathrm{K}$ and $\mathrm{Na}$ in the digestive tract. J. Agric. Sci. 82:321-330.

Graham, C., I. Gatherar, I. Haslam, M. Glanville, and N. L. Simmons. 2007. Expression and localization of monocarboxylate transporters and sodium/proton exchangers in bovine rumen epithelium. Am. J. Physiol. Regul. Integr. Comp. Physiol. 292:R997-R1007. 
Graham, C., and N. L. Simmons. 2005. Functional organization of the bovine rumen epithelium. Am. J. Physiol. Regul. Integr. Comp. Physiol. 288:R173-R181.

Graham, T. W. 1991. Trace element deficiencies in cattle. Vet. Clin. North Am. Food Anim. Pract. 7:153-215.

Greene, L. W., J. P. Fontenot, and K. E. Webb Jr. 1983. Site of magnesium and other macromineral absorption in steers fed high levels of potassium. J. Anim. Sci. 57:503-510.

Greene, L. W., B. J. May, G. T. Schelling, and F. M. Byers. 1988. Site and extent of apparent magnesium and calcium absorption in steers fed monensin. J. Anim. Sci. 66:2987-2991.

Große Ruse, M., L. R. Søndergaard, S. Ditlevsen, M. Damgaard, S. Fuglsang, J. T. Ottesen, and J. L. Madsen. 2015. Absorption and initial metabolism of 75Se-l-selenomethionine: A kinetic model based on dynamic scintigraphic data. Br. J. Nutr. 114:1718-1723.

Gummow, B. 1996. Experimentally induced chronic copper toxicity in cattle. Onderstepoort J. Vet. Res. 63:277-288.

Günzel, D., and M. Fromm. 2012. Claudins and other tight junction proteins. Compr. Physiol. 2:1819-1852.

Guo, R., P. R. Henry, R. A. Holwerda, J. Cao, R. C. Littell, R. D Miles, and C. B. Ammerman. 2001. Chemical characteristics and relative bioavailability of supplemental organic copper sources for poultry. J. Anim. Sci. 79:1132-1141.

Gurney, M. A., D. Laubitz, F. K. Ghishan, and P. R. Kiela. 2017. Pathophysiology of intestinal $\mathrm{Na}+\mathrm{H}+$ exchange. Cell. Mol. Gastroenterol. Hepatol. 3:27-40.

Gutzwiller, A. 1993. The effect of a diet containing cyanogenic glycosides on the selenium status and the thyroid function of sheep. Anim. Prod. 57:415-419.

Ha, J. H., C. Doguer, and J. F. Collins. 2017. Consumption of a highiron diet disrupts homeostatic regulation of intestinal copper absorption in adolescent mice. Am. J. Physiol. Gastrointest. Liver Physiol. 313:G353-G360. https://doi.org/10.1152/ajpgi.00169 2017.

Hakim, A. A., and N. Lifson. 1969. Effects of pressure on water and solute transport by dog intestinal mucosa in vitro. Am. J. Physiol. 216:276-284

Hambridge, K. M., C. C. Casey, and N. F. Krebs. 1986. Zinc. Pages 1-137 in Trace Elements in Human and Animal Nutrition. Vol. 2. W. Mertz, ed. Acad. Press, New York, NY.

Hansen, S. L., P. Schlegel, L. R. Legleiter, K. E. Lloyd, and J. W. Spears. 2008. Bioavailability of copper from copper glycinate in steers fed high dietary sulfur and molybdenum. J. Anim. Sci. 86:173-179.

Hansen, S. L., N. Trakooljul, H. C. Liu, A. J. Moeser, and J. W Spears. 2009. Iron transporters are differentially regulated by dietary iron, and modifications are associated with changes in manganese metabolism in young pigs. J. Nutr. 139:1474-1479.

Harrison, J. H., and H. R. Conrad. 1984a. Effect of selenium intake on selenium utilization by the nonlactating dairy cow. J. Dairy Sci. $67: 219-223$.

Harrison, J. H., and H. R. Conrad. 1984b. Effect of calcium on selenium absorption by the nonlactating dairy cow. J. Dairy Sci. 67:1860-1864.

Harrison, J. H., D. D. Hancock, and H. R. Conrad. 1984. Vitamin E and selenium for reproduction of the dairy cow. J. Dairy Sci. $67: 123-132$.

Hartmans, J. 1974. Tracing and treating mineral disorders in cattle under field conditions. Pages 261-273 in Trace Element Metabolism in Animals. Vol. 2. W. G. Hoekstra, ed. University Park Press, Baltimore, MD

Hartsock, A., and W. J. Nelson. 2008. Adherens and tight junctions: Structure, function and connections to the actin cytoskeleton. Biochim. Biophys. Acta 1778:660-669.

Hashimoto, A., and T. Kambe. 2015. Mg, $\mathrm{Zn}$ and $\mathrm{Cu}$ transport proteins: A brief overview from physiological and molecular perspectives. J. Nutr. Sci. Vitaminol. (Tokyo) 61(Suppl.):S116-S118.

Hasselbalch, K. A. 1917. Die Berechnung der Wasserstoffzahl des Blutes aus der freien und gebundenen Kohlensäure desselben, und die Sauerstoffbindung des Blutes als Funktion der Wasserstoffzahl. Biochem. Z. 78:112-144.
Heitzmann, D., and R. Warth. 2008. Physiology and pathophysiology of potassium channels in gastrointestinal epithelia. Physiol. Rev. 88:1119-1182.

Hellman, N. E., and J. D. Gitlin. 2002. Ceruloplasmin metabolism and function. Annu. Rev. Nutr. 22:439-458.

Hemken, R. W. 1970. Iodine. J. Dairy Sci. 53:1138-1143.

Hemken, R. W. 1983. Potassium in ruminant nutrition. Page 1 in Sodium and Potassium in Ruminant Nutrition. National Feed Ingredients Association, West Des Moines, IA.

Henry, P. R. 1995. Cobalt bioavailability. Pages 119-126 in Bioavailability of Nutrients for Animals. C. B. Ammerman, D. H. Baker, and A. J. Lewis, ed. Academic Press, San Diego, CA.

Hetzel, B., and M. Welby. 1997. Iodine. Pages 557-581 in Handbook of Nutritionally Essential Mineral Elements. B. L. O'Dell and R. A. Sunde, ed. Marcel Dekker, New York, NY.

Hibbs, J. W., and H. R. Conrad. 1983. The relationship of calcium and phosphorus intake and digestion and the effects of vitamin D feeding on the utilization of calcium and phosphorus by lactating dairy cows. Pages 1-23 in Research Bulletin 1150. Ohio State University, Ohio Agric. Res. and Dev. Center, Wooster.

Hidmi, L., and M. Edwards. 1999. Role of temperature and $\mathrm{pH}$ in $\mathrm{Cu}(\mathrm{OH}) 2$ solubility. Environ. Sci. Technol. 33:2607-2610.

Hildmann, B., A. Schmidt, and H. Murer. 1982. Ca ${ }^{2}$-transport across basal-lateral plasma membranes from rat small intestinal epithelial cells. J. Membr. Biol. 65:55-62.

Ho, S. Y., W. J. Miller, R. P. Gentry, M. W. Neathery, and D. M. Blackmon. 1984. Effects of high, but nontoxic dietary manganese and iron on their metabolism by calves. J. Dairy Sci. 67:1489-1495.

Hoenderop, J. G., B. Nilius, and R. J. Bindels. 2005. Calcium absorption across epithelia. Physiol. Rev. 85:373-422.

Höller, H., G. Breves, M. Kocabatmaz, and H. Gerdes. 1988. Flux of calcium across the sheep rumen wall in vivo and in vitro. Q. J. Exp. Physiol. 73:609-618.

Holtenius, K., and K. Dahlborn. 1990. Water and sodium movement across the ruminal epithelium in fed and food-deprived sheep. Exp. Physiol. 75:57-67.

Holtug, K., M. B. Hansen, and E. Skadhauge. 1996. Experimental studies of intestinal ion and water transport. Scand. J. Gastroenterol. Suppl. 216:95-110.

Hortin, A. E., P. J. Bechtel, and D. H. Baker. 1991. Efficacy of pork loin as a source of zinc and effect of added cysteine on zinc bioavailability. J. Food Sci. 56:1505-1507.

Hu, W., and M. R. Murphy. 2004. Dietary cation-anion difference effects on performance and acid-base status of lactating dairy cows: A meta-analysis. J. Dairy Sci. 87:2222-2229.

Hu, W., M. R. Murphy, P. D. Constable, and E. Block. 2007. Dietary cation-anion difference and dietary protein effects on performance and acid-base status of dairy cows in early lactation. J. Dairy Sci. 90:3355-3366.

Hyde, M. L., and D. R. Fraser. 2014. In vivo measurement of the absorption of strontium in the rumen and small intestine of sheep as an index of calcium absorption capacity. Br. J. Nutr. 112:718-724.

Ivan, M., D. M. Veira, and C. A. Kelleher. 1986. The alleviation of chronic copper toxicity in sheep by ciliate protozoa. Br. J. Nutr. $55: 361-367$.

Ivancic, J. 1999. Effect of dietary selenium and sulfate on selenium balance in Holstein cows. MS Thesis. Ohio State Univ., Columbus.

Jenkitkasemwong, S., C. Y. Wang, B. Mackenzie, and M. D. Knutson. 2012. Physiologic implications of metal-ion transport by ZIP14 and ZIP8. Biometals 25:643-655.

Jesse, B. W., J. W. Thomas, and R. S. Emery. 1981. Availability of magnesium from magnesium oxide particles of differing sizes and surfaces. J. Dairy Sci. 64:197-205.

Jittakhot, S., J. T. Schonewille, H. Wouterse, A. W. Uijttewaal, C. Yuangklang, and A. C. Beynen. 2004. Increasing magnesium intakes in relation to magnesium absorption in dry cows. J. Dairy Res. 71:297-303.

Johnson, C. L., and D. A. Aubrey-Jones. 1989. Effect of change of diet on the mineral composition of rumen fluid, on magnesium metabolism and on water balance in sheep. Br. J. Nutr. 61:583-594. 
Johnson, W. T., and G. W. Evans. 1984. Effects of the interrelationship between dietary protein and minerals on tissue content of trace metals in streptozotocin-diabetic rats. J. Nutr. 114:180-190.

Johnston, H., L. Beasley, and N. MacPherson. 2014. Copper toxicity in a New Zealand dairy herd. Ir. Vet. J. 67:20-24.

Kabaija, E., and O. B. Smith. 1988. Trace element kinetics in the digestive tract of sheep fed diets with graded levels of dietary fibre. J. Anim. Physiol. Anim. Nutr. (Berl.) 59:218-224.

Kale, S. S., S. S. Tamhankar, and R. V. Chaudhari. 1979. Solubility of cuprous chloride in aqueous hydrochloric acid solutions. J. Chem. Eng. Data 24:110-111.

Kaplan, J. H., and S. Lutsenko. 2009. Copper transport in mammalian cells: Special care for a metal with special needs. J. Biol. Chem. 284:25461-25465.

Karbach, U., and R. Wanitschke. 1984. Influence of serosal hydrostatic pressure on net water and electrolyte transport across the isolated rat colonic mucosa exposed to different secretagogues. Naunyn Schmiedebergs Arch. Pharmacol. 327:336-341.

Kearney, P. E., P. J. Murray, J. M. Hoy, M. Hohenhaus, and A. Kotze. 2016. The "Toolbox" of strategies for managing Haemonchus contortus in goats: What's in and what's out. Vet. Parasitol. 220:93107.

Kegley, E. B., and J. W. Spears. 1994. Bioavailability of feed-grade copper sources (oxide, sulfate, or lysine) in growing cattle. J. Anim. Sci. 72:2728-2734

Kendall, N. R., H. R. Holmes-Pavord, P. A. Bone, E. L. Ander, and S. D. Young. 2015. Liver copper concentrations in cull cattle in the UK: Are cattle being copper loaded? Vet. Rec. 177:493.

Kennedy, D. G., S. Kennedy, and P. B. Young. 1996. Effects of low concentrations of dietary cobalt on rumen succinate concentration in sheep. Int. J. Vitam. Nutr. Res. 66:86-92.

Kennedy, D. W., W. M. Craig, and L. L. Southern. 1993. Ruminal distribution of zinc in steers fed a polysaccharide-zinc complex or zinc oxide. J. Anim. Sci. 71:1281-1287.

Khorasani, G. R., R. A. Janzen, W. B. McGill, and J. J. Kennelly. 1997. Site and extent of mineral absorption in lactating cows fed whole-crop cereal grain silage of alfalfa silage. J. Anim. Sci. 75:239-248.

Kies, C. C. J., and H. M. Fox. 1989. Copper utilization in humans as affected by amino acid supplements. FASEB J. 3:A360.

Kincaid, R. L., and J. D. Cronrath. 1979. Effects of dietary zinc upon tissue zinc and percent unsaturated plasma-zinc binding capacity. J. Dairy Sci. 62:572-576.

Koenig, K. M., W. T. Buckley, and J. A. Shelford. 1991. True absorption of selenium in dairy cows: Stable isotope tracer methodology and effect of dietary copper. Can. J. Anim. Sci. 71:175-183.

Koenig, K. M., L. M. Rode, L. M. Cohen, and W. T. Bucklet. 1997. Effects of diet and chemical form of selenium on selenium metabolism in sheep. J. Anim. Sci. 75:817-827.

Kronqvist, C., U. Emanuelson, R. Spörndly, and K. Holtenius. 2011. Effects of prepartum dietary calcium level on calcium and magnesium metabolism in periparturient dairy cows. J. Dairy Sci. 94:1365-1373.

Kronshage, N., and S. Leonhard-Marek. 2009. Potassium transport across gastrointestinal epithelium of ruminants. Pages 248-249 in Proc. XIth International Symposium on Ruminant Physiology. Y. Chilliard, F. Glasser, Y. Faulconnier, F. Bocquier, I. Veissier, and M. Doreau, ed. Wageningen Academic Publishers, Wageningen, the Netherlands.

Krug, S. M., D. Günzel, M. P. Conrad, I. F. Lee, S. Amasheh, M. Fromm, and A. S. Yu. 2012. Charge-selective claudin channels. Ann. N. Y. Acad. Sci. 1257:20-28.

Kühn, L. C. 2015. Iron regulatory proteins and their role in controlling iron metabolism. Metallomics 7:232-243.

Kunzelmann, K., and M. Mall. 2002. Electrolyte transport in the mammalian colon: Mechanisms and implications for disease. Physiol. Rev. 82:245-289.

Kutuzova, G. D., F. Sundersingh, J. Vaughan, B. P. Tadi, S. E. Ansay, S. Christakos, and H. F. DeLuca. 2008. TRPV6 is not required for 1 $\alpha, 25$-dihydroxyvitamin D3-induced intestinal calcium absorption in vivo. Proc. Natl. Acad. Sci. USA 105:19655-19659.
Lassiter, J. W., W. J. Miller, F. M. Pate, and R. P. Gentry. 1972. Effect of dietary calcium and phosphorus on 54Mn metabolism following single tracer intraperitoneal and oral doses in rats. Proc. Soc. Exp. Biol. Med. 139:345-348.

Lassiter, J. W., and J. D. Morton. 1968. Effects of low manganese diet on certain bovine characteristics. J. Anim. Sci. 27:776-779.

Laszlo, J. A. 1989. Effect of gastrointestinal conditions on the mineral-binding properties of dietary fibers. Adv. Exp. Med. Biol. 249:133-145

Legleiter, L. R., J. W. Spears, and K. E. Lloyd. 2005. Influence of dietary manganese on performance, lipid metabolism, and carcass composition of growing and finishing steers. J. Anim. Sci. 83:2434-2439.

Leonhard-Marek, S., and H. Martens. 1996. Effects of potassium on magnesium transport across rumen epithelium. Am. J. Physiol. 271:G1034-G1038.

Leonhard-Marek, S., F. Stumpff, I. Brinkmann, G. Breves, and H. Martens. 2005. Basolateral $\mathrm{Mg}^{+} / \mathrm{Na}^{+}$exchange regulates apical nonselective cation channel in sheep rumen epithelium via cytosolic Mg2 ${ }^{+}$. Am. J. Physiol. Gastrointest. Liver Physiol. 288:G630G645

Leonhard-Marek, S., F. Stumpff, and H. Martens. 2010. Transport of cations and anions across forestomach epithelia: Conclusions from in vitro studies. Animal 4:1037-1056.

Linder, M. C. 2016. Ceruloplasmin and other copper binding components of blood plasma and their functions: An update. Metallomics 8:887-905.

Lönnerdal, B. 2008. Intestinal regulation of copper homeostasis: A developmental perspective. Am. J. Clin. Nutr. 88:846S-850S.

Lucas, M. L., W. Schneider, J. F. Haberich, and J. A. Blair. 1975. Direct measurement by $\mathrm{pH}$ microelectrode of the $\mathrm{pH}$ microclimate in rat proximal jejunum. Proc. R. Soc. Lond. B Biol. Sci. 192:39-48.

Lutsenko, S., N. L. Barnes, M. Y. Bartee, and O. Y. Dmitriev. 2007. Function and regulation of human copper-transporting ATPases. Physiol. Rev. 87:1011-1046.

Lutsenko, S., A. Gupta, J. L. Burkhead, and V. Zuzel. 2008. Cellular multitasking: The dual role of human $\mathrm{Cu}$-ATPases in cofactor delivery and intracellular copper balance. Arch. Biochem. Biophys. $476: 22-32$

Mackenzie, B., and M. D. Garrick. 2005. Iron Imports. II. Iron uptake at the apical membrane in the intestine. Am. J. Physiol. Gastrointest. Liver Physiol. 289:G981-G986.

Madara, J. L., R. Moore, and S. Carlson. 1987. Alteration of intestinal tight junction structure and permeability by cytoskeletal contraction. Am. J. Physiol. 253:C854-C861.

Madara, J. L., and J. R. Pappenheimer. 1987. Structural basis for physiological regulation of paracellular pathways in intestinal epithelia. J. Membr. Biol. 100:149-164.

Mangkoewidjojo, S., S. D. Sleight, and E. M. Convey. 1980. Pathologic features of iodide toxicosis in calves. Am. J. Vet. Res. 41:10571061.

Mao, X., B. E. Kim, F. Wang, D. J. Eide, and M. J. Petris. 2007. A histidine-rich cluster mediates the ubiquitination and degradation of the human zinc transporter, hZIP4, and protects against zinc cytotoxicity. J. Biol. Chem. 282:6992-7000.

Markossian, K. A., and B. I. Kurganov. 2003. Copper chaperones, intracellular copper trafficking proteins. Function, structure, and mechanism of action. Biochemistry (Mosc.) 68:827-837.

Markou, K., N. Georgopoulos, V. Kyriazopoulou, and A. G. Vagenakis. 2001. Iodine-induced hypothyroidism. Thyroid 11:501-510.

Markovich, D. 2001. Physiological roles and regulation of mammalian sulfate transporters. Physiol. Rev. 81:1499-1533.

Martens, H. 1983. Saturation kinetics of magnesium efflux across the rumen wall in heifers. Br. J. Nutr. 49:153-158.

Martens, H., and I. Blume. 1987. Studies on the absorption of sodium and chloride from the rumen of sheep. Comp. Biochem. Physiol. A Comp. Physiol. 86:653-656.

Martens, H., and G. Gäbel. 1986. Pathogenesis and prevention of grass tetany from the physiologic viewpoint. Dtsch. Tierarztl. Wochenschr. 93:170-177. 
Martens, H., and G. Gäbel. 1988. Transport of $\mathrm{Na}$ and $\mathrm{Cl}$ across the epithelium of ruminant forestomachs: Rumen and omasum. A review. Comp. Biochem. Physiol. A Comp. Physiol. 90:569-575.

Martens, H., G. Gäbel, and B. Strozyk. 1991. Mechanism of electrically silent $\mathrm{Na}$ and $\mathrm{Cl}$ transport across the rumen epithelium of sheep. Exp. Physiol. 76:103-114.

Martens, H., and J. Harmeyer. 1978. Magnesium transport by isolated rumen epithelium of sheep. Res. Vet. Sci. 24:161-168.

Martens, H., and H. Kasebieter. 1983. In vitro studies of the effect of sodium and potassium ions on magnesium transport across the isolated rumen mucosa of sheep. Zentralbl. Veterinarmed. A 30:1-14.

Martens, H., and M. Schweigel. 2000. Pathophysiology of grass tetany and other hypomagnesemias. Implications for clinical management. Vet. Clin. North Am. Food Anim. Pract. 16:339-368.

Martin, A., and L. D. Quarles. 2012. Evidence for FGF23 involvement in a bone-kidney axis regulating bone mineralization and systemic phosphate and vitamin D homeostasis. Adv. Exp. Med. Biol. 728:65-83.

Martz, F. A., A. T. Belo, M. F. Weiss, R. L. Belyea, and J. P. Goff. 1990. True absorption of calcium and phosphorus from alfalfa and corn silage when fed to lactating cows. J. Dairy Sci. 73:1288-1295.

Maverakis, E., P. J. Lynch, and N. Fazel. 2007. Acrodermatitis enteropathica. Dermatol. Online J. 13:11.

Mayland, H. 1988. Grass tetany. Page 511 in The Ruminant Animal: Digestive Physiology and Nutrition. D. Church, ed. Waveland Press, Prospect Heights, IL.

McAllister, M. M., D. H. Gould, M. F. Raisbeck, B. A. Cummings, and G. H. Loneragan. 1997. Evaluation of ruminal sulfide concentrations and seasonal outbreaks of polioencephalomalacia in beef cattle in a feedlot. J. Am. Vet. Med. Assoc. 211:1275-1279.

McCord, J. M., and I. Fridovich. 1988. Superoxide dismutase: The first twenty years (1968-1988). Free Radic. Biol. Med. 5:363-369.

McEwan, G. T., H. Daniel, C. Fett, M. N. Burgess, and M. L. Lucas. 1988. The effect of Escherichia coli STa enterotoxin and other secretagogues on mucosal surface $\mathrm{pH}$ of rat small intestine in vivo. Proc. R. Soc. Lond. B Biol. Sci. 234:219-237.

McNamara, J. P., and F. Valdez. 2005. Adipose tissue metabolism and production responses to calcium propionate and chromium propionate. J. Dairy Sci. 88:2498-2507.

McNeil, N. I., K. L. Ling, and J. Wager. 1987. Mucosal surface pH of the large intestine of the rat and of normal and inflamed large intestine in man. Gut 28:707-713.

Mertz, W. 1993. Chromium in human nutrition: A review. J. Nutr. 123:626-633

Miller, E. R. 1995. Potassium bioavailability. Pages 295-301 in Bioavailability of Nutrients for Animals. C. B. Ammerman, D. H Baker, and A. J. Lewis, ed. Acad. Press, New York, NY.

Miller, J. K., E. Brzezinska-Slebodzinska, and F. C. Madsen. 1993. Oxidative stress, antioxidants, and animal function. J. Dairy Sci. $76: 2812-2823$

Miller, J. K., N. Ramsey, and F. C. Madsen. 1988. The trace elements Pages 342-400 in The Ruminant Animal: Digestive Physiology and Nutrition. D. C. Church, ed. Prentice-Hall, Englewood Cliffs, NJ.

Miller, J. K., E. W. Swanson, and G. E. Spalding. 1975. Iodine absorption, excretion, recycling, and tissue distribution in the dairy cow. J. Dairy Sci. 58:1578-1593.

Miller, W. J. 1979. Dairy Cattle Feeding and Nutrition. Academic Press, New York, NY.

Miller, W. J., H. E. Amos, R. P. Gentry, D. M. Blackmon, R. M. Durrance, C. T. Crowe, A. S. Fielding, and M. W. Neathery. 1989 Long term feeding of high zinc sulfate diets to lactating and gestating dairy cows. J. Dairy Sci. 72:1499-1508.

Mills, C. F., A. C. Dalgarno, R. B. Williams, and J. Quarterman. 1967. Zinc deficiency and the zinc requirements of calves and lambs. Br. J. Nutr. 21:751-768.

Mills, C. F., and G. K. Davis. 1987. Molybdenum. Pages 429-463 in Trace Elements in Human and Animal Nutrition. Vol. 1. W. Mertz, ed. Academic Press, New York, NY.

Möllerberg, L., and J. Moreno-Lopez. 1975. The response of normal and iron anemic calves to nasal infection with an attenuated strain of parainfluenza-3 virus. Acta Vet. Scand. 16:186-196.
Mongin, P. 1981. Recent advances in dietary anion-cation balance: Applications in poultry. Proc. Nutr. Soc. 40:285-294.

Mugharbil, A., R. G. Knickelbein, P. S. Aronson, and J. W. Dobbins. 1990. Rabbit ileal brush-border membrane $\mathrm{Cl}-\mathrm{HCO}_{3}$ exchanger is activated by an internal pH-sensitive modifier site. Am. J. Physiol. 259:G666-G670.

Muñiz-Naveiro, O., R. Domínguez-González, A. Bermejo-Barrera J. A. Cocho de Juan, J. M. Fraga Bermúdez, A. Goris Pereiras, A. López Santamariña, I. Martínez Lede, J. Valledor Puente, L. Fernández-Couto Gómez, and P. Bermejo-Barrera. 2005. Selenium content and distribution in cow's milk supplemented with two dietary selenium sources. J. Agric. Food Chem. 53:9817-9822.

National Research Council. 1989. Nutrient Requirements of Dairy Cattle. 6th ed. Natl. Acad. Press, Washington, DC.

National Research Council. 2001. Nutrient Requirements of Dairy Cattle. 7th ed. Natl. Acad. Press, Washington, DC.

National Research Council. 2005. Mineral Tolerances of Domestic Animals. 2nd rev. ed. Nat. Acad. Press, Washington DC.

Nellans, H. N. 1988. Contributions of cellular and paracellular pathways to transepithelial intestinal calcium transport. Pages 269-276 in Cellular Calcium and Phosphate Transport in Health and Disease. F. Bronner and M. Peterlik, ed. Liss, New York, NY.

Nellans, H. N. 1991. Mechanisms of peptide and protein absorption (l) paracellular intestinal transport: Modulation of absorption. Adv. Drug Deliv. Rev. 7:339-364.

Nickel, A., G. Kottra, G. Schmidt, J. Danier, T. Hofmann, and H. Daniel. 2009. Characteristics of transport of selenoamino acids by epithelial amino acid transporters. Chem. Biol. Interact. 177:234241.

Nicola, J. P., N. Carrasco, and A. M. Masini-Repiso. 2015. Dietary $\mathrm{I}(-)$ absorption: Expression and regulation of the $\mathrm{Na}(+) / \mathrm{I}(-)$ symporter in the intestine. Vitam. Horm. 98:1-31.

Nielsen, F. H., M. L. Sunde, and W. G. Hoekstra. 1966. Effect of dietary synthetic and natural chelating agents on the zinc-deficiency syndrome in the chick. J. Nutr. 89:35-42.

Oh, M. S., and H. J. Caroll. 1977. Current concepts. The anion gap. N. Engl. J. Med. 297:814-817.

Olson, W. G., J. B. Stevens, J. Anderson, and D. W. Haggard. 1984 Iodine toxicosis in six herds of dairy cattle. J. Am. Vet. Med. Assoc. $184: 179-181$

Ong, C. B., T. H. Herdt, and S. D. Fitzgerald. 2014. Hyperplastic goiter in two adult dairy cows. J. Vet. Diagn. Invest. 26:810-814.

Pal, D. T., N. K. Gowda, C. S. Prasad, R. Amarnath, U. Bharadwaj, G. Suresh Babu, and K. T. Sampath. 2010. Effect of copper- and zinc-methionine supplementation on bioavailability, mineral status and tissue concentrations of copper and zinc in ewes. J. Trace Elem. Med. Biol. 24:89-94.

Pappenheimer, J. R., and K. Z. Reiss. 1987. Contribution of solvent drag through intercellular junctions to absorption of nutrients by the small intestine of the rat. J. Membr. Biol. 100:123-136.

Paterson, J. E., and A. MacPherson. 1990. The influence of a low cobalt intake on the neutrophil function and severity of Ostertagia infection in cattle. Br. Vet. J. 146:519-530.

Pesce, L., and P. Kopp. 2014. Iodide transport: Implications for health and disease. Int. J. Pediatr. Endocrinol. 2014:8. https://doi.org/10 .1186/1687-9856-2014-8

Petering, D. H., and A. Mahim. 2017. Proteomic high affinity $\mathrm{Zn}^{+2}$ trafficking: Where does metallothionein fit in? Int. J. Mol. Sci 18:E1289. https://doi.org/10.3390/ijms18061289.

Peterson, A. B., M. W. Orth, J. P. Goff, and D. K. Beede. 2005 Periparturient responses of multiparous Holstein cows fed different dietary phosphorus concentrations prepartum. J. Dairy Sci. 88:3582-3594.

Phillippo, M., W. R. Humphries, and P. H. Garthwaite. 1987. The effect of dietary molybdenum and iron on copper status and growth in cattle. J. Agric. Sci. Camb. 109:315-320.

Pogge, D. J., M. E. Drewnoski, and S. L. Hansen. 2014. High dietary sulfur decreases the retention of copper, manganese, and zinc in steers. J. Anim. Sci. 92:2182-2191. 
Pond, W. G., and R. R. Oltjen. 1988. Response of large and medium frame beef steers to protein and zinc supplementation of a corn silage-corn finishing diet. Nutr. Rep. Int. 38:737-743.

Puls, R. 1994. Mineral Levels in Animal Health: Diagnostic Data. Canada Sherpa International, Clearbrook, BC, Canada.

Rabbani, I., C. Siegling-Vlitakis, B. Noci, and H. Martens. 2011. Evidence for NHE3-mediated $\mathrm{Na}$ transport in sheep and bovine forestomach. Am. J. Physiol. Regul. Integr. Comp. Physiol. 301:R313R319.

Ram, L., J. T. Schonewille, H. Martens, A. T. Van't Klooster, and A. C. Beynen. 1998. Magnesium absorption by wethers fed potassium bicarbonate in combination with different dietary magnesium concentrations. J. Dairy Sci. 81:2485-2492.

Reuss, L. 1989. Ion transport across gallbladder epithelium. Physiol. Rev. 69:503-545.

Riner, K., A. Boos, M. Hassig, and A. Liesegang. 2008. Vitamin D receptor distribution in intestines of domesticated sheep Ovis ammon f. aries. J. Morphol. 269:144-152.

Rickard, D., and G. W. Luther III.. 2006. Metal sulfide complexes and clusters. Rev. Mineral. Geochem. 61:421-504.

Roberts, E. A., and B. Sarkar. 2008. Liver as a key organ in the supply, storage, and excretion of copper. Am. J. Clin. Nutr. 88:851S-854S.

Röder, P. V., K. E. Geillinger, T. S. Zietek, B. Thorens, H. Koepsell, and H. Daniel. 2014. The role of SGLT1 and GLUT2 in intestinal glucose transport and sensing. PLoS One 9:e89977. https://doi .org/10.1371/journal.pone.0089977.

Rojas, L. X., L. R. McDowell, F. G. Martin, N. S. Wilkinson, A. B. Johnson, and C. A. Njeru. 1996. Relative bioavailability of zinc methionine and two inorganic zinc sources fed to cattle. J. Trace Elem. Med. Biol. 10:205-209.

Roman, M., P. Jitaru, and C. Barbante. 2014. Selenium biochemistry and its role for human health. Metallomics 6:25-54.

Rosenthal, R., D. Günzel, D. Theune, C. Czichos, J. D. Schulzke, and M. Fromm. 2017. Water channels and barriers formed by claudins. Ann. N. Y. Acad. Sci. 1397:100-109.

Rossier, B. C., M. E. Baker, and R. A. Studer. 2015. Epithelial sodium transport and its control by aldosterone: The story of our internal environment revisited. Physiol. Rev. 95:297-340.

Reid, R. S., and M. A. Attaelmannan. 1998. NMR studies of copper speciation in the bovine rumen environment. J. Inorg. Biochem. 69:59-65.

Sabbagh, Y., H. Giral, Y. Caldas, M. Levi, and S. C. Schiavi. 2011. Intestinal phosphate transport. Adv. Chronic Kidney Dis. 18:85-90.

Said, H. M., J. A. Blair, M. L. Lucas, and M. E. Hilburn. 1986. Intestinal surface acid microclimate in vitro and in vivo in the rat. J. Lab. Clin. Med. 107:420-424.

Sales, J., and F. Jancík. 2011. Effects of dietary chromium supplementation on performance, carcass characteristics, and meat quality of growing-finishing swine: A meta-analysis. J. Anim. Sci. 89:40544067.

Salgueiro, M. J., M. Zubillaga, A. Lysionek, M. I. Sarabia, R. Caro, T. De Paoli, A. Hager, and J. Boccio. 2000. Zinc as an essential micronutrient: A review. Nutr. Res. 20:737-755.

Salyer, G. B., M. L. Galyean, P. J. Defoor, G. A. Nunnery, C. H. Parsons, and J. D. Rivera. 2004. Effects of copper and zinc source on performance and humoral immune response of newly received, lightweight beef heifers. J. Anim. Sci. 82:2467-2473.

San Martin, C. D., C. Garri, F. Pizarro, T. Walter, E. C. Theil, and M. T. Núñez. 2008. Caco-2 intestinal epithelial cells absorb soybean ferritin by mu2 (AP2)-dependent endocytosis. J. Nutr. 138:659666.

Sanchez, W. K., D. K. Beede, and M. A. Delorenzo. 1994. Macromineral element interrelationships and lactational performance: Empirical models from a large data set. J. Dairy Sci. 77:3096-3110.

Sandle, G. I. 1998. Salt and water absorption in the human colon: A modern appraisal. Gut 43:294-299.

Sangkhae, V., and E. Nemeth. 2017. Regulation of the iron homeostatic hormone hepcidin. Adv. Nutr. 8:126-136.

Sansom, B. F., H. W. Symonds, and M. J. Vagg. 1978. The absorption of dietary manganese by dairy cows. Res. Vet. Sci. 24:366-369.
Sauer, A. K., S. Pfaender, S. Hagmeyer, L. Tarana, A. K. Mattes, F. Briel, S. Küry, T. M. Boeckers, and A. M. Grabrucker. 2017. Characterization of zinc amino acid complexes for zinc delivery in vitro using Caco-2 cells and enterocytes from hiPSC. Biometals 30:643-661. https://doi.org/10.1007/s10534-017-0033-y.

Scaletti, R. W., D. S. Trammell, B. A. Smith, and R. J. Harmon. 2003 Role of dietary copper in enhancing resistance to Escherichia coli mastitis. J. Dairy Sci. 86:1240-1249

Scheers, N. 2013. Regulatory effects of $\mathrm{Cu}$, Zn, and Ca on Fe absorption: The intricate play between nutrient transporters. Nutrients 5:957-970.

Schonewille, J. T., H. Everts, S. Jittakhot, and A. C. Beynen. 2008. Quantitative prediction of magnesium absorption in dairy cows. J. Dairy Sci. 91:271-278.

Schonewille, J. T., A. T. van't Klooster, and M. van Mosel. 1992 A comparative study of the in vitro solubility and availability of magnesium from various sources for cattle. Tijdschr. Diergeneeskd. 117:105-108.

Schröder, B., and G. Breves. 2006. Mechanisms and regulation of calcium absorption from the gastrointestinal tract in pigs and ruminants: Comparative aspects with special emphasis on hypocalcemia in dairy cows. Anim. Health Res. Rev. 7:31-41.

Schröder, B., W. Goebel, K. Huber, and G. Breves. 2001. No effect of vitamin D3 treatment on active calcium absorption across ruminal epithelium of sheep. J. Vet. Med. A Physiol. Pathol. Clin. Med. 48:353-363.

Schröder, B., I. Rittmann, E. Pfeffer, and G. Breves. 1997. In vitro studies on calcium absorption from the gastrointestinal tract in small ruminants. J. Comp. Physiol. B 167:43-51.

Schröder, B., S. Vossing, and G. Breves. 1999. In vitro studies on active calcium absorption from ovine rumen. J. Comp. Physiol. B 169:487-494

Schroder, B., M. R. Wilkens, G. E. Ricken, S. Leonhard-Marek, D. R. Fraser, and G. Breves. 2015. Calcium transport in bovine rumen epithelium as affected by luminal $\mathrm{Ca}$ concentrations and $\mathrm{Ca}$ sources. Physiol. Rep. 3:e12615. https://doi.org/10.14814/Phy2 .12615

Schweigel, M., J. Kuzinski, C. Deiner, and M. Kolisek. 2009a. Rumen epithelial cells adapt magnesium transport to high and low extracellular magnesium conditions. Magnes. Res. 22:133-150.

Schweigel, M., and H. Martens. 2000a. Magnesium transport in the gastrointestinal tract. Front. Biosci. 5:D666-D677.

Schweigel, M., and H. Martens. 2000b. Electrophysiologic changes in rumen epithelium in their effect on magnesium transport-A review. Berl. Munch. Tierarztl. Wochenschr. 113:97-102.

Schweigel, M., and H. Martens. 2003. Anion-dependent $\mathrm{Mg}^{2+}$ influx and a role for a vacuolar $\mathrm{H}+$-ATPase in sheep ruminal epithelial cells. Am. J. Physiol. Gastrointest. Liver Physiol. 285:G45-G53.

Schweigel, M., H. S. Park, B. Etschmann, and H. Martens. 2006. Characterization of the Na+-dependent $\mathrm{Mg} 2+$ transport in sheep ruminal epithelial cells. Am. J. Physiol. Gastrointest. Liver Physiol. 290:G56-G65.

Schweigel, M., J. Voigt, and E. Mohr. 2009b. Indication of intracellular magnesium deficiency in lactating dairy cows revealed by magnesium loading and renal fractional excretion. J. Anim. Physiol. Anim. Nutr. (Berl.) 93:105-112.

Scott, M. L., and T. R. Ziegler. 1963. Evidence for natural chelates which aid in the utilization of zinc by chicks. J. Agric. Food Chem. 11:123-125.

Sehested, J., L. Diernaes, P. D. Moller, and E. Skadhauge. 1996. Transport of sodium across the isolated bovine rumen epithelium: Interaction with short-chain fatty acids, chloride and bicarbonate. Exp. Physiol. 81:79-94.

Sesmilo, G., O. Sim, L. Choque, R. Casamitjan, M. Puig-Domingo, and I. Halperin. 2011. Serum free triiodothyronine (T3) to free thyroxine (T4) ratio in treated central hypothyroidism compared with primary hypothyroidism and euthyroidism. Endocrinol. Nutr. 58:9-15.

Shawki, A., M. A. Engevik, R. S. Kim, P. B. Knight, R. A. Baik, S. R. Anthony, R. T. Worrell, G. E. Shull, and B. Mackenzie. 2016. 
Intestinal brush-border $\mathrm{Na}+/ \mathrm{H}+$ exchanger-3 drives $\mathrm{H}+$-coupled iron absorption in the mouse. Am. J. Physiol. Gastrointest. Liver Physiol. 311:G423-G430.

Shi, H., K. Z. Bencze, T. L. Stemmler, and C. C. Philpott. 2008 A cytosolic iron chaperone that delivers iron to ferritin. Science 320:1207-1210.

Shiau, Y. F. 1990. Mechanism of intestinal fatty acid uptake in the rat: The role of an acidic microclimate. J. Physiol. 421:463-474.

Shiau, Y. F., P. Fernandez, M. J. Jackson, and S. McMonagle. 1985. Mechanisms maintaining a low-pH microclimate in the intestine. Am. J. Physiol. 248:G608-G617.

Shimada, T., and T. Hoshi. 1988. Na+-dependent elevation of the acidic cell surface $\mathrm{pH}$ (microclimate $\mathrm{pH}$ ) of rat jejunal villus cells induced by cyclic nucleotides and phorbol ester: Possible mediators of the regulation of the $\mathrm{Na}+/ \mathrm{H}+$ antiporter. Biochim. Biophys. Acta 937:328-334.

Sidler-Lauff, K., A. Boos, M. Kraenzlin, and A. Liesegang. 2010. Influence of different calcium supplies and a single vitamin D injection on vitamin $\mathrm{D}$ receptor and calbindin D9k immunoreactivities in the gastrointestinal tract of goat kids. J. Anim. Sci. 88:3598-3610.

Sitar, M. E., S. Aydin, and U. Cakatay. 2013. Human serum albumin and its relation with oxidative stress. Clin. Lab. 59:945-952.

Sjövall, H., I. Hagman, and H. Abrahamsson. 1990. Relationship between interdigestive duodenal motility and fluid transport in humans. Am. J. Physiol. 259:G348-G354.

Sklan, D., and S. Hurwitz. 1985. Movement and absorption of major minerals and water in ovine gastrointestinal tract. J. Dairy Sci. 68:1659-1666

Smyth, D. H. 2013. Chapter 14.12 Regional variations and their significance. Pages 751-752 in Intestinal Absorption. D. H. Smyth, ed. Springer Science and Business Media, New York, NY.

Søli, N. E., and J. P. Rambaek. 1978. Excretion of intravenously injected copper-64 in sheep. Acta Pharmacol. Toxicol. (Copenh.) 43:205-210.

Sorensen, P. 1962. Studies of thyroid function in cattle and pigs. Page 455 in Use of Radioisotopes in Animal Biology and Medical Sciences. Vol. 1. Academic Press, New York, NY.

Spears, J. W. 1990. Ionophores and nutrient digestion and absorption in ruminants. J. Nutr. 120:632-638.

Spears, J. W. 2003. Trace mineral bioavailability in ruminants. J. Nutr. 133(Suppl. 1):1506S-1509S

Spears, J. W., and E. B. Kegley. 2002. Effect of zinc source (zinc oxide vs zinc proteinate) and level on performance, carcass characteristics, and immune response of growing and finishing steers. J. Anim. Sci. 80:2747-2752.

Spears, J. W., K. E. Lloyd, and R. S. Fry. 2011. Tolerance of cattle to increased dietary sulfur and effect of dietary cation-anion balance. J. Anim. Sci. 89:2502-2509.

Spears, J. W., K. E. Lloyd, and K. Krafka. 2017. Chromium concentrations in ruminant feed ingredients. J. Dairy Sci. 100:3584-3590.

Spears, J. W., C. S. Whisnant, G. B. Huntington, K. E. Lloyd, R. S. Fry, K. Krafka, A. Lamptey, and J. Hyda. 2012. Chromium propionate enhances insulin sensitivity in growing cattle. J. Dairy Sci. 95:2037-2045

Stearns, D. M., J. P. Wise Sr., S. R. Patierno, and K. E. Wetterhahn. 1995. Chromium(III) picolinate produces chromosome damage in Chinese hamster ovary cells. FASEB J. 9:1643-1648.

Stewart, P. A. 1981. How to Understand Acid-Base: A Quantitative Acid-Base Primer for Biology and Medicine. Elsevier North Holland, New York, NY.

Stumpff, F., M. I. Georgi, L. Mundhenk, I. Rabbani, M. Fromm, H Martens, and D. Günzel. 2011. Sheep rumen and omasum primary cultures and source epithelia: Barrier function aligns with expression of tight junction proteins. J. Exp. Biol. 214:2871-2882.

Suttle, N. F. 1975. Effects of age and weaning on the apparent availability of dietary copper to young lambs. J. Agric. Sci. 84:255-261.

Suttle, N. F. 1991. The interactions between copper, molybdenum and sulphur in ruminant nutrition. Annu. Rev. Nutr. 11:121-140.

Suttle, N. F. 2012. Residual effects of Mycobacterium avium infection on the susceptibility of sheep to copper toxicity and the effi- cacy of conservative treatment with tetrathiomolybdate. Vet. Rec. 171:246.

Suttle, N. F., and M. McLauchlan. 1976. Predicting the effects of dietary molybdenum and sulphur on the availability of copper to ruminants. Proc. Nutr. Soc. 35:22A-23A.

Taylor, C. M., J. Bacon, P. Aggett, and I. Bremner. 1991. Homeostatic regulation of zinc absorption and endogenous losses in zincdeprived men. Am. J. Clin. Nutr. 53:755-763.

Thilsing, T., R. J. Jørgensen, and H. D. Poulsen. 2006. In vitro binding capacity of zeolite A to calcium, phosphorus and magnesium in rumen fluid as influenced by changes in $\mathrm{pH}$. J. Vet. Med. A Physiol. Pathol. Clin. Med. 53:57-64.

Thornton, I., and B. J. Alloway. 1974. Geochemical aspects of the soil-plant-animal relationship in the development of trace element deficiency and excess. Proc. Nutr. Soc. 33:257-266.

Toepfer, E. W., W. Mertz, M. Polansky, E. Roginski, and W. Wolf 1976. Preparation of chromium-containing material of glucose tolerance factor activity from brewer's yeast extracts and by synthesis. J. Agric. Food Chem. 25:162-166.

Tomas, F. M., and B. J. Potter. 1976. The site of magnesium absorption from the ruminant stomach. Br. J. Nutr. 36:37-45.

Trefz, F. M., P. D. Constable, and I. Lorenz. 2015. Quantitative physicochemical analysis of acid-base balance and clinical utility of anion gap and strong ion gap in 806 neonatal calves with diarrhea. J Vet. Intern. Med. 29:678-687.

Turanov, A. A., X. M. Xu, B. A. Carlson, M. H. Yoo, V. N. Gladyshev, and D. L. Hatfield. 2011. Biosynthesis of selenocysteine, the 21st amino acid in the genetic code, and a novel pathway for cysteine biosynthesis. Adv. Nutr. 2:122-128.

Underwood, E. J. 1977. Trace Elements in Human and Animal Nutrition. 4th ed. Academic Press, New York, NY.

Underwood, E. J. 1981. The Mineral Nutrition of Livestock. 2nd ed. Commonwealth Agricultural Bureaux, Slough, UK.

US Food and Drug Administration. 2000. Compliance Policy Guide Sec. 651.100 Ethylenediamine Dihydroiodide (EDDI). Revised 05/01/2000. US FDA, Washington, DC.

US Food and Drug Administration. 2015. Selenium. 21CFR573.920. US FDA, Washington, DC.

Valko, M., K. Jomova, C. J. Rhodes, K. Kuča, and K. Musílek. 2016. Redox- and non-redox-metal-induced formation of free radicals and their role in human disease. Arch. Toxicol. 90:1-37.

Van Bruwaene, R., G. B. Gerber, R. Kirchmann, J. Colard, and J. Van Kerkom. 1984. Metabolism of 51Cr, 54Mn, 59Fe and $60 \mathrm{Co}$ in lactating dairy cows. Health Phys. 46:1069-1082.

Van Campen, D. R. 1969. Copper interference with intestinal absorption of Zn-65 by rats. J. Nutr. 97:104-108.

van den Berghe, P. V., and L. W. Klomp. 2009. New developments in the regulation of intestinal copper absorption. Nutr. Rev. 67:658 672.

Van Winden, S. C., K. E. Müller, R. Kuiper, and J. P. Noordhuizen. 2002. Studies on the $\mathrm{pH}$ value of abomasal contents in dairy cows during the first 3 weeks after calving. J. Vet. Med. A Physiol Pathol. Clin. Med. 49:157-160.

Vincent, J. B. 2014. Is chromium pharmacologically relevant? J. Trace Elem. Med. Biol. 28:397-405.

Vincent, J. B. 2015. Is the pharmacological mode of action of chromium(III) as a second messenger? Biol. Trace Elem. Res. 166:7-12.

Wadhwa, D. R., and A. D. Care. 2002. The absorption of phosphate ions from the ovine reticulorumen. Vet. J. 163:182-186.

Waghorn, G. C., I. D. Shelton, and B. R. Sinclair. 1990. Distribution of elements between solid and supernatant fractions of digesta in sheep given six diets. N. Z. J. Agric. Res. 33:259-269.

Wagner, C. A., N. Hernando, I. C. Forster, and J. Biber. 2014. The SLC34 family of sodium-dependent phosphate transporters. Pflugers Arch. 466:139-153.

Waldner, C., J. Campbell, G. K. Jim, P. T. Guichon, and C. Booker 1998. Comparison of three methods of selenium assessment in cattle. Can. Vet. J. 39:225-231. 
Waldvogel-Abramowski, S., G. Waeber, C. Gassner, A. Buser, B. M. Frey, B. Favrat, and J. D. Tissot. 2014. Physiology of iron metabolism. Transfus. Med. Hemother. 41:213-221.

Ward, J. D., and J. W. Spears. 1993. Comparison of copper lysine and copper sulfate as copper sources for ruminants using in vitro methods. J. Dairy Sci. 76:2994-2998.

Wasserman, R. H. 1981. Intestinal absorption of calcium and phosphorus. Fed. Proc. 40:68-72.

Wasserman, R. H., and A. N. Taylor. 1976. Gastrointestinal absorption of calcium and phosphorus. Pages 137-155 in Handbook of Physiology. Vol. VII: Parathyroid Gland. G. D. Aubach, ed. Am. Physiol. Soc., Washington, DC.

Weiss, W. P. 2004. Macromineral digestion by lactating cows: Factors affecting digestibility of magnesium. J. Dairy Sci. 87:2167-2171.

Weiss, W. P., and M. T. Socha. 2005. Dietary manganese for dry and lactating Holstein cows. J. Dairy Sci. 88:2517-2523.

West, J. W., K. D. Haydon, B. G. Mullinix, and T. G. Sandifer. 1992. Dietary cation-anion balance and cation source effects on production and acid-base status of heat-stressed cows. J. Dairy Sci. 75:2776-2786.

White, S. D., P. Bourdeau, R. A. Rosychuk, B. Cohen, T. Bonenberger, K. V. Fieseler, P. Ihrke, P. L. Chapman, P. Schultheiss, G. Zur, A. Cannon, and C. Outerbridge. 2001. Zinc-responsive dermatosis in dogs: 41 cases and literature review. Vet. Dermatol. 12:101-109.

Wiles, M., H. Huebner, E. Afriyie-Gyawu, R. Taylor, G. Bratton, and T. Phillips. 2004. Toxicological evaluation and metal bioavailability in pregnant rats following exposure to clay minerals in the diet. J. Toxicol. Environ. Health A 67:863-874.

Wilkens, M. R., C. Praechter, G. Breves, and B. Schröder. 2016. Stimulating effects of a diet negative in dietary cation-anion difference on calcium absorption from the rumen in sheep. J. Anim. Physiol. Anim. Nutr. (Berl.) 100:156-166.

Wollenberg, P., and W. Rummel. 1987. Dependence of intestinal iron absorption on the valency state of iron. Naunyn Schmiedebergs Arch. Pharmacol. 336:578-582.

Wright, E. M. 1993. The intestinal Na+/glucose cotransporter. Annu. Rev. Physiol. 55:575-589.

Wright, P. L., and M. C. Bell. 1966. Comparative metabolism of selenium and tellurium in sheep and swine. Am. J. Physiol. 211:6-10.
Wrightt, C. L., and J. W. Spears. 2004. Effect of zinc source and dietary level on zinc metabolism in Holstein calves. J. Dairy Sci 87:1085-1091.

Wu, Z., L. D. Satter, A. J. Blohowiak, R. H. Stauffacher, and J. H. Wilson. 2001. Milk production, estimated phosphorus excretion, and bone characteristics of dairy cows fed different amounts of phosphorus for two or three years. J. Dairy Sci. 84:1738-1748.

Yamashita, M. M., L. Wesson, G. Eisenman, and D. Eisenberg. 1990. Where metal ions bind in proteins. Proc. Natl. Acad. Sci. USA 87:5648-5652

Yasui, T., J. A. McArt, C. M. Ryan, R. O. Gilbert, D. V. Nydam, F. Valdez, K. E. Griswold, and T. R. Overton. 2014. Effects of chromium propionate supplementation during the periparturient period and early lactation on metabolism, performance, and cytological endometritis in dairy cows. J. Dairy Sci. 97:6400-6410.

Yeh, J. Y., Q. P. Gu, M. A. Beilstein, N. E. Forsberg, and P. D. Whanger. 1997. Selenium influences tissue levels of selenoprotein W in sheep. J. Nutr. 127:394-402.

Yoshida, M. 2012. Is chromium an essential trace element in human nutrition? Nippon Eiseigaku Zasshi 67:485-491.

Yost, G. P., J. D. Arthington, L. R. McDowell, F. G. Martin, N. S. Wilkinson, and C. K. Swenson. 2002. Effect of copper source and level on the rate and extent of copper repletion in Holstein heifers. J. Dairy Sci. 85:3297-3303.

Yuzbasiyan-Gurkan, V., and E. Bartlett. 2006. Identification of a unique splice site variant in SLC39A4 in bovine hereditary zinc deficiency, lethal trait A46: An animal model of acrodermatitis enteropathica. Genomics 88:521-526.

Zhu, C., Z. Chen, and Z. Jiang. 2016. Expression, distribution and role of aquaporin water channels in human and animal stomach and intestines. Int. J. Mol. Sci. 17(E1399):1-18.

Zimnicka, A. M., K. Ivy, and J. H. Kaplan. 2011. Acquisition of dietary copper: A role for anion transporters in intestinal apical copper uptake. Am. J. Physiol. Cell Physiol. 300:C588-C599.

Zuo, L., T. Zhou, B. K. Pannell, A. C. Ziegler, and T. M. Best. 2015. Biological and physiological role of reactive oxygen species-The good, the bad and the ugly. Acta Physiol. (Oxf.) 214:329-348. 